\title{
Epistemic uncertainties and natural hazard risk assessment - Part 2: Different natural hazard areas
}

K. J. Beven ${ }^{1,2}$, S. Almeida ${ }^{3}$, W. P. Aspinall ${ }^{4}$, P. D. Bates ${ }^{5}$, S. Blazkova ${ }^{6}$, E. Borgomeo ${ }^{7}$, K. Goda ${ }^{4}$, J. C. Phillips ${ }^{4}$, M. Simpson ${ }^{7}$, P. J. Smith ${ }^{1}$, D. B. Stephenson ${ }^{8}$, T. Wagener ${ }^{3,9}$, M. Watson ${ }^{4}$, and K. L. Wilkins ${ }^{4}$

${ }^{1}$ Lancaster Environment Centre, Lancaster University, Lancaster, UK

${ }^{2}$ Department of Earth Sciences, Uppsala University, Uppsala, Sweden

${ }^{3}$ Department of Engineering, Bristol University, Bristol, UK

${ }^{4}$ School of Earth Sciences, Bristol University, Bristol, UK

${ }^{5}$ School of Geographical Sciences, Bristol University, Bristol, UK

${ }^{6}$ T. G. Masaryk Water Resource Institute, Prague, Czech Republic

${ }^{7}$ Environmental Change Institute, Oxford University, UK

${ }^{8}$ Department of Mathematics and Computer Science, Exeter University, Exeter, UK

${ }^{9}$ Cabot Institute, University of Bristol, Bristol, UK

\section{Epistemic \\ uncertainties and natural hazard risk assessment - Part 2 \\ K. J. Beven et al.}

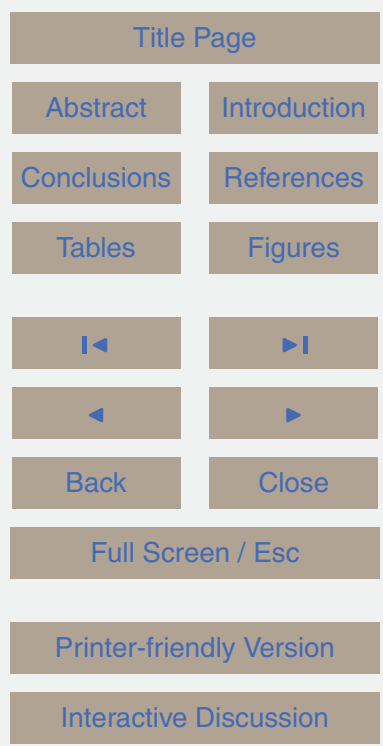


Received: 21 October 2015 - Accepted: 26 November 2015 - Published: 15 January 2016

Correspondence to: K. J. Beven (k.beven@lancaster.ac.uk)

Published by Copernicus Publications on behalf of the European Geosciences Union.

\section{NHESSD}

doi:10.5194/nhess-2015-295

\section{Epistemic}

uncertainties and natural hazard risk assessment - Part 2

K. J. Beven et al.

Title Page

Abstract

Introduction

Conclusions

References

Tables

Figures

14

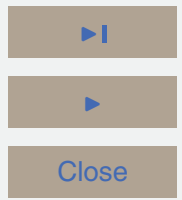

Back

Close

Full Screen / Esc

Printer-friendly Version

Interactive Discussion 


\section{Abstract}

This paper discusses how epistemic uncertainties are considered in a number of different natural hazard areas including floods, landslides and debris flows, dam safety, droughts, earthquakes, tsunamis, volcanic ash clouds and pyroclastic flows, and wind 5 storms. In each case it is common practice to treat most uncertainties in the form of aleatory probability distributions but this may lead to an underestimation of the resulting uncertainties in assessing the hazard, consequences and risk. It is suggested that such analyses might be usefully extended by looking at different scenarios of assumptions about sources of epistemic uncertainty, with a view to reducing the element of surprise in future hazard occurrences. Since every analysis is necessarily conditional on the assumptions made about the nature of sources of epistemic uncertainty it is also important to follow the guidelines for good practice suggested in the companion Part 1 by setting out those assumptions in a condition tree.

\section{Introduction}

15 In Part 1 we have discussed the issues and difficulties of trying to account for epistemic uncertainties in natural hazard risk assessment, including: the difficulties of evaluating model structures, the difficulties of estimating effective parameter values for particular assessments, the difficulties of assigning probabilities to epistemic sources of uncertainties and eliciting expert opinions about the potential probabilities; the possibility that some of the information available might not be informative in calibrating or evaluating models; the possibility of models not being fit-for-purpose, and the problem of communicating the meaning of uncertainty assessments to potential users and decision makers. In this paper we review how these issues have been addressed in different natural hazard areas, including floods, droughts, landslides and debris flows, dam failures, seismic hazards, tsunamis, the dispersion of volcanic ash clouds, pyroclastic density currents, and damaging wind storms.
NHESSD
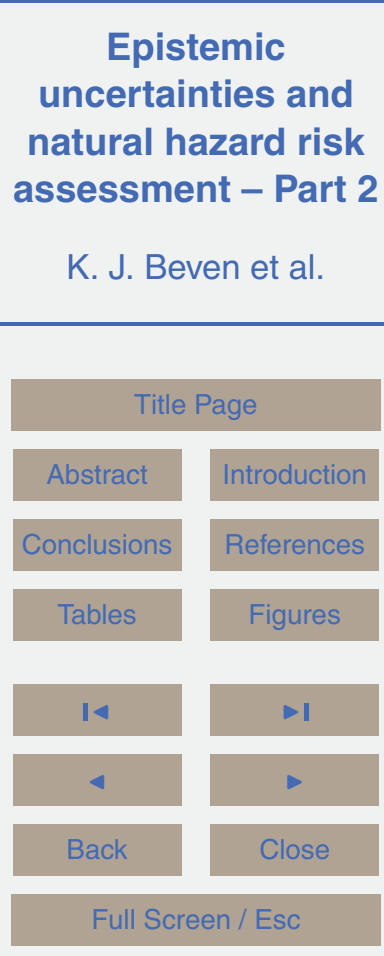

Printer-friendly Version

Interactive Discussion 
The different natural hazards areas have dealt with these issues in different ways, although there are some commonalities, for example in the use of expert elicitation of probabilities in cases where information is lacking. In some areas the treatment of different types of uncertainty is contested, for good epistemic reasons of course, be5 tween Bayesian statistical probability approaches, formal imprecise methods (including fuzzy possibilistic reasoning, imprecise probabilities, interval methods, belief functions, rough sets and other variants) and informal qualitative approaches. In fact, there can be no right answer since if we had sufficient knowledge about epistemic uncertainties for practical applications they would no longer be epistemic. That does not mean that we 10 should neglect the issues, however, since a proper assessment of uncertainty, including the potential for future surprise, might affect the way in which decisions are made in assessing the risks, particularly where the probability component of the risk = probability $x$ consequences equation is subject to arbitrary variation (e.g. Rougier and Beven, 2013).

\section{Flooding}

There are five aspects of flood risk assessment that involve important epistemic uncertainties. The first is the assessment of how much rainfall or snowmelt input occurs (either in past or future events); the second is the frequency with which such events might occur and how that might be changing; the third is how much of that input becomes flood runoff; the fourth is the footprint of the flood inundation; and the fifth is the assessment of either past or potential damages. These all apply in the assessment of expected damages for events of different magnitude for making decisions in managing the flood risk and in the management of flood incidents in real time (e.g. Sayers et al., 2002).

25 In the context of flood risk management, risk is generally treated as the product of a probability of exceedance and an estimate of consequences (often evaluated as a cost of the impacts of an event). Uncertainties in inputs and runoff generation are
NHESSD

doi:10.5194/nhess-2015-295

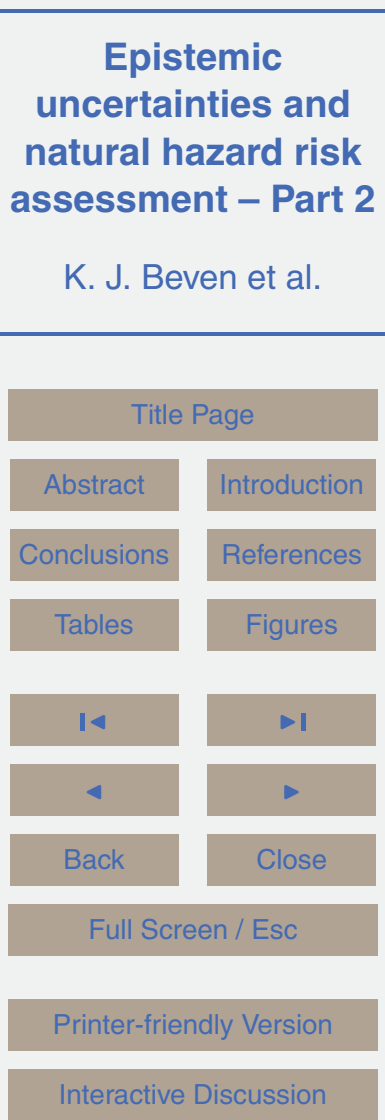


often avoided in this context by estimating the probability of exceedance for different magnitudes of event in terms of an extreme value distribution of discharges. That does not mean that such uncertainties are not important (such as lack of knowledge about the effects of a poorly known spatial pattern of inputs on runoff generation, the role of 5 antecedent conditions in controlling runoff generation, or estimates of historical flood peak discharges), only that they are assumed to contribute to some underlying statistical distribution of events that is fitted to the available historical data. That provides can estimate of frequency as if the series of historical floods is drawn from a stationary distribution. It is not easily modified to allow for future change (e.g. Prudhomme et al., 10 2010).

The epistemic uncertainty then is convolved into a question of what statistical distribution should be used. This question has often been resolved by institutionalizing the uncertainty into a particular choice of standard distribution. Different countries have chosen different distributions and, in some cases, have changed that choice over time. 15 There are good theoretical reasons to choose the Generalised Extreme Value (GEV) distribution. Asymptotically a sample of extremes with Poisson distribution of occurrences in successive time periods (e.g. years) from an arbitrary underlying distribution of events should have the form of the GEV distribution. It was the distribution of choice for the analysis of annual maximum floods in the UK Flood Studies Report (NERC, 1975). However, the time series available for the analysis of floods are often relatively short, so the asymptotic condition may not be approached and the distribution of events may not be Poisson distributed in time (e.g. Eastoe and Tawn, 2009). Thus in revising the UK methodology in the Flood Estimation Handbook, a change was made to recommend the Generalised Logistic Distribution since it resulted in less sites being assigned parameters that suggested some upper limit to flood magnitudes $(\mathrm{IH}, 1999)$. Many other distributions have been used elsewhere. A recent development in flood risk management has been a concern with the joint occurrences of flood events, rather than looking at individual sites independently. This requires specifying not only one
NHESSD

doi:10.5194/nhess-2015-295
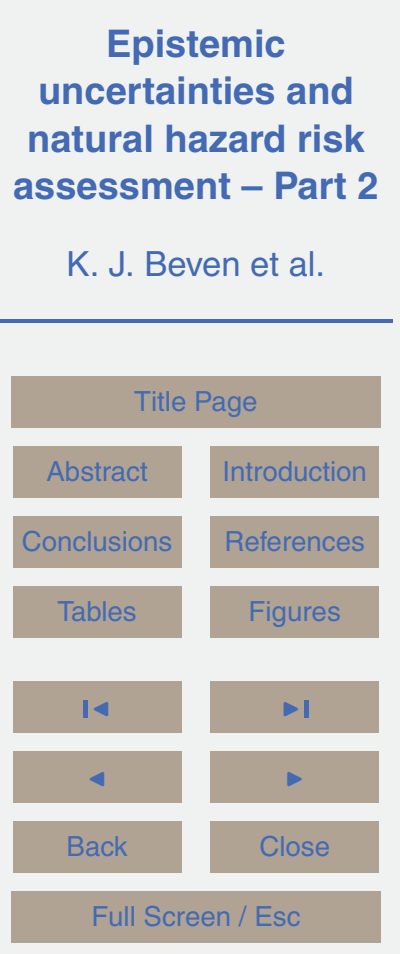

Printer-friendly Version

Interactive Discussion 
distribution but multiple distributions and the correlation structure between them (e.g. Keef et al., 2013).

The choice of a particular distribution essentially controls the form of the upper tail of the distribution and consequently the assessment of risk. This is common to the other 5 natural hazards that are considered below. Good practice suggests that the statistical uncertainty associated with the tail of the fitted distribution should be evaluated (although this is rarely reported even where it is provided by the analysis software) but essentially we have additional epistemic uncertainties as to what distribution to choose and whether to treat that distribution as stationary or whether clusters of events might come from some more complex stochastic structure (e.g. Koutsoyiannis, 2003, 2010; Montanari and Koutsoyiannis, 2012). If this is the case, then it might result in a significant increase in the range of uncertainty relative to classical statistical analysis (e.g. Koutsoyiannis and Montanari, 2007) irrespective of other sources of epistemic uncertainty.

15 These issues have led some people to step back to considering the inputs and runoff generation over a catchment more directly in flood risk estimation. This approach was pioneered by Eagleson (1970) using a simple derived distribution model of runoff generation, but increased computer power has allowed continuous simulation over long periods of time using rainfall-runoff models which has the advantage that the variation in antecedent wetness of a catchment prior to an event is part of the simulation (e.g. Beven, 1987; Cameron et al., 1999; Lamb and Kay, 2004; Blazkova and Beven, 2004, 2009). In some cases it is possible to use long series of observed rainfall data to simulate discharges; but for the very long series that are needed to estimate more extreme events it is necessary to use a stochastic model of the inputs (similar to the weather generators used to produce future sequences in climate change impact assessments). This then only shifts the epistemic uncertainty issue of the choice of appropriate distributions or more complex stochastic structures for the space-time characteristics of rainfall (e.g. Chandler et al., 2014). The extreme events generated from such a weather generator depend on the tails of the assumed distribution(s) and it might not be clear

\section{NHESSD}

doi:10.5194/nhess-2015-295
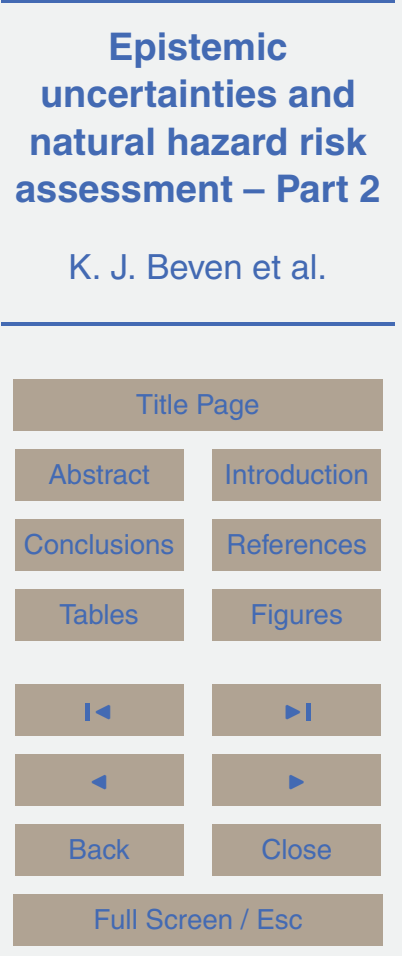

Printer-friendly Version

Interactive Discussion 
what type of distribution to use, even where rainfall series are longer than discharge records. It has also been shown that whether a model matches the historical floods data might depend on the particular stochastic input realization and the historical period considered (Blazkova and Beven, 2009).

A further advantage of the continuous simulation approach is that the weather generator can be modified to represent future climates (e.g. Cameron et al., 2000; Wilby and Dessai, 2010; Prudhomme and Davies, 2009; Prudhomme et al., 2010), and that input data might be more readily available for sites for which there are no discharge records (the prediction of ungauged basins problem, Blöschl et al., 2013; Hrachowitz

et al., 2013). This latter case still requires that the parameters of a rainfall-runoff model be specified. This is also an epistemic uncertainty issue, even if extrapolations from gauged sites are often made using statistical regression or pooling group methods (e.g. Lamb and Kay, 2004) a process that will be influenced by model structural uncertainty and other uncertainty sources (e.g. Mclntyre et al., 2005; Wagener and Wheater, 15 2006). Experience in predicting the flood characteristics in this way has been somewhat mixed; successful in some basins, but with significant over or underestimation in others (Lamb and Kay, 2004). Improvements to such methods might still be possible but epistemic uncertainty will remain a constraint on accuracy.

Further uncertainties arise in the estimation of the footprint of the flood event. There 20 may be different areas at risk of inundation according to whether the risk is from pluvial, fluvial, coastal or groundwater flooding. By making assumptions about various sources of uncertainty in the modelling of inundation, a forward uncertainty analysis can be used to predict uncertainties in inundation areas and depths using Monte Carlo simulation methods (e.g. Berry et al., 2008). In some cases, historical flood mapping is available that can be used to condition hydraulic models of inundation and constrain the uncertainty in model predictions (Bates et al., 2014). Both Generalised Likelihood Uncertainty Estimation (GLUE, Aronica et al., 1998; Romanowicz and Beven, 2003; Pappenberger et al., 2007; Beven et al., 2014; Neal et al., 2013; Beven and Lamb, 2016) and more formal Bayesian methods (Romanowicz et al., 1996; Hall et al., 2011)

\section{NHESSD}

doi:10.5194/nhess-2015-295

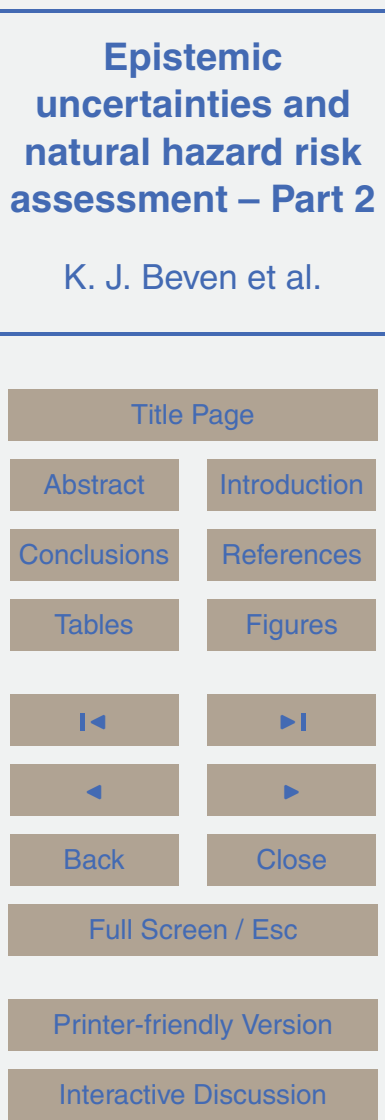

Interactive Discussion 
have been used in this type of conditioning process (e.g. Fig. 1; see also other examples in Beven et al., 2014) but the results will depend on how the various model runs are evaluated as well as what type of inundation model is being used. Recent improvements in flood inundation modelling, however, have been less a result of reducing 5 uncertainties in inputs and conveyance parameters, but rather due to the much better definition of flood plain topography as LIDAR surveys have become more widely available. Even LIDAR however cannot identify all the barriers to flow on a flood plain (e.g. Sampson et al., 2012), and therefore we should expect some interaction between effective conveyance parameters and other features of model implementation in matching 10 historical flood data. Even then there is some suggestion that the effective conveyance parameters identified for one magnitude of event, might not hold for a larger magnitude event (e.g. Romanowicz and Beven, 2003) so that the simple assumption that conveyance parameters are constant might introduce epistemic uncertainty. It is also common to assume that the effective conveyance parameters are spatially constant 5 which, when interacting with other sources of uncertainty might mean that it is not possible to get good fits to inundation observations everywhere in the modelled domain (e.g. Pappenberger et al., 2007).

In many situations, flooding is constrained by the existence of natural levees or artificial flood defences. Such defences are always associated with a residual risk of 20 being overtopped and/or failing, a risk that will vary with the construction methods, programme of maintenance, unauthorised modifications and other factors (van Gelder and Vrijling, 2014). These are all subject to epistemic uncertainties, but are often dealt with using fragility curves that give a probability of failure as a function of water level. Although expressed in terms of probabilities, such fragility curves are often treated as deterministically known. The difficulties of including epistemic uncertainties are discussed, for example, by Goulding et al. (2010) who used forward uncertainty estimation to cascade uncertainty assumptions through the RASP framework used in the UK National Flood Risk Assessments (NaFRA).

\section{NHESSD}

doi:10.5194/nhess-2015-295
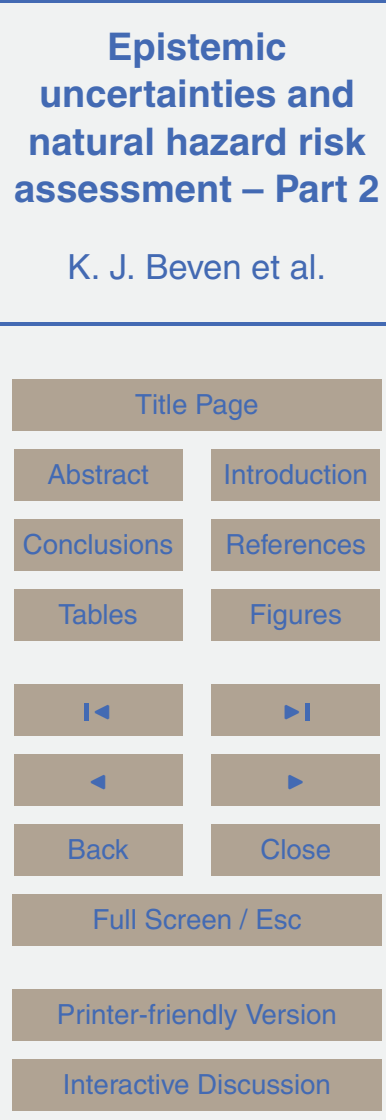

Interactive Discussion 
The other part of the risk equation is the evaluation of the consequences of an event. For past events there is some epistemic uncertainty about the damages associated with the event, but there is often considerable uncertainty about what is actually at risk (e.g. Chatterton et al., 2014). Damages that are covered by insurance are generally 5 well known (but subject to commercial confidentiality restrictions and not readily available), but, not all damages are insured and not all are easily expressed in monetary terms (such as damage to habitats, cultural heritage, and loss of life). Indirect damages to businesses and individuals (e.g. as a result of infrastructure failures, health and psychological impacts) can also be difficult to assess). All potential sources of damage are even more difficult to estimate for future events, as a result of epistemic uncertainties about policy changes in flood risk management, planning decisions for flood plain developments, changes in availability of insurance cover, etc. Different loss models might result in quite different estimates of the consequences of an event (e.g. Jongman et al., 2012; Chandler et al., 2014). In the UK there has been a recent debate about the evaluation of flood damages, and therefore the justification of government expenditure on flood defence and maintenance, instigated by Penning-Rowsell (2015) who led the team that developed the standard methodology for evaluating flood damages (Penning-Rowsell et al., 2013).

In flood incident management, epistemic uncertainties might lead to deterministic 20 predictions being quite wrong, even where models of flood discharges and extent of inundation have been calibrated for past events. This is usually handled in one of two ways. Traditionally it was handled by the experience and expertise of the flood forecasters who would make adjustments to model outputs available to them as an event progressed and more information became available. In doing so they would qualitatively allow for perceived epistemic uncertainties. This approach is still used in many countries. An extension of this approach is to base estimates of the uncertainty in model predictions based on the performance of the model in past events. A method such as quantile regression can be used for this (Weerts et al., 2013). The problem for

\section{NHESSD}

doi:10.5194/nhess-2015-295

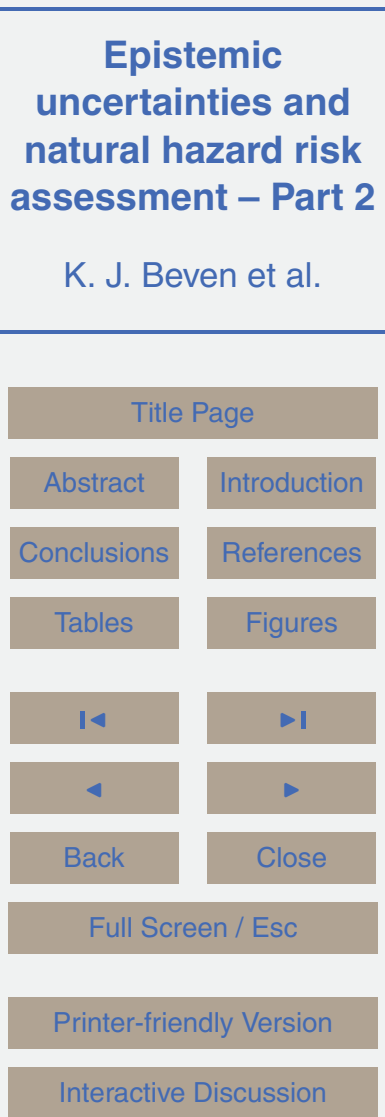


both approaches is that past experience may not be a good guide to the peculiarities of a new event.

An alternative approach is to assume that all uncertainties can be treated statistically and use a data assimilation approach to correct for over or under-prediction as

5 the event proceeds. Techniques such as the Kalman filter, or stochastic autoregressive modelling, can be used with the advantage that an estimate of the variance of the forecast can also be updated at the same time (see for example, Sene et al., 2014; Young et al., 2014; Smith et al., 2012, 2013a). No explicit account of potential epistemic uncertainties is made in this approach; the aim is only to improve the forecast and min10 imize the forecast variance at the required lead time as new data become available for assimilation. The approach will often work well when the required lead time is less than the response time of the upstream catchment so that the data assimilation can rely on measured inputs. It works less well in flash flood situations in small catchments with short response times so that forecasts of the inputs are needed to produce a forecast with reasonable response time (Alfieri et al., 2011; Smith et al., 2013b). Rainfall forecasts from Numerical Weather Prediction (NWP) models are still not sufficiently accurate for this purpose but are now used routinely (such as in the European Flood Awareness System hosted at ECMWF, Bartholmes et al., 2009; De Roo et al., 2011) for providing flood alerts some days ahead.

\section{Landslides and debris flows}

Landslides can also have large negative societal and economic impacts, such as loss of life and damage to infrastructure. Globally, landslides are directly responsible for several thousand deaths per year (e.g. Petley, 2012). A widely cited example is that of the Welsh village of Aberfan, where a flowslide from a colliery spoil tip killed 144 people, 116 of which were children, at the Pantglas Junior School in October 1966 (Johnes, 2000). More recently, the Gunsu mudslide that occurred after heavy rain in August 2010 in China, killed an estimated 1765 people. However, despite the large risks posed by
NHESSD

doi:10.5194/nhess-2015-295

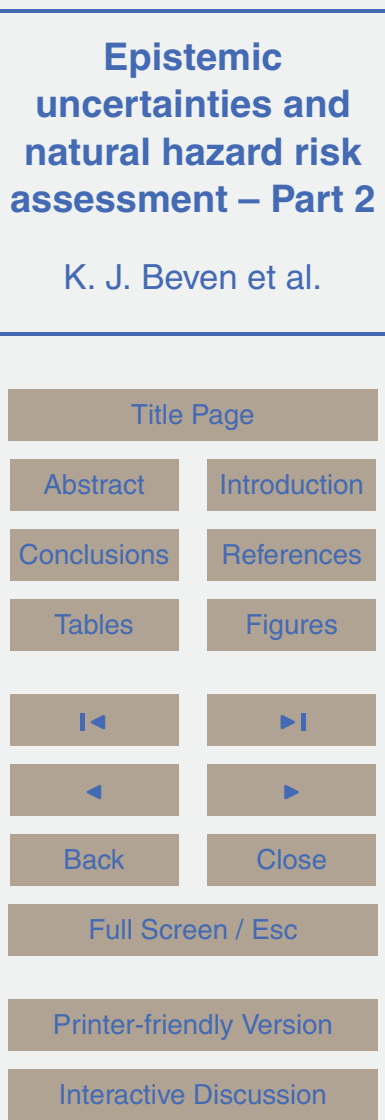


landslides, the ability of research to guide and inform management decisions is limited by high levels of uncertainty in model assessments of slope stability. In landslide risk assessment epistemic uncertainties arise from a range of sources, including errors in measurement data, gaps in the understanding of landslide processes and their 5 representation in models, and from uncertain projections of future socio-economic and biophysical conditions (Lee and Jones, 2004).

Landslide risk can be assessed qualitatively or quantitatively. The choice depends on the scale of work (national, regional, local or site-specific), and also on the quality and quantity of data available. For site-specific slopes, physically-based deterministic 10 models centred on slope stability analysis are commonly used to assess the probability of landslide occurrence. Stability conditions are generally evaluated by means of limit equilibrium methods, where the available soil strength and the destabilising effect of gravity are compared in order to calculate a measure of the relative stability of the slope known as the factor of safety. The limit equilibrium method relies on signifi15 cant simplifications, such as that failing soil mass is rigid, the failure surface is known and the material's failure criterion is verified for each point along this surface, limiting its accuracy and applicability. Whilst widely applied, epistemic uncertainties related to the limited understanding of system processes and functioning can lead to large errors in model predictions. For example, in 1984 an embankment dam in Carsington, England, slipped, despite the fact that limit equilibrium analysis had indicated that the slope was not expected to be at risk of failure. This discrepancy has been shown to be caused by epistemic errors, as brittle soils may exhibit strain-softening behaviour when loaded, leading to progressive failure, a phenomenon which cannot be reproduced using conventional limit equilibrium stability analyses. For this type of soils, finite element to achieve a more accurate prediction of stability (Potts et al., 1990).

Physically-based slope stability models are, however, subject to epistemic uncertainties in both the constitutive relationships chosen and the parameter values required by those relationships. Parameter variability is often assessed by making small scale lab-
NHESSD

doi:10.5194/nhess-2015-295
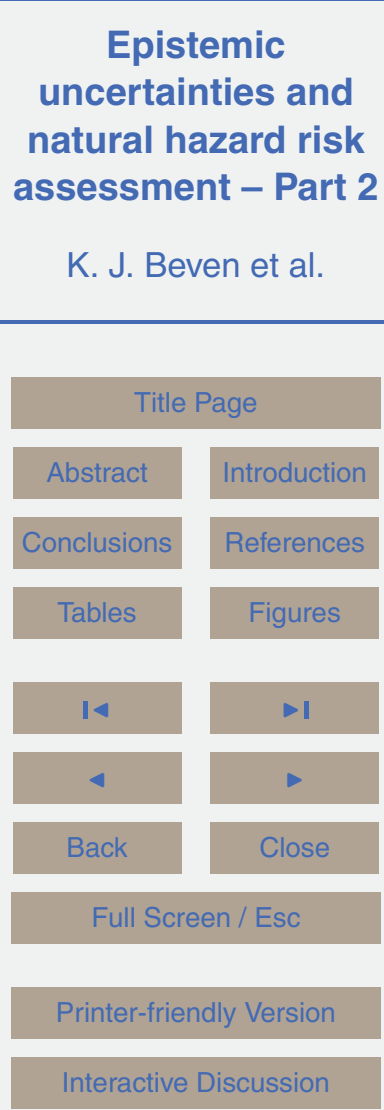
oratory measurements of parameters such as cohesion and coefficient of friction but the resulting values may not be directly applicable at the large scale because of the effects of spatial heterogeneities, and additional factors such as root strength (Christian et al., 1994; Rubio et al., 2004; Hall et al., 2004; Hencher, 2010). Although spatial variability of soil properties has been recognised as an important source of epistemic uncertainty in the literature (e.g. El-Ramly et al., 2002; Griffiths and Fenton, 2004), it has often been ignored in previous analyses using limit equilibrium methods. The use of constant values for soil properties over soil deposits may lead to unreliable estimates of the probability of failure of a slope (El-Ramly et al., 2002; Griffiths and Fenton, 2004; Cho, 2007; Griffiths et al., 2009). To account for this source of uncertainty in slope stability problems, some investigators combine limit equilibrium methods with random field theory (e.g. Cho, 2007). Random field theory allows soil properties to be described by a randomly-generated distribution, instead of a single value across the entire modelled space. Moreover, random field theory also allows spatial correlation to be preserved,

\section{between slices which are further apart.}

However, given that limit equilibrium methods are based on a two-dimensional analysis where the critical failure surface is a line of arbitrary shape, the influence of the random field is only considered along that line and therefore, when this method of analysis is used, it can be seen as a one-dimensional approach (Griffiths et al., 2009). To overcome this limitation inherent to limit equilibrium methods, while accounting for spatial variability of soil properties, Griffiths et al. (2009) suggest combining a finite-element model with random field theory. The finite-element method is particularly attractive as, in addition to satisfying equilibrium and compatibility, it allows any constitutive frame25 work to be used for the simulation of the mechanical behaviour of the geomaterial. The decision then is what constitutive framework to employ to allow more accurate predictions to be obtained.

The finite-element method has the added advantage of being capable of simulating water flow and coupled hydro-mechanical behaviour under saturated and unsatu-

\section{NHESSD}

doi:10.5194/nhess-2015-295
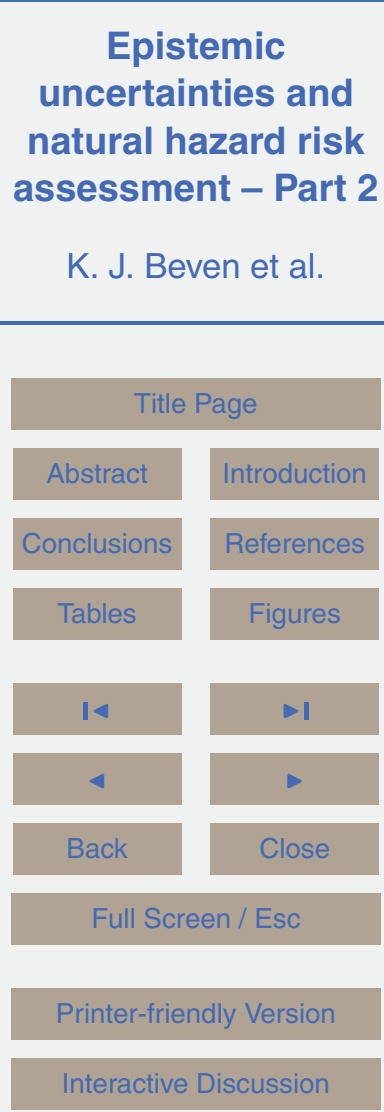
rated conditions (Alonso et al., 2003; Gens, 2010). Time-varying boundary conditions to simulate the effect of rainfall and vegetation can be used (e.g. Nyambayo and Potts, 2010), although this will require greater computational power and may still not represent the water flow processes adequately, such as the role of preferential flows and 5 bedrock fracture systems in inducing conditions for failure (e.g. Montgomery et al., 2009; Hencher, 2010; Beven, 2010; Beven and Germann, 2013). Even at sites where the costs of extensive field investigations can be justified, there is much that remains unknown about the subsurface including the detail of water flow pathways and knowledge of the hydro-mechanical behaviour of soils.

10 To accommodate uncertainty caused by parameter variability in both limit equilibrium and finite element methods of analysis, Monte Carlo simulation and/or the first-ordersecond-moment (FOSM) method are commonly used (e.g. Christian et al., 1994; Wu and Abdel-Latif, 2000; Haneberg, 2004; Cho, 2007). These methods consider the uncertainties introduced by the inputs in different ways. Monte Carlo simulation starts by 15 repeatedly sampling from the probability distributions of the random variables. A deterministic computation on each of generated input set is performed, and the factor of safety calculated. Subsequently, the aggregated results of all sets provide an approximation of the probability distribution of the factor of safety. Alternatively, the FOSM method can be used to estimate the probability of slope failure. This probabilistic method determines the stochastic moments of the performance function. As the input variables are randomly distributed, the performance function is also randomly distributed, which the FOSM method characterises in terms of its mean and standard deviation. In both methods, therefore, the uncertain parameters are treated as aleatory variables.

25 Detailed slope stability models require geotechnical information on site conditions that can be prohibitively costly to obtain and so tend to be employed only in small areas for cases where high risk is anticipated. Over large and complex areas, where the use of detailed physically-based models is not feasible, statistical/data-driven models relating the probability of landslide spatial occurrence (i.e. susceptibility) and local geo-
NHESSD

doi:10.5194/nhess-2015-295

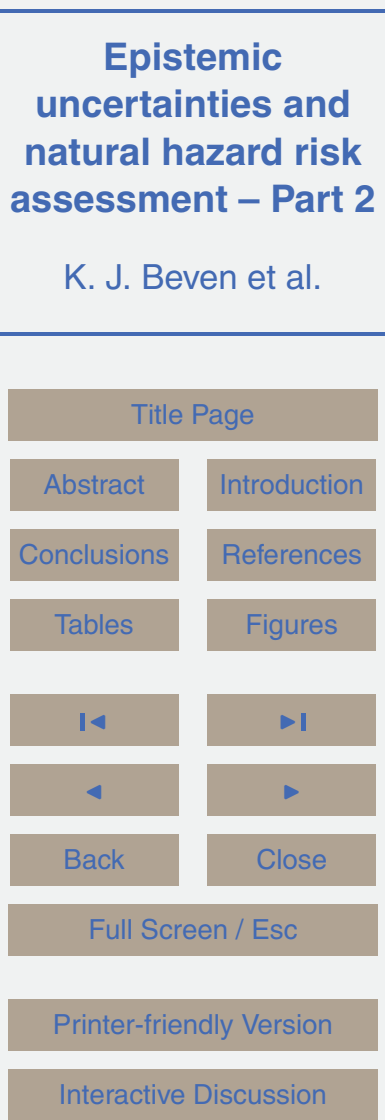


environmental conditions (e.g. geological, topographical and land-cover conditions) are used instead (e.g. Guzzetti et al., 1999, 2005, 2006; Ercanoglu and Gokceoglu, 2002). These models have become standard in landslide susceptibility assessment at a regional scale (Corominas et al., 2014). By estimating where the slope is most likely to 5 fail (but not the recurrence of failure, i.e. the temporal frequency, or magnitude of the expected landslide), these models can be of great help in land-use planning, guiding planners in the delimitation of suitable areas for future development.

Guzzetti et al. (2006), for example, established for the Collazzone area, Italy, a landslide susceptibility model, through discriminant analysis by finding a combination of predictor variables that maximises the difference between the populations of stable and unstable slopes with minimal error. The generalisation of a very complex problem into a relatively simple statistical model, necessarily introduces errors in model predictions, arising from errors in the predictors used to establish the model, uncertainty in the classification of the terrain units, etc. To estimate uncertainty, Guzzetti et al. (2006) 15 suggest a bootstrapping re-sampling technique. Several landslide susceptibility models are determined, by varying the selected terrain units considered. These ensembles of models are run for the study area and descriptive statistics for estimated susceptibility, including the mean and the standard deviation, are determined. A model relating the mean value and $2 \sigma$ (a proxy for the model error) is fitted using least square method. This model is used subsequently to provide estimates of the model error.

Another large source of uncertainty affecting the assessment of landslide susceptibility is often introduced by the imprecision with which experts approach a problem. To account for the uncertain and inexact character of the available information and for the possibility of limited information concerning a real system, fuzzy-based risk assessment models have been suggested in the literature (e.g. Ercanoglu and Gokceoglu, 2002; Lin et al., 2012). For example, Ercanoglu and Gokceoglu (2002) deal with uncertainty in the assessment of landslide susceptibility at the regional scale using fuzzy sets and if-then rules. Based on a landslide inventory database, factor analysis is applied to determine the important weights of the factors conditioning landslides in the

\section{NHESSD}

doi:10.5194/nhess-2015-295

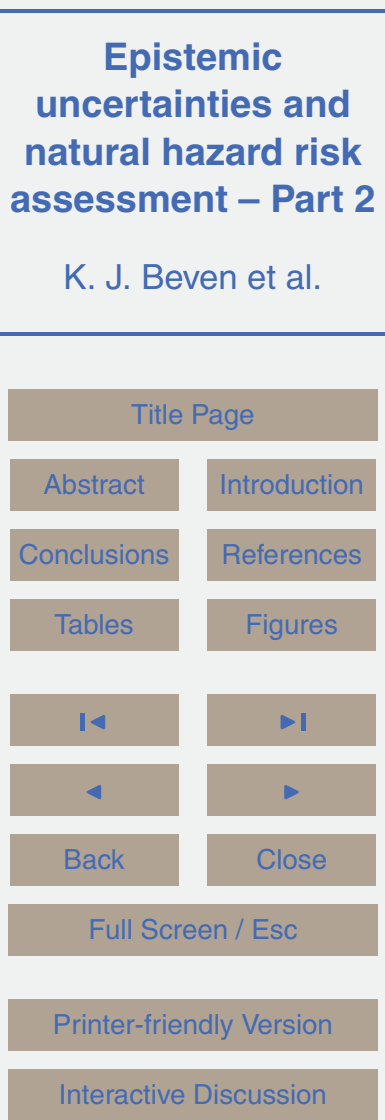


area (slope angle, land use, topographical elevation, dip direction of movement, water conditions and weathering depth). Fuzzy-set theory is then applied, allowing accounting for the judgemental uncertainty (fuzziness, vagueness, imprecision) introduced by the way experts approach the problems. In a rule-based fuzzy model, the fuzzy prepo5 sitions are represented by an implication function (e.g. "If slope angle is very low then landslide susceptibility is non-susceptible") commonly called fuzzy if-then rule or fuzzy conditional statement. The fuzzy if-then rules are then used to produce a fuzzified index map for each factor conditioning landslides. These maps are thereafter combined (by overlaying) to produce a landslide susceptibility map.

10 In the context of real-time warning systems, slope failure is commonly estimated by establishing landslide-triggering thresholds of the initiating agent. The application of triggering thresholds has been used, for example, in early warning systems in areas prone to rainfall-induced landslides, by establishing relationships between landslide occurrence and rainfall indicators, such as antecedent rainfall, duration, intensity and cumulative rainfall (Aleotti, 2004). An empirical model between rainfall and landslide initiation has been used to issue warnings during the storms of 12 to 21 February 1986 in the San Francisco Bay Region (Keefer et al., 1987). Since information regarding data quality is often lacking, one common way to deal with uncertainty involves tracing the rainfall threshold curves that correspond to different percentiles and then deciding on a minimum threshold satisfying some performance criterion (e.g. rainfall threshold curve established so that includes $90 \%$ of the historical events) (Aleotti, 2004).

In the context of long term landslide risk management, as for other natural hazards fields, such as floods or earthquakes, the probability of exceedance is often calculated for different sizes of events in terms of an extreme value distribution. This approach has advantages over a simulation based analysis, the results of which may be affected by uncertainties in input forcing data. However, this does not mean that uncertainties in factors contributing to landslides are ignored in probabilistic estimates of landslide risk. Instead, probabilistic estimates implicitly account for input uncertainty by fitting the statistical distribution of events to available historical data. As for floods, the epistemic

\section{NHESSD}

doi:10.5194/nhess-2015-295

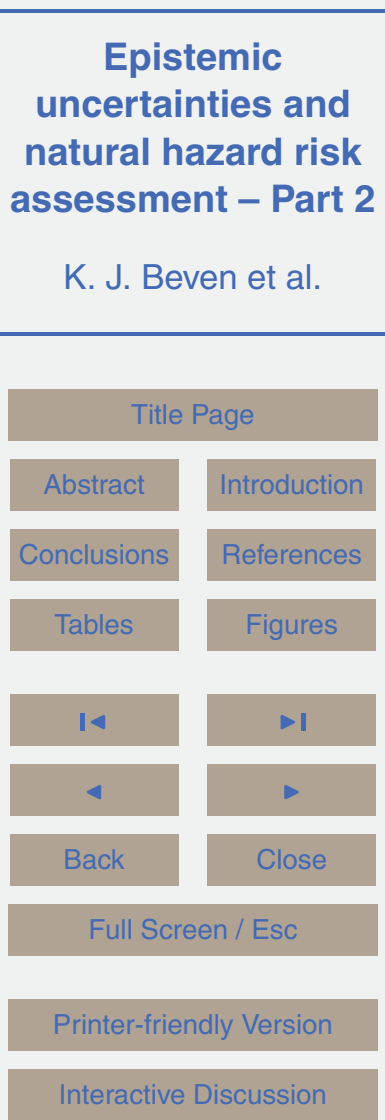


uncertainty is convolved into a question of what statistical distribution should be used. Probabilistic models such as binomial model, Poisson model (Crovelli, 2000) and the power-law distribution (Hungr et al., 1999; Dussauge-Peisser et al., 2002) have been suggested in the literature to estimate the frequency (or return period) of landslides of 5 a given size.

Assessment of the probability of land-sliding is only one part of the risk equation. The other part is the evaluation of the consequences of an event to estimate the damages and losses that can be expected. This involves delineating the extent of endangered areas, which requires predicting the runout behaviour of a landslide, namely how far and how fast landslide travels once mobilised. Runout behaviour is most commonly assessed using historical records but where models are used, the runout footprint may be highly dependent on the choice of model parameters (e.g. Hürlimann et al., 2008).

\section{The safety of dams}

The safety of dams is one example of a hazard that involves both natural forcing and 15 engineering design, but one in which the consequences of failure can be catastrophic. Failures can be due to poor engineering design, poor geological assessments of the location, poor maintenance of the structure, or an extreme flood event or landslide into the reservoir. Lists of dam failures (Vogel, 2001) ${ }^{12}$ show that such events are not common, but the International Commission on Large Dams (ICOLD, 1995) has estimated that some $0.5 \%$ of all dams failed in the period 1951-1986 and there have been cases with hundreds or thousands of fatalities downstream. There have, no doubt, been many other cases of near failure. A recent example is in the Sheffield area of England where the Ully dam came close to failure as a result of erosion of the downstream dam face during a period of extreme rainfalls in 2007 . In the same area, the failure of the Dale

\footnotetext{
${ }^{1} \mathrm{http}: / /$ www.damsafety.org/news/?p=412f29c8-3fd8-4529-b5c9-8d47364c1f3e

${ }^{2}$ http://en.wikipedia.org/wiki/Dam_failure
}

\section{NHESSD}
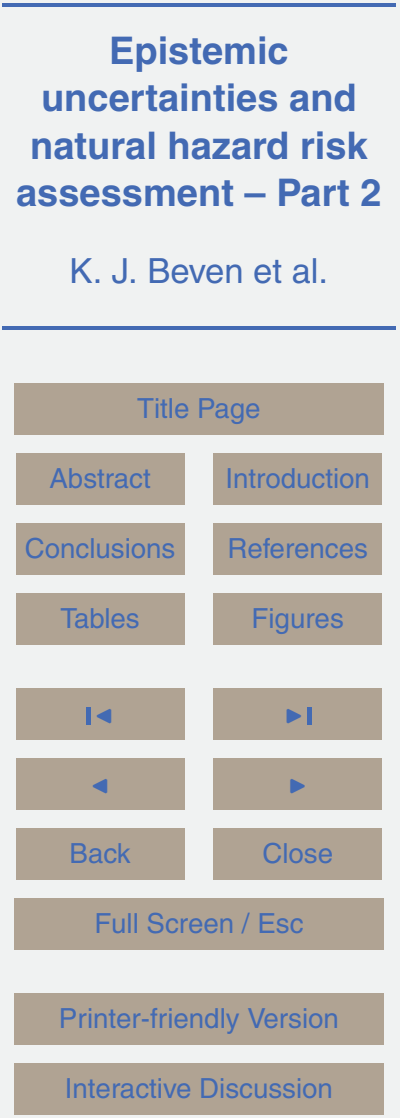
Dike dam in 1864, while being filled for the first time, caused 244 fatalities and destroyed 600 houses (Smith et al., 2014). The most fatalities estimated are for the failure of several dams in Henan Province in China in 1975 which killed an estimated 171000 people and destroyed the houses of 11 million people, following prolonged heavy rain.

5 A well-known European example was the failure of the Malpasset arch dam in France in 1959 that caused the deaths of 423 people (Londe, 1987; Duffaut, 2014).

Multiple causes make dam failures difficult to predict, and most countries take a highly precautionary approach to regulating for dam safety. The design of the dam and spillway channels for large dams are commonly designed to cope with the estimate of the flood with an annual exceedance probability of 0.0001 . This is a much smaller probability than for designing normal flood defences, because of the potential consequences of a failure. Thus there is an issue of defining of such an extreme event, and also what characteristics of such an event might impose the greatest forcing on the dam. The greatest forcing might not come from the highest flood peak if it is of short duration, but from the inflow volume associated with an event of longer duration but smaller peak.

One way of assessing such effects is to run a stochastic event model (as in the use of continuous simulation for flood frequency estimation described earlier). Since hydrological records are generally short, it will not be sufficient to sample from the historical records of extreme events. Instead, a stochastic model of rainfalls, consistent with the historical rainfall statistics, can be used to drive a continuous rainfall-runoff model calibrated on historical discharge data, to generate very long time series of events (e.g. Blazkova and Beven, 2004, 2009). Figure 2a shows the outputs from such a stochastic simulation for the Skalka dam site in the Czech Republic after conditioning parameters of the inputs and rainfall-runoff model on historical flow, snowpack and rainfall records within the Generalised Likelihood Uncertainty Estimation methodology (see Blazkova and Beven, 2009). The variability arising from different parameter sets is clearly seen. Running one of the parameter sets for 100000 years of simulation, to get a good estimate of the AEP 0.0001 event magnitude, also generates significant variability when
NHESSD

doi:10.5194/nhess-2015-295
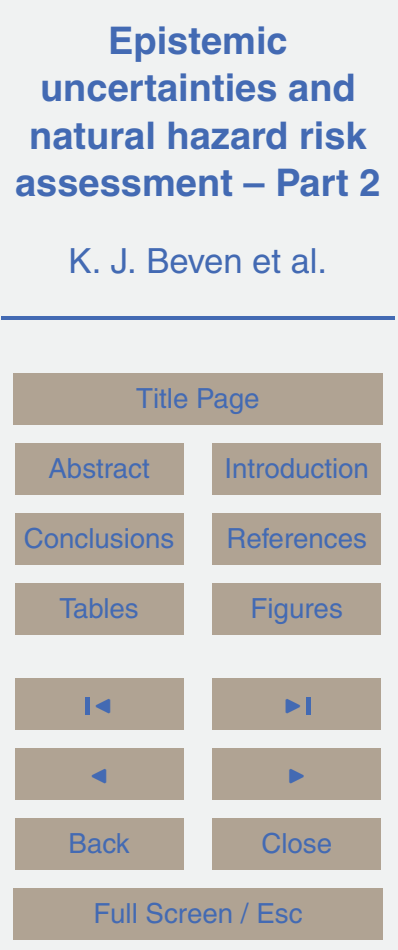

Printer-friendly Version

Interactive Discussion 
broken down to periods of 100 years (Fig. 2b). All of the most extreme events in such a simulation can then be routed through the reservoir (Fig. 2c) to test for failure modes. The continuous simulation approach means that the antecedent conditions prior to any event are handled naturally, but clearly the outputs from such simulations are depen5 dent on the epistemic uncertainties associated with all the model components, including the tail assumptions for the driving distributions, the choice of rainfall-runoff model, and the estimation of model parameters given the historical data. A particular feature of fitting such a stochastic model is that whether a model appears to give a good fit to the observed statistics might depend on the particular realisation of generated inputs 10 (Blazkova and Beven, 2009).

Predicting the downstream footprint of a dam failure and consequent potential damages can also be difficult. There are hydraulic models available designed to cope with the high discharges and sharp wave fronts expected with a dam failure (Cao et al., 2004; Xia et al., 2010), but the application in any real case study will depend on the

15 epistemic uncertainty associated with the characteristics of a breach in the dam acting as an upstream boundary conditions for the hydraulic model and the momentum losses in the downstream area as a highly sediment-laden fluid interacts with the valley bottom infrastructure and vegetation. It is also difficult to verify the outputs of such a model (except for small scale physical experiments in the laboratory, though see Hevouet and 20 Petitjean (1999), Begnudelli and Sanders (2007), and Gallegos et al. (2009); for examples of field scale validation) while many damage assessment schemes are based on predictions of flood depths. In the dam break case, velocities will also be important in the threat to life and damage to buildings.

\section{Droughts}

25 Drought is one of the most significant natural hazards, with the potential to cause widespread fatality and economic damage, particularly when a drought event might last for years or even decades. As with floods, droughts may be characterised either
NHESSD

doi:10.5194/nhess-2015-295

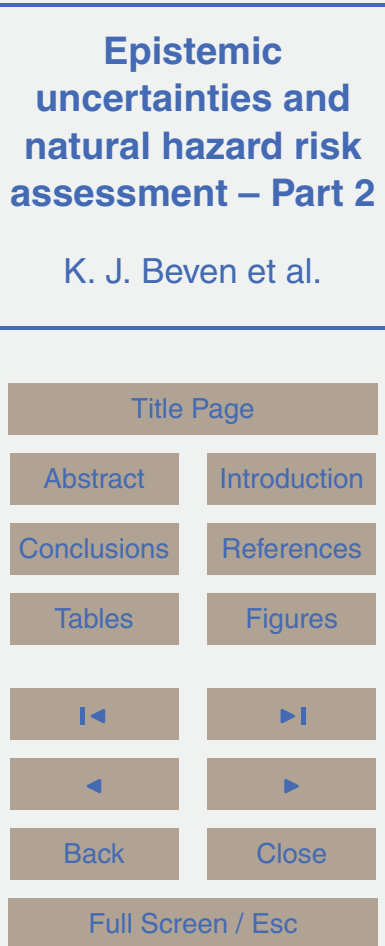

Printer-friendly Version

Interactive Discussion 
in terms of their natural severity or their impacts. The definition of drought depends on the type of water deficit being considered (rainfall, stream flow etc.). Drought follows the hydrological cycle, as precipitation deficits (meteorological droughts) lead to low soil moisture levels (agricultural/soil drought) and decreased river flows (hydrological 5 drought) which in turn may lead to lowering of reservoir levels and water shortages (socioeconomic drought). Drought periods associated with high temeperatures may also have other impacts such as the large number of excess deaths in Europe in the summer of 2003 (Robine et al., 2003).

Drought hazard is widely assessed using indices, such as the standardized pre10 cipitation index (SPI) or Palmer Drought Severity Index (PDSI). The most straightforward of these consider single environmental variables, such as precipitation (SPI) or groundwater level (Standardized Groundwater Index, Bloomfield et al., 2013). In such cases sources of uncertainty are restricted to commensurability of recorded observation, which may arise for instance from missing data, incomplete or short records (Hong 15 et al., 2014; Hu et al., 2014).

However, the information content of such indices can be low as rainfall or groundwater levels are not the sole drivers of drought impacts. By contrast, more complex indices such as PDSI and the Crop Moisture Index provide a more applicable representation of drought, but with more sources of potential uncertainty due to multiple data sources, parameterizations, and model structures imposed by the indices. For instance, the Palmer Drought Severity Index or the Crop Moisture Index assume that land use and soil properties are uniform over large spatial scales; which makes it difficult to accurately identify the spatial extent affected by a drought (Narasimhan and Srinivasan, 2005). Parameter uncertainty in some drought indices is rarely considered when characterizing drought, yet it has been shown to play a significant role in the identification of major drought events and in the derivation of relevant drought statistics (Samaniego et al., 2013).

Under specific local conditions, shortage of rainfall can have an influence on water availability for human use at a regional scale within 4 months (Marsh et al., 2008).
NHESSD

doi:10.5194/nhess-2015-295
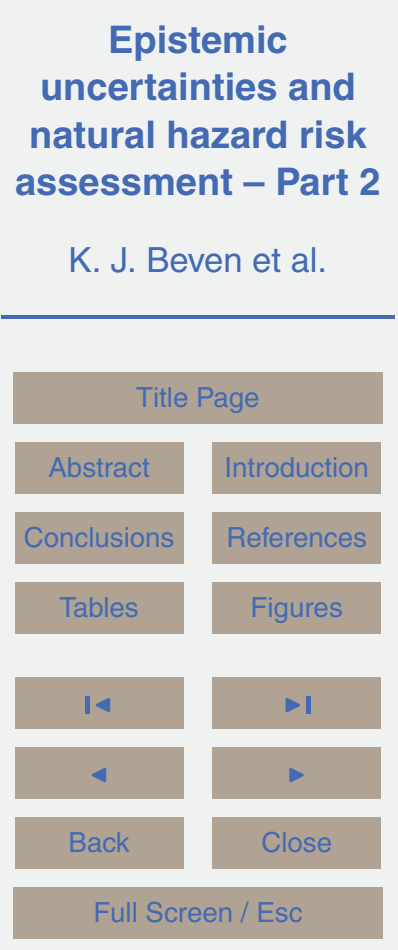

Printer-friendly Version

Interactive Discussion 
Long droughts can be difficult to characterise as multiple periods of drought can be interrupted by wet weather events, without sufficient rainfall arriving to restore water storage. Acknowledging this, long drought events such as the 1890-1910 drought in England and Wales and the Millennium drought in Australia can be pernicious, gradu5 ally depleting water stored in aquifers and reservoirs. Historically, drought indices and other water availability metrics such as Deployable Output (DO) in the UK have been presented without associated quantification of uncertainty. This is unfortunate, both in terms of the complexity of the calculation of such figures and as these terms are widely adopted by legal and regulatory systems. Recently, a risk-based approach has 10 been proposed by Hall et al. (2012). Under this approach, probabilistic uncertainties are considered explicitly within the model and simulations are based on environmental time series, allowing metrics such as the probability of water shortages to be determined. This allows uncertainties to be examined simultaneously - conditional on the time series used to inform the model being representative of those driving the real sys15 tem. As with other hazard areas the probabilities required may also be subject to lack of knowledge.

Estimation of stream flow, and in particular low flows, is essential for hydrological drought analysis, thus the choice of methods to model and estimate low flow characteristics can introduce epistemic uncertainties in drought risk assessment. Distributions fitted to low flows are susceptible to bias introduced by the fitting methodology and distribution choice (Ries and Friesz, 2000). Error is introduced in observations, with many river gauging methodologies especially poor at recording low flows (Barmah and Varley, 2012; Tomkins, 2014). As gauging methods record proxy observations of flow, epistemic uncertainty in functional relationships (i.e. changes in channel cross-section a relatively greater effect on the absolute errors of low flow observations (Tomkins, 2014; McMillan and Westerberg, 2015). While there is significant attention paid to information-rich events such as recession rates following flood events, the assumption that recession parameters determined in this way are optimal for determining the

\section{NHESSD}

doi:10.5194/nhess-2015-295

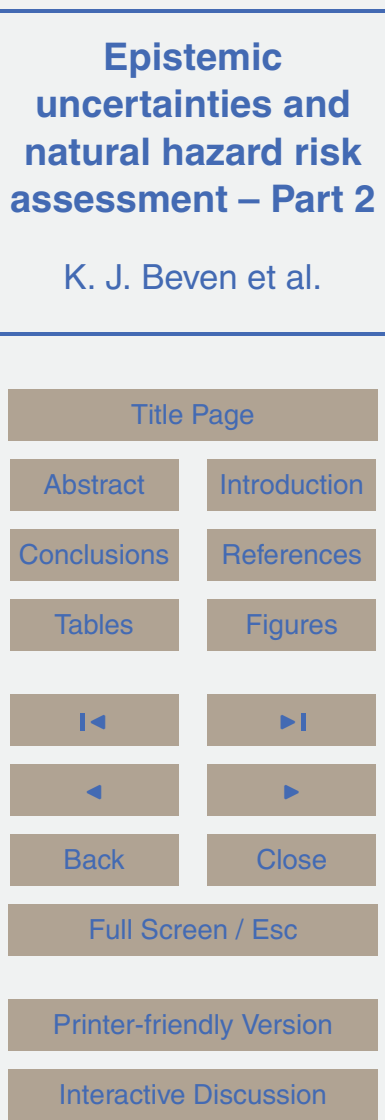

Interactive Discussion 
hydrology of extended low flow series is not valid (Prudhomme et al., 2012, 2013). Hydrological models, which are routinely applied to model low flow occurrence and to characterize hydrological drought duration and deficits in response to particular climatological conditions, also introduce epistemic uncertainty in drought risk assessments, 5 and Duan and Mei (2014) have shown that hydrological model structural uncertainty induces large differences in drought simulation.

In flood risk assessment, extreme value theory is applied to identify a representative flood event for a given return period. In drought risk assessment, this approach does not provide a satisfactory representation of drought characteristics, because drought

10 flows are not well represented as extreme values as they are truncated to zero and because drought characteristics are influenced by the temporal dependence properties of climatological and hydrological time series (Pelletier and Turcotte, 1997; Chung et al., 2000). These properties are not well captured by traditional extreme value theory.

Drought risk can be characterized using metrics of drought duration and intensity 15 (the deficit of water during a drought event), or the joint probability of a sequence of reduced flow events either in isolation or in combination with a water supply system model to assess future drought risk. Drought duration is indicative of drought severity rather than directly responsible for consequence in itself, as a long period of low flow is not necessarily worse than a short, sharp drought. Intensity can be considered a more robust metric of shortage as deviation from a threshold state can develop as a consequence of brief periods of extreme shortfall, longer mild shortfall or some combination of the two. Both these methods are sensitive to the identification of a threshold, which can be non-stationary due to environmental factors. Autocorrelation in drought series can be difficult to identify due to the requirement of capturing both the different temporal scales (daily, annual) and the continuous range of low flows, as correlation in $Q_{99}$ events may be independent from correlation in $Q_{95}$ events).

Epistemic uncertainties related to future climate conditions influence drought risk assessment for water resource planning purposes. A number of studies have looked at forward uncertainty analysis of the potential impacts of climate change on droughts

\section{NHESSD}

doi:10.5194/nhess-2015-295

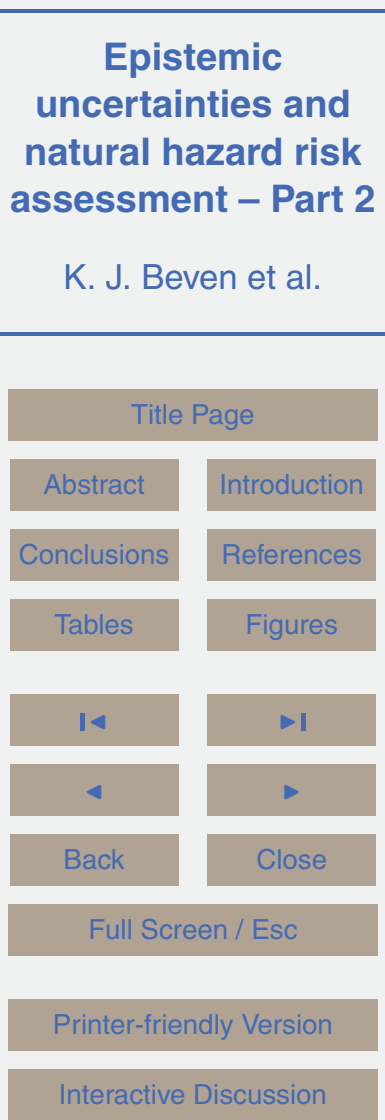

Interactive Discussion 
(e.g. Wilby and Harris, 2006). Borgomeo et al. (2014) developed a risk-based method to incorporate epistemic uncertainties in water resources planning and to assess drought and water shortage risk in water supply systems. This risk-based method incorporates climate change epistemic uncertainty by sampling the UK Climate Projections 5 (UKCP09) change factor distribution. Sampling different vectors of change factors allows for exploration of epistemic uncertainty in future climate. Similarly, climate model information was used by Paton et al. (2013) to assess drought risk in the southern Adelaide water supply system. In this study climate-related epistemic uncertainty was accounted for by developing hydro-climatological scenarios based on six different greenhouse gas emissions trajectories and several general circulation models.

Although climate models may provide information about future drought risks, there are issues here about how far current climate models can reproduce the type of blocking high pressure conditions that lead to significant droughts in Europe. In addition, the probabilities of multi-year droughts under future climates will almost certainly be poorly estimated. In this context, the historical periods of 1933-1934 and 1975-1976 in the UK are still used as extreme cases for water resource planning purposes. This is a form of precautionary approach, that does not require any estimate of probability associated with that event, but one which involves some epistemic uncertainty about whether a more extreme event might occur in future. Similar worst-case scenario approaches have been applied by Kasprzyk et al. (2009) and Harou et al. (2010) to assess drought risk and evaluate drought management strategies in water resources supply systems undergoing change when, in addition to any climate changes, human interventions modify exposure, vulnerability etc. (i.e. the non-hazard related component of the risk equation) (Mechler et al., 2010).

Epistemic uncertainty arising from uncertain demand characteristics is also intrinsic to any analysis of drought risk. For instance, epistemic uncertainties arise from incomplete knowledge of how demand responds during times of drought to both environmental conditions (weather) and management actions (i.e. water use restrictions, price increases) (Kenney et al., 2008). Although hot/dry weather may increase demand, it is
NHESSD

doi:10.5194/nhess-2015-295

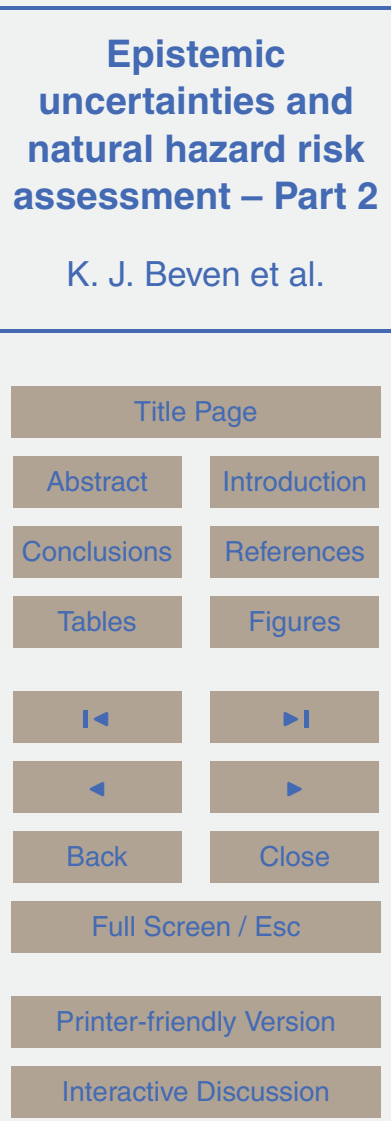


not clear which climatic variables are best suited to explain water consumption patterns (Kenney et al., 2008). Demand modelling also plays a key-role in long-term drought risk assessments in water resources. Changes in the spatial and temporal scale of water demand are difficult to project and add a level of epistemic uncertainty to any water 5 resources planning decision. Water managers often rely on extrapolation processes (Jorgensen et al., 2009; House-Peters and Chang, 2011), yet this process has not been entirely successful, with the UK's largest reservoir at Kielder built to meet projections which did not foresee the decline in heavy industry in the North of England (Walker, 2012), a clear case of the impact of epistemic uncertainty about future bound10 ary conditions.

Agricultural drought risk assessments are also faced with epistemic uncertainties. The complexity of drought generating processes and the incomplete knowledge of the effects of drought on soil water characteristics and crop growth mean that epistemic uncertainty impacts any agricultural drought analysis. Crop models are often used to 15 predict drought impacts on yield, yet the unknown duration of drought development, and the possibility of rainfall events that might help crop survival while not being hydrologically effective, is a major source of epistemic uncertainty (Yu et al., 2014) in modelling biomass development and yield.

In many climates severe droughts are rare events and, while not as rare as earthquakes or volcanic events, the extent of the observation record is not sufficient to have captured representative samples of the distribution of the natural processes forcing drought events, even if that distribution can be considered as stationary. Because of their long duration, they are also more prone to mitigation or exacerbation by socio-economic drivers than some other natural hazards. Those responding to or managing water resources during drought will make use of nearby water resources or stored water, taking advantage where possible of independence of drought events in space or time These factors are difficult to predict and thus make droughts subject to a broad range of epistemic uncertainty sources. In addition, the climate characteristics of drought may alter. Where there are projects of greater propensity to drought
NHESSD

doi:10.5194/nhess-2015-295

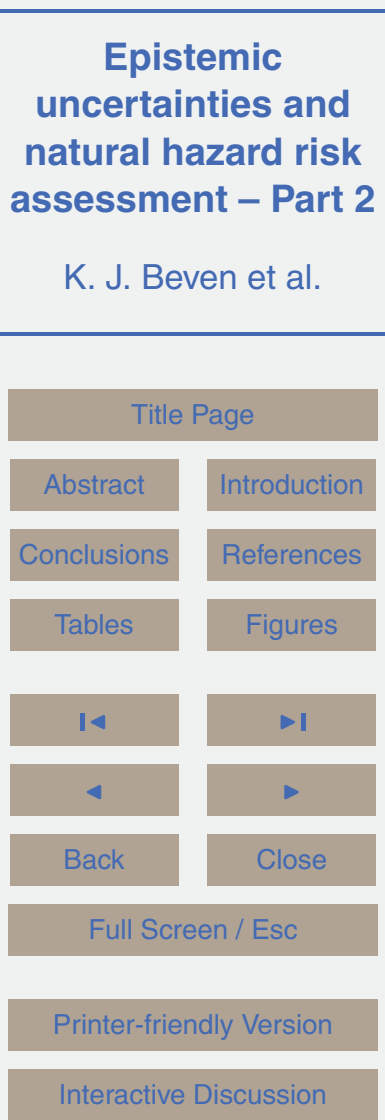


under climate change, making more robust drought planning essential. A risk-based approach allows multiple sources of drought uncertainty to be evaluated simultaneously and to be presented in terms of the probability of failure (Hall et al., 2012). The usefulness of this approach is determined by the extent to which uncertainties can be 5 identified and quantified as probabilities, individually and in terms of their joint probabilities and effects.

\section{Seismic hazards}

Probabilistic seismic hazard analysis (PSHA) is a standard approach for characterising potential impacts of future earthquakes (Cornell, 1968; McGuire, 2004). It takes 10 into account numerous earthquake sources and scenarios and integrates their contributions probabilistically as if all the variables considered are aleatory in nature. The primary objective of PSHA is to develop a set of seismic hazard estimates for aiding the revision and implementation of seismic design, for example for provisions in national building codes.

15 Outputs from PSHA are provided in various forms, such as site-specific hazard curve for safety-critical facilities and regional hazard contour map. The contour map shows expected ground motions (e.g. peak ground acceleration and spectral accelerations) at a selected annual exceedance probability level (typically $1 / 500$ to $1 / 10000$ ). PSHA involves various types and sources of uncertainties, and thus it is crucial to adopt an adequate mathematical framework to handle uncertainties as probabilities for individual model components and their dependency (Woo, 2011). Physically, these uncertainties can be associated with earthquake source processes in time and space, seismic wave propagation, and seismic effects on structures and socioeconomic systems. PSHA also allows the identification of critical hazard scenarios at different prob(Mcisuire, 2004). This essentially closes the loop between probabilistic and deterministic seismic hazard approaches, which are complementary in nature (McGuire, 2001). The deterministic scenario approaches
NHESSD
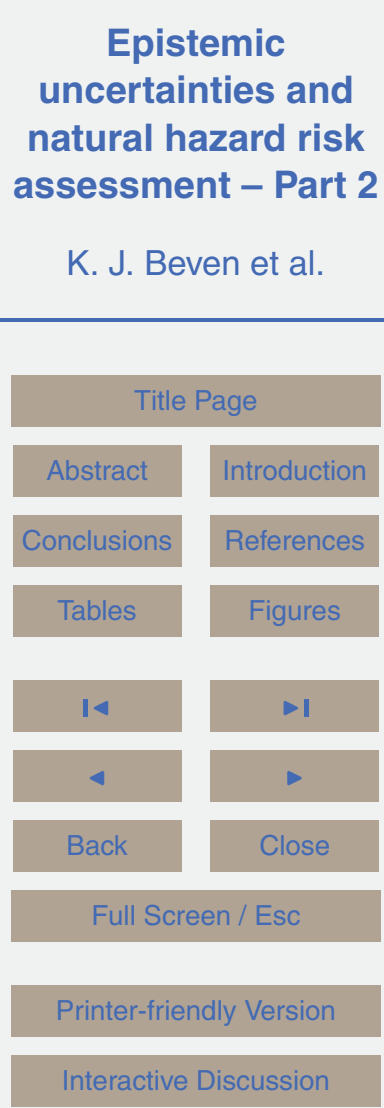
(e.g. Zuccolo et al., 2011) allow the use of more sophisticated models and data, but without attempting to associate a probability with a given scenario. For evaluating seismic risk impact to safety-critical facilities and infrastructure, both approaches should be implemented and should also be accompanied by rigorous sensitivity analysis.

Epistemic uncertainties arise both in the choice of structure for the component models and in the effective values of the parameters necessary. As with the other natural hazards, this means that when model predictions are compared to observational data the prediction errors can have a complex structure that may not be simply aleatory, even if it is common practice to treat them as if they can be described by probability o distributions. Representations of alternative hypotheses and assumptions for individual model components are often framed with a logic tree approach (Kulkarni et al., 1984), and the final estimates of seismic hazard parameters are obtained by integrating relevant uncertain model components and by probability weighting of alternative assumptions. Nevertheless, difficulties arise, because not all models, which analysts 15 wish to apply, are based on consistent data/assumptions, and the probabilities of alternatives in the logic tree are often poorly known, unknown, or unknowable (Bommer, 2012; Stein and Stein, 2013). Thus evaluating a full range of alternatives and their associated uncertainties will generally not be feasible.

In practice, given these epistemic sources of uncertainty, it is not a trivial task to assign weights to individual branches of the constructed logic tree and resort is often made to expert elicitation. For major industrial facilities (e.g. dams and nuclear power plants), the development of the logic tree is often carried out according to the Senior Seismic Hazard Analysis Committee (SSHAC) guidelines for expert elicitation (Budnitz et al., 1997). In the face of deep epistemic uncertainties and wide spreads in experts' opinions, special care is essential to avoid the inflation of elicited uncertainties and parameter distributions (Aspinall and Cooke, 2013). Notably, the ways a PSHA is conducted analytically and uncertainties are classified have led to different representations of seismic hazard results with respect to epistemic uncertainties: unconditional fractile (i.e. mean) vs. conditional fractiles (e.g. median or 84th percentile) (Abrahamson and
NHESSD

doi:10.5194/nhess-2015-295

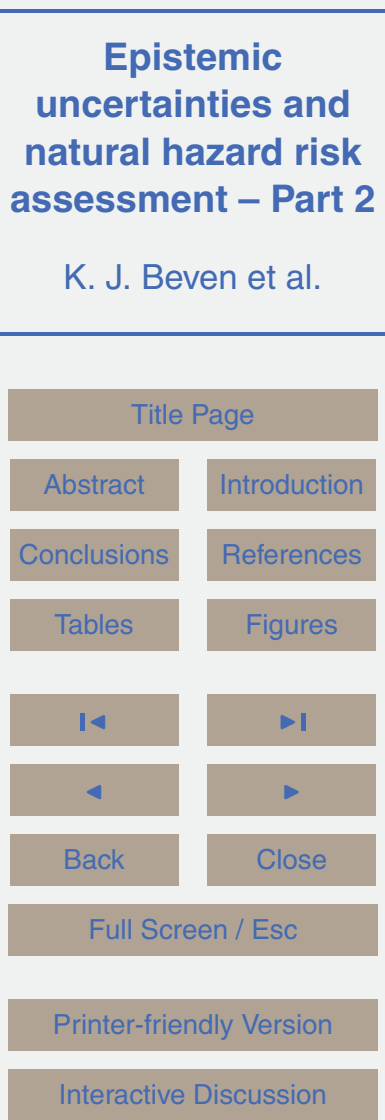


Bommer, 2005; McGuire et al., 2005). Typically, because of long-tailed uncertainty distributions, mean hazard estimates are greater than median, and differences between mean and median estimates tend to increase with longer return period or smaller probability of exceedance. The motivation of different approaches is not only rooted in the 5 theoretical aspects but also is related to the practical consequences of the PSHA results, e.g. for safety-critical facilities for which the consideration of very low probability levels is required.

Two of the critical elements in PSHA, which are linked but both subject to considerable epistemic uncertainties, are the estimation of long-term occurrence rates of large extreme or "characteristic" earthquakes (e.g. $M_{\mathrm{w}}=7.5$ to $M_{\mathrm{w}}=9$ ) and the evaluation of the "maximum magnitude" to use in a PSHA, for a given seismotectonic environment. On occasion, the upper bound of the maximum magnitude may not be constrained physically nor statistically (Kagan and Jackson, 2013). The difficulty simply stems from the fact that records of seismicity data are insufficient to derive such long-term occur15 rence rates reliably, solely from historical catalogues or instrumental databases. The quality, completeness and reliability of an earthquake catalogue evolves over time, affected by the distribution of human settlements and the way in which major events in the historical record have been reported (e.g. newspaper and missionary journals). Since the beginning of the 20th century, seismographic networks have been expanded significantly in terms of instrument numbers and detection sensitivity. But advances in measurement technology and wider geographical coverage of such networks often result in inhomogeneous detection and monitoring capabilities of instrumental catalogues (Tiampo et al., 2007).

Recent PSHA studies for potentially active but less well-instrumented seismically active regions (e.g. the East African Rift) have extended the modelling basis for regional seismicity beyond historical/instrumental earthquake catalogues by using information from mapped geological faults and geodetically-determined rates of strain accumulation (e.g. Hodges et al., 2015). It is noteworthy that such PSHA assessments involve considerable uncertainties but may be better able to capture potential extreme (sur-

\section{NHESSD}

doi:10.5194/nhess-2015-295
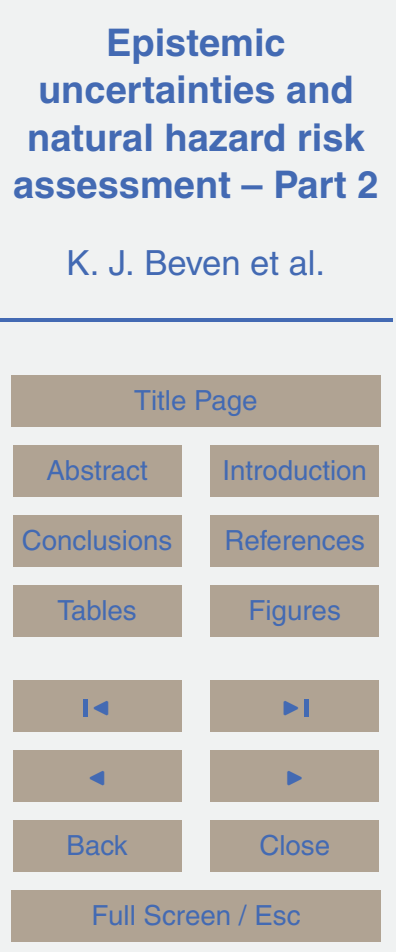

Printer-friendly Version

Interactive Discussion 
prise) events. Rigorous sensitivity investigations should be accompanied by testing alternative hypotheses and by comparing the impacts of the adopted assumptions on regional seismic hazard assessments. In this regard, a PSHA should be reviewed, from an instrumental perspective, such that a better understanding of seismic hazard 5 assessments and their uncertainties can be achieved (Woo and Aspinall, 2015).

It has become more established in recent years that the recurrence of earthquakes on many mature fault systems and in subduction zones (where multiple plates meet and interact) can be non-Poissonian and quasi-periodic, and thus the hazard and risk potential posed by specific faults or subduction zones may be regarded as time10 dependent (Sykes and Menke, 2006). Both physics-driven recurrence models (Shimazaki and Nakata, 1980) and statistics-based renewal models (Cornell and Winterstein, 1988; Matthews et al., 2002) have been adopted in PSHA. A notable example of active seismic regions that are affected by a renewal earthquake process is the Cascadia subduction zone. This involves the geodynamics of the oceanic Juan 5 de Fuca, Gorda, and Explorer plates moving against the continental North American plate. A unique aspect of this subduction zone is that repeated occurrences of $M_{\mathrm{w}} 9$ class mega-thrust earthquakes - due to subduction plate motions - have been recognised from field evidence only relatively recently and reported in the scientific literature (Satake et al., 2003; Goldfinger et al., 2012). In other words, the recurrence and rupture processes of the Cascadia subduction zone involve major epistemic uncertainties, and yet detailed hazard and risk assessments are necessary from an earthquake disaster preparedness viewpoint. In the last decade, various seismic hazard and risk studies for possible risk mitigation have been carried out by adopting a wide range of time-dependent recurrence models and possible rupture scenarios as a way of trying wide, 2013). This situation contrasts with the case for the 2011 Tōhoku earthquake, where the consideration of extreme events was not taken up in risk mitigation actions prior to this event, even though there were indications of the impacts of past major tsunami-inducing events in the region. The current knowledge and understanding of

\section{NHESSD}

doi:10.5194/nhess-2015-295

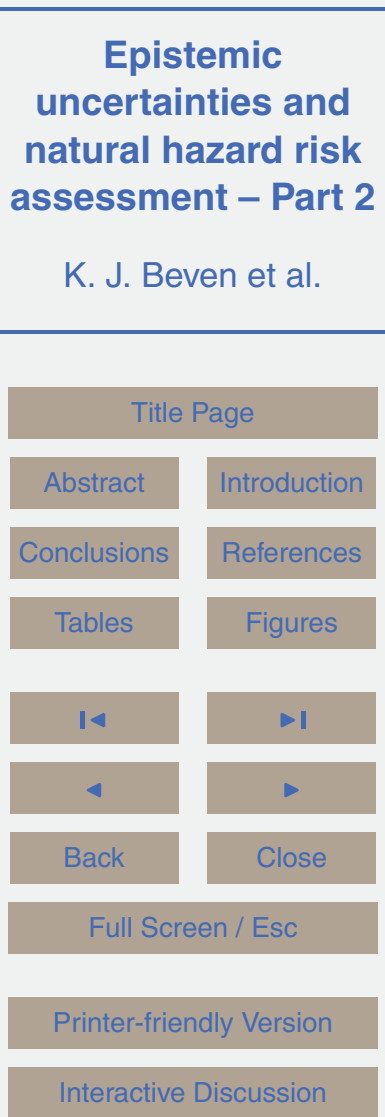

Interactive Discussion 
the Cascadia subduction events are likely to be further updated in the future, and so the scientific assessment framework and tools for quantifying the characteristics and patterns of such earthquakes should also evolve dynamically.

Ground motion models that are used in PSHA constitute another major source 5 of uncertainties. Empirically derived prediction models using observed strong motion records are inherently limited by the availability of strong motion recordings. Even following the dramatic expansions of strong motion networks in active seismic regions (e.g. California, Japan, Taiwan, New Zealand, and Turkey), near-source strong motion data and strong motion data for very large earthquakes (with the notable exception of the 2011 Tohoku earthquake) are still lacking. This reality forces us to update existing empirical ground motion models from time-to-time by incorporating newly available data or to use computational model simulations of strong motion. Another important issue, related to ground motion modelling using observed ground motion records, is that the majority of the existing ground motion models have been developed based on the ergodic assumption (Anderson and Brune, 1999). The ergodic assumption in the context of ground motion modelling implies that the ground motions required at a specific location can be substituted by recorded ground motions at different locations. There may be limited physical validity for this assumption in reality and, at best, adopting it faute de mieux engenders exaggerated epistemic uncertainty in the site-specific case via regression scatter estimates. Practical consequences of adopting this working hypothesis are biased seismic hazard assessments (Atkinson, 2006).

A new generation of ground motion models addresses the problem more rigorously (Stafford, 2014). New strong motion data also offer new insights regarding the earthquake source processes via source inversion (e.g. slip distribution and asperities, i.e. concentrated slip patches; Mai and Beroza, 2002; Lavallee et al., 2006). The improved knowledge of the earthquake source process in turn necessitates updated definitions of the seismological parameters and their use in PSHA. For instance, the asperity-based earthquake source model requires additional parameters to characterise the location and concentration of earthquake slips within a fault plane. Furthermore, measures that
NHESSD

doi:10.5194/nhess-2015-295

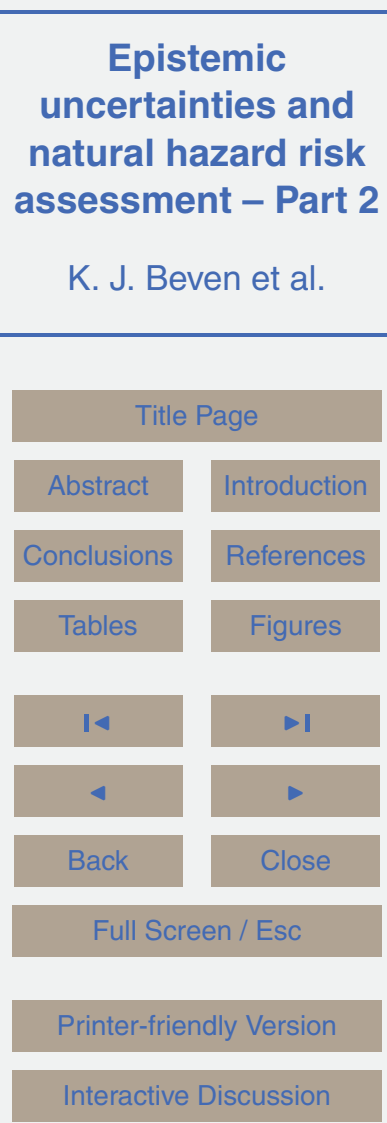


are used to represent the source-to-site distance (e.g. hypocentral distance and rupture distance) may not be relevant within the extended methodology and may introduce epistemic uncertainties in ground motion predictions for future earthquakes (Goda and Atkinson, 2014). New data and theories facilitate the refinements of existing ground 5 models and PSHA methods in a complex manner that may require the specification of additional uncertain parameters. Further uncertainties may be introduced by the nonlinear relationships between ground motion characteristics and structural response and damage in assessing seismic risk.

Improvements in PSHA methods and recent earthquake disasters (e.g. 2004 Suma10 tra event and 2011 Tōhoku event) have stimulated the development of a new cascading multi-hazard approach for mega-thrust subduction earthquakes. The approach promotes an integrated earthquake impact assessment for a sequence of earthquaketriggered hazards, i.e. mainshock followed by tsunami and multiple aftershocks. The novel multi-hazard methodology takes into account both uncertainty and physical dependency of common earthquake source characteristics for multi-hazard processes (Goda et al., 2015). Coupled simulation of strong motion and tsunami can be performed for the multi-hazard impact assessment.

To account for time-dependent aftershock hazards and risks, occurrence of aftershocks can be simulated by employing the modified Omori's law and then the aftershock hazards can be integrated with the mainshock hazards (e.g. Yeo and Cornell, 2009). Time-dependent aftershock hazards are applicable to both moderate crustal earthquakes and mega-thrust subduction earthquakes. The 2010-2011 Canterbury Plains, New Zealand, sequences (Shcherbakov et al., 2012) highlighted major challenges in seismic risk assessment. This is because the sequences of quakes, which initiated with the $2010 M_{\mathrm{w}}=7.1$ Darfield earthquake, migrated towards the east and eventually entailed destructive earthquakes near downtown Christchurch in 2011. Currently, forecasting such evolving spatial aftershock sequences is difficult and including a full accounting for epistemic uncertainties associated with cascading multi-hazards is still at an early stage of development. Nevertheless, it is important, and intellectu-
NHESSD

doi:10.5194/nhess-2015-295
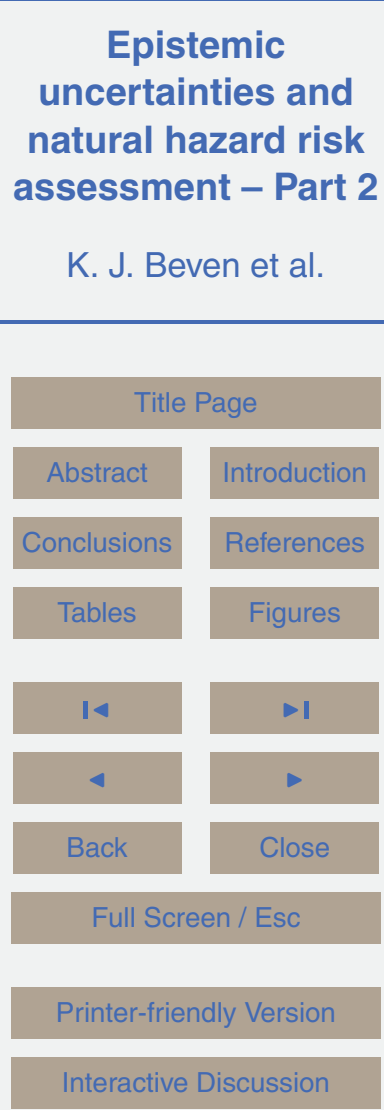
ally stimulating, to tackle the challenges of extending current quasi-static, fragmented approaches to dynamic, coherent methods for cascading hazards.

\section{Tsunamis}

Massive tsunamis triggered by large earthquakes pose major threats to modern soci5 ety, generating fatalities, disrupting socioeconomic activities, and causing grave economic impact across the world. Forecasting tsunamigenic earthquakes is challenging for the same reasons discussed above for earthquake prediction. Major sources of epistemic uncertainties are related to earthquake rupture procesess (e.g. source areas and size, asperity, and kinematic/dynamic rupture process) and inundation/run-up process (e.g. topographical effects, land surface friction, and flow dynamics in urban areas).

Estimating potential earthquake size is one of the most critical factors in predicting the impact of great tsunamis. Inappropriate application of seismological theories could result in gross underestimation of earthquake magnitude of mega-thrust subduction earthquakes (Kagan and Jackson, 2013). Moreover, the earthquake rupture process is complex and highly uncertain, and is governed by pre-rupture stress conditions and frictional properties of the fault that are largely unknown/unobservable and heterogeneous in space. A large earthquake may also trigger a submarine landslide, which acts as secondary sources for tsunami generation (Tappin et al., 2014). To gain fur-

\section{ther insights into the earthquake rupture process, source inversions can be carried out} to characterise the space-time evolution of the rupture by matching key features of simulated data with observations. Although sophisticated mathematical frameworks for source inversion have been developed and implemented, derived earthquake rupture models vary significantly, depending on the methods and data used for inversion (Mai plitude of slip asperities differ significantly among inversion models for the 2011 Tohoku earthquake (Goda et al., 2014), reflecting the complexity and uncertainty in imaging the

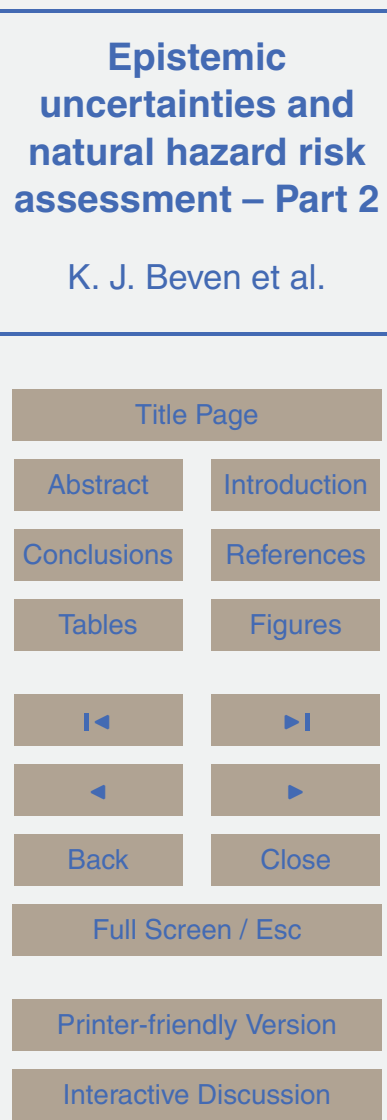


rupture process for mega-thrust subduction earthquakes. Additionally, different source modelling approaches, such as surface rupture to ocean bottom, effects of horizontal deformation of steep slopes on vertical deformation, hydrodynamic response of water column, and time-dependent rupture process, slow vs. fast rupture propagation speed, will influence the resulting tsunami waves (Geist, 2002; McCloskey et al., 2008; Løvholt et al., 2012; Satake et al., 2013). All these factors contribute to epistemic uncertainties related to tsunami source modelling.

Topographical features of near- and on-shore areas have major effects on tsunami waves and inundation/run-up. The spatial resolution and accuracy of digital elevation 10 models (DEM) are important for representing local terrain features realistically. Typically, the frictional properties of terrain features are modelled by Manning's roughness coefficients. Different data resolutions will require different effective roughness coefficients, thus affecting tsunami inundation extents. The impacts of uncertainty in the DEM and roughness coefficients will depend on tsunami hazard parameters (Kaiser et al., 15 2011). For instance, the inundation depths are less sensitive to the data resolutions and characteristics, whereas the flow velocity and momentum, which are also important in evaluating the tsunami-induced forces on buildings (Koshimura et al., 2009), are more sensitive. This issue becomes even more critical when tsunami inundation in dense urban areas is investigated, where buildings are represented as (impermeable) elevation data. The simulated flow velocities in urban streets can be very high.

It is rare that that uncertainties of the DEM data and roughness coefficients are taken into account in conducting tsunami simulations but adopting the same modelling philosophy as probabilistic seismic hazard assessment, probabilistic tsunami hazard analysis (PTHA) has been developed and applied to some major tsunami-prone regions (e.g. 25 Annaka et al., 2007; Thio et al., 2007; Horspool et al., 2014). The main focus and advantage of PTHA are to integrate potential tsunami hazards from various sources (both near-field and far-field) in a probabilistic framework. Epistemic uncertainties are mathematically represented in PTHA through a logic-tree approach by assigning weights to alternatives for different model components. The final output is a tsunami hazard curve
NHESSD

doi:10.5194/nhess-2015-295
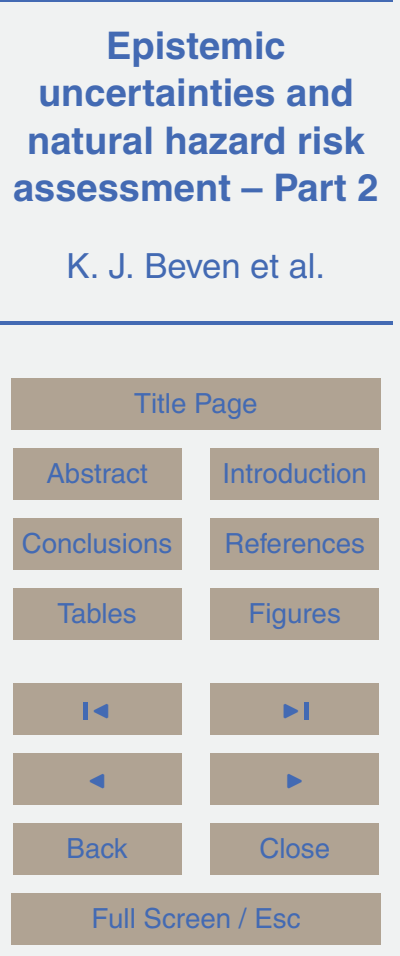

Printer-friendly Version

Interactive Discussion 
and probabilistic tsunami inundation maps of inundation depth and other relevant parameters. A major difference between PTHA and PSHA is that differential equations of tsunami wave propagation (typically shallow water equations) in ocean are evaluated directly, whereas in PSHA, seismic wave propagation (as well as earthquake rupture 5 and site response) is approximated using empirical ground motion models. The direct simulation of tsunami waves reduces the uncertainties associated with tsunami hazard assessment, and provides additional information on the tsunami wave time-history and arrival time.

However, PTHA can be computationally demanding. To achieve computational effi10 ciency, PTHA is often formulated based on linear superposition of tsunami waves (i.e. Green's functions) for simplified earthquake sources and is carried out only for nearshore locations (e.g. at $30 \mathrm{~m}$ depth). The inundation and run-up processes are often modelled by applying amplification factors (e.g. Løvholt et al., 2014). To improve the tsunami hazard prediction and quantify the effects of epistemic uncertainties, it is desirable to integrate the stochastic source modelling approach (which carries out fully nonlinear inundation simulation of tsunami waves) into the PTHA methodology. Such an extended PTHA could reflect the variability of source characteristics for specific scenarios as well as numerous tsunami sources in developing tsunami hazard curves and maps.

\section{Volcanic eruptions and ash clouds}

The 2010 eruption of Eyjafjallajökull in Iceland provided a dramatic demonstration of the potential for volcanic ash clouds as a natural hazard. Because of the synoptic weather at the time of the eruption the ash cloud caused enormous disruption to air travel across Europe and the Atlantic with some 10 million air travellers being affected, at a total estimated cost of EUR 1 billion per day (Oxford Economics, 2010). Since then there has been considerable effort expended in the monitoring and prediction of volcanic ash clouds. Ash clouds can also be a problem in many other parts of the world,

\section{NHESSD}

doi:10.5194/nhess-2015-295
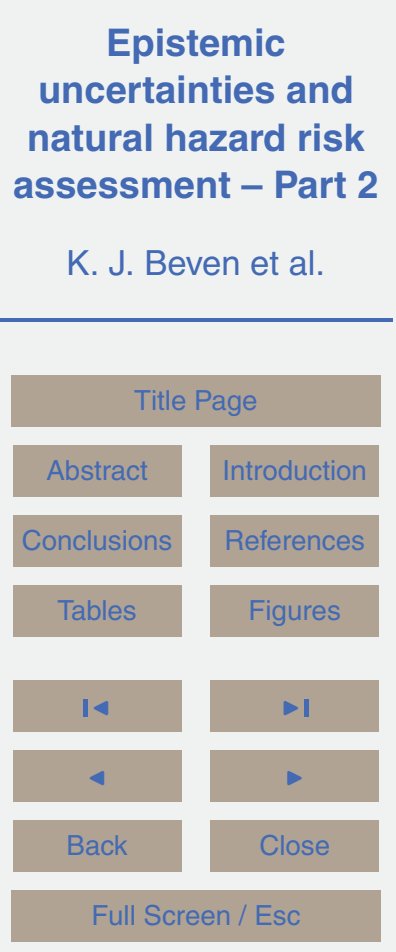

Printer-friendly Version

Interactive Discussion 
for example as a result of the continuing eruption of Mount Sinabung in Indonesia and the recent 2015 eruption of the Calbuco volcano in Chile. Globally, a network of nine Volcanic Ash Advisory Centres (VAACs) provide a warning service based on monitoring and modelling.

Infrared satellite observations are perhaps the most important tools for monitoring ash but are not without their problems. Ash detection is complicated by a number of factors. The brightness temperature difference (BTD; the difference between brightness temperatures at two infrared channels) used as the basis for infrared ash detection can be affected by false positives and false negatives due to e.g. atmospheric conditions 10 (Simpson et al., 2000; Mackie and Watson, 2015), land surface type and temperature, presence of other aerosols (Prata, 1989; Prata et al., 2001; Pavolonis et al., 2006; Lee et al., 2014) and water/ice (Rose et al., 1995), in addition to particle size (e.g. Millington et al., 2012) and ash cloud opacity (Rose et al., 2001) (see Fig. 3). Sophisticated volcanic ash retrieval schemes such as Francis et al. (2012) and Pavolonis et al. (2013) 15 use a third infrared channel to help with removing these false alarms (Stevenson et al., 2015).

Many assumptions are made about the physical properties of ash in order to make estimates on other physical properties such as ash column loading, ash cloud height and effective radius. For example, in the Met Office 1-D-Variational (1-D-Var) volcanic ash retrieval scheme (Francis et al., 2012) it is assumed that ash particles are spherical to simplify the absorption and scattering calculations, the particle size distribution (PSD) is assumed to be lognormal in shape, and the geometric standard deviation of the distribution is selected from a number of possible values. However, this value can have a significant effect on retrieved ash column loading (e.g. Western et al., 2015).

25 Ash composition, and hence, refractive index data must also be assumed, adding considerable uncertainty (Mackie et al., 2014). There are limited ash refractive index data available, and this choice can also have a significant effect on derived ash properties (e.g. Francis et al., 2012). The PSD geometric standard deviation and refractive index data set are varied within the 1-D-Var algorithm and the solution with the lowest cost is
NHESSD

doi:10.5194/nhess-2015-295

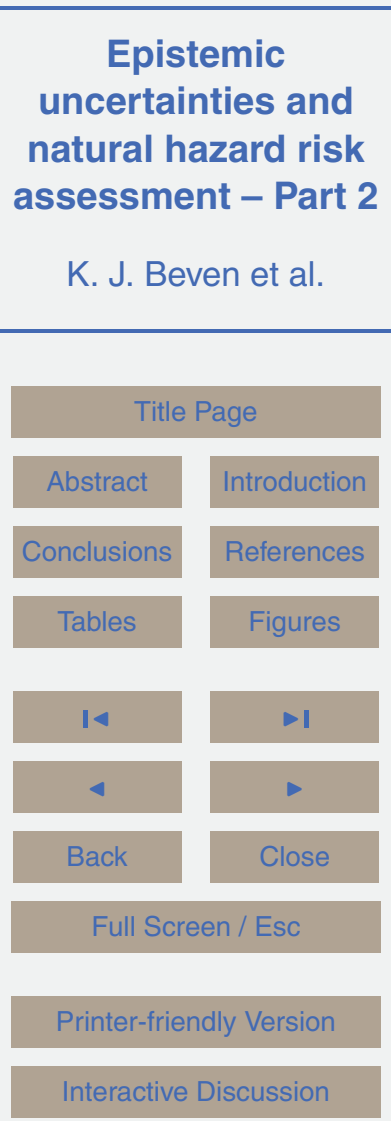


generally used; the solution cost of the 1-D-Var scheme can be used as an uncertainty measure, with high costs indicating high uncertainty (Stevenson et al., 2015).

Other sources of uncertainty are introduced in the simulation of satellite imagery using a radiative transfer model, in the meteorological data used within the model, in5 terpolation of that data and so on. Some of these are very generally accounted for the in 1-D-Var algorithm but not all. Other types of observations (e.g. hyperspectral satellite observations, satellite, aircraft or ground-based lidar) are used to add information and/or reduce uncertainty in these types of derived observational data, but are often of much lower temporal or spatial resolution and carry their own assumptions and un10 certainties (e.g. Wilkins et al., 2016). Clearly, many of these sources of uncertainty are epistemic in nature and not necessarily aleatory in their characteristics.

Modelling of the hazard is, however, a problem of forecasting. At the UK Met Office the Numerical Atmospheric-dispersion Modelling Environment (NAME) model (Jones et al., 2007) is used in both simulation and forecasting of ash to inform the London 15 VAAC which covers eruptions in Iceland and the impacts on northwest Europe. As with all models, NAME is a simplified representation of the problem, and does not include some of the complex physical processes that control the behaviour of an ash field close to the source of the eruption, notably plume behaviour and particle aggregation. Nearfield processes are still the subject of current research (e.g. Taddeucci et al., 2011). Currently, the effects of gravity currents (Bursik et al., 1992a; Sparks, 1986) are also not included in most atmospheric dispersion models. These near-source processes are likely to dominate ash dispersion and transport close to the source, and for large eruptions they could dominate for hundreds of kilometres (Bursik et al., 1992a, b; Sparks et al., 1997), but far from the source are unlikely to affect downwind ash clouds for weak eruptions (Devenish et al., 2012a; Costa et al., 2013).

In NAME an effective source term is used as a boundary condition for the far-field transport and deposition of ash. This includes assumptions about the PSD of the ash. Plume behaviour can vary significantly over time and information derived from deposited ash, often after an event, does not necessarily give a good indication of
NHESSD

doi:10.5194/nhess-2015-295

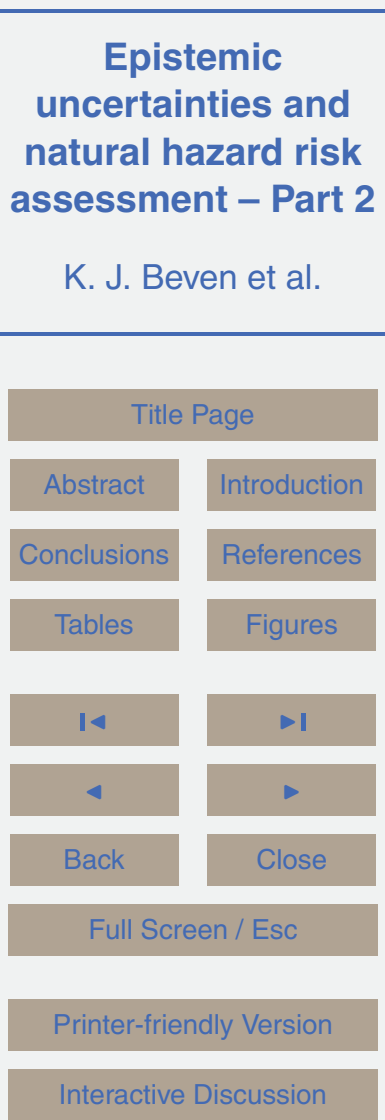


the PSD within the distal ash cloud (Bonadonna and Houghton, 2005). Operationally, a default source term PSD has been used by the London VAAC, based on empirical measurements from Hobbs et al. (1991) which aims to represent the fine ash that survives near-source fall-out (Webster et al., 2012). This component may be of the or5 der of $0.05-10 \%$ of the total erupted mass (Mastin et al., 2009). Mass emission rate (MER) and particle density are also required and are also very difficult to determine experimentally. MER is often represented as a simple empirical power law as a function of plume height with fixed parameters (e.g. Mastin et al., 2009), while in a study of the Eyjafjallajökull eruption, Webster et al. (2012) used a fixed ash density value of $102300 \mathrm{~kg} \mathrm{~m}^{-3}$. It is thought that the empirical function for MER may be biased towards observed data from larger eruptions (Woodhouse et al., 2013). Plume height measurements used to determine MER (e.g. radar) are subject to uncertainties (Arason et al., 2011; Folch et al., 2012), and plumes from weak eruptions such as Eyjafjallajökull can become distorted by local winds, increasing plume height measurement uncertainty

and therefore affecting the MER calculation (Webster et al., 2012). All of these factors represent primary epistemic uncertainties in the application of such models. Even a cursory treatment of those uncertainties results in a significant predictive uncertainty (Devenish et al., 2012b).

One way of constraining such uncertainty is to use inversion modelling to learn more about dispersion parameters and model eruption source parameters (ESPs) based on the available observations and prior information (e.g. Stohl et al., 2011; Kristiansen et al., 2012; Moxnes et al., 2014; Pelley et al., 2015). In this way, Kristiansen et al. (2012) estimated optimal volcanic ash source terms for the Eyjafjallajökull eruption using an inversion algorithm with satellite-retrieved ash column loadinversion-estimated source terms were applied within the models a posteriori to perform long-range forecasts and results were validated using LIDAR and in-situ PSD measurements from research flights. Uncertainties in the a priori emission estimates, model and observations were taken into account within the inversion algorithm, allow-

\section{NHESSD}
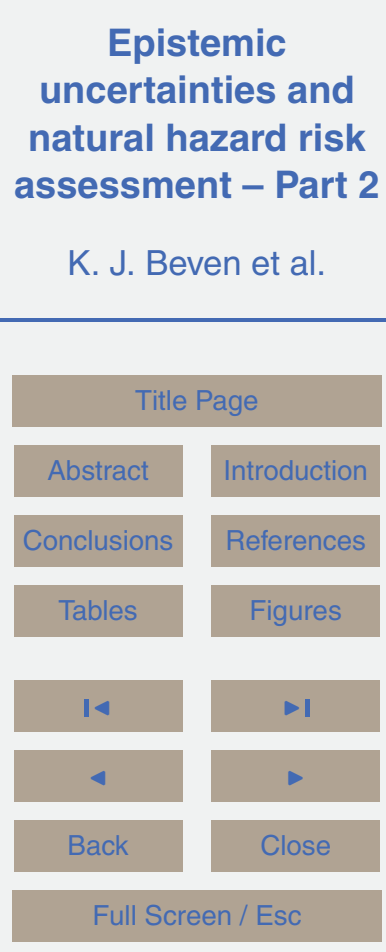

Printer-friendly Version

Interactive Discussion 
ing the result to deviate from the a priori emissions and the observations according to the errors. A genetic algorithm variational method was applied by Schmehl et al. (2011) to elucidate wind direction, wind speed and mass emission rate to be used for forward assimilation in a dispersion model. In this approach a cost function based on the differ5 ence between observed and modelled fields was minimised over a series of iterations or until the solution converged. By sampling the source term parameter ranges iteratively, the results could be used to constrain uncertainty in ESPs and/or meteorological fields.

In a different approach to data assimilation, a Bayesian method was adopted by Den10 linger et al. (2012) to propagate uncertainty in ESPs within an atmospheric dispersion model and estimate forecast uncertainty. A model was run with ESPs sampled from probability distributions. The model outputs were then assessed by comparison with satellite observations, a likelihood function defined, and a posterior probability distribution determined using Bayes theorem. Wilkins et al. $(2014,2015)$ used data insertion to 15 initialise NAME using measurement-derived data. Instead of releasing ash with a defined release rate from the volcano vent, it was released several times from "snapshots" of downwind ash clouds defined using retrieved data from infrared satellite imagery, insitu and other remotely sensed data. While this method does not explicitly deal with uncertainties in the model or observations, it could potentially be used to bypass a lack of knowledge of the ESPs, for instance where the location of the volcano is unknown. The method does, however, require estimations of ash layer thickness, vertical distribution and PSD.

When such models are used for forecasting it is possible to compensate for epistemic uncertainties, at least can be in part, by the assimilation of information about the ash cloud derived from remote sensing and other direct sources such as experimental flights. Data assimilation will then implicitly compensate for some of the epistemic uncertainty associated with the model. However, the propagation of complex epistemic uncertainty in computationally expensive atmospheric-dispersion models is a time con-
NHESSD

doi:10.5194/nhess-2015-295
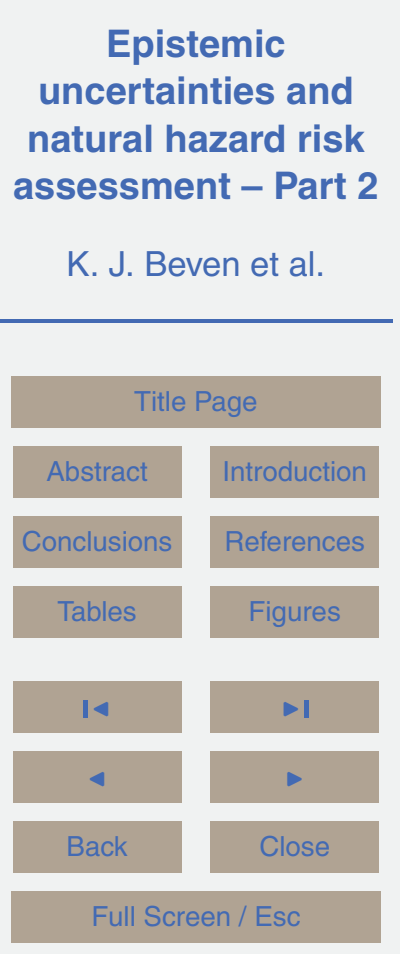

Printer-friendly Version

Interactive Discussion 
suming and difficult problem to quantify. The characterisation of volcanic ash forecast uncertainties in an operational time scale therefore remains a challenging task.

\section{Pyroclastic density currents}

Rapidly-moving flows of hot, fragmented gas-rich magmatic products in pyroclastic 5 density currents (PDC; also known as 'nuées ardentes or pyroclastic flows and surges) are the biggest killers in explosive volcanic eruptions. However, much is still to be learned about the factors that control their initial formation, their movement across terrain and the ways they injure and kill people, and damage structures. Thus there are multiple sources of epistemic uncertainty about the hazards and risks associated with 10 these dangerous phenomena.

The 79 CE eruption of Vesuvius and the remains found at Herculaneum and Pompeii represent a classic historic example of the disastrous impacts of PDCs, and any repeat at this volcano in the future, even on a smaller, less intense scale, could have massive consequences for the heavily-populated surrounding area. Hazard and risk assessments for this situation, undertaken in the last twenty years for the National Emergency Plan (DPC, 1995, 2001), were mostly based on the characterization of a single "Maximum Expected Event" (MEE). Such an event largely corresponds in the expected intensity of effects to the hazardous phenomena that occurred during the last sub-Plinian eruption of Vesuvius, in $1631 \mathrm{CE}$. However, that definition was not based on a fully quantitative analysis of the whole system and potential ranges of eruptive activity, and no probabilistic estimates were provided of the likelihood of occurrence of the hazard events being considered.

In work for the EXPLORIS project (Neri et al., 2008), probabilistic characterizations of possible future eruptive scenarios at Vesuvius volcano were elaborated and organized within a risk-based framework, and a wide variety of topics relating to this basic problem were pursued: updates of historical data, reinterpretation of previous geological field data and the collection of new fieldwork results, the development of novel

\section{NHESSD}

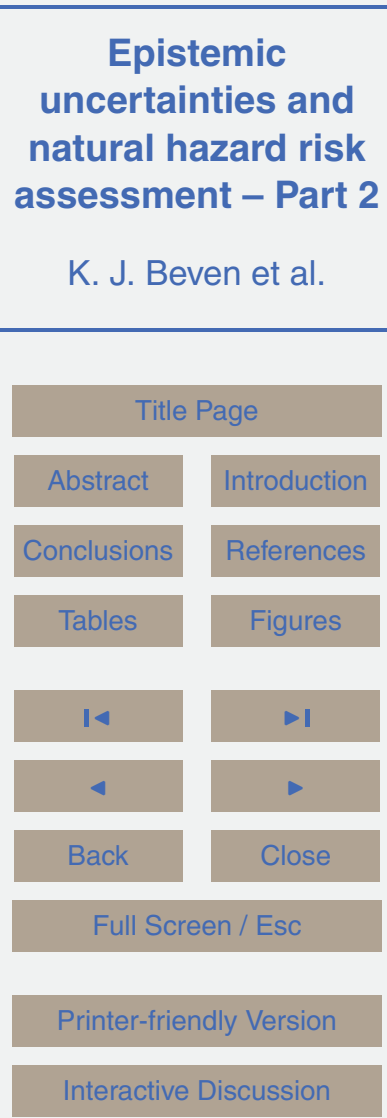

Interactive Discussion 
numerical modelling codes and of risk assessment techniques. To achieve coherence, many diverse strands of evidence had to be unified within a formalised structure, and linked together by expert knowledge. For this purpose, a Vesuvius "Event Tree" (ET) was created to summarise in a numerical-graphical form, at different levels of detail, 5 all the relative likelihoods relating to the genesis and style of eruption, development and nature of volcanic hazards, and the probabilities of occurrence of different volcanic risks in the next eruption crisis. In order to achieve a complete parameterization for this all-inclusive approach, exhaustive hazard and risk models were needed, quantified with comprehensive uncertainty distributions for all factors involved, rather than sim10 ple "best-estimate" or nominal values. Thus, a structured expert elicitation procedure was implemented to complement more traditional data analysis and interpretative approaches, and to add a formalized approach to the generic incorporation of epistemic uncertainty in the assessment by way of the Event Tree formulation.

Here, we focus on the issues of epistemic uncertainty in relation to the physical char15 acterization of PDC potential during a Sub-Plinian column collapse eruption, and how the topography of the volcano influences hazard and risk mapping results. Basic effort in this regard, during EXPLORIS, was dedicated to the development and application of a transient 3-D parallel code PDAC, able to simulate the dynamics of the collapse of the volcanic column and the propagation of the associated PDCs (Esposti Ongaro et al., 2007). The model solves the fundamental multiphase flow transport equation of Neri et al. (2003) and provides a means to describe the complexities of the column collapse and the temporal and spatial evolution of flows over the whole 3-D topography of the volcano. However, the full ranges of plausible volcanic and other physical input parameter variations are not amenable to comprehensive exploration in a restricted number of scenario runs, which are limited by computing power and cost. Under these circumstances, the few PDAC runs that were possible were used as indicative references, with expert elicitations used to derive rational, quantitative statements about the most appropriate values to use for variables of interest and, more importantly, to give expression to the scientific uncertainty that attaches to the outcomes of such model runs. For
NHESSD

doi:10.5194/nhess-2015-295
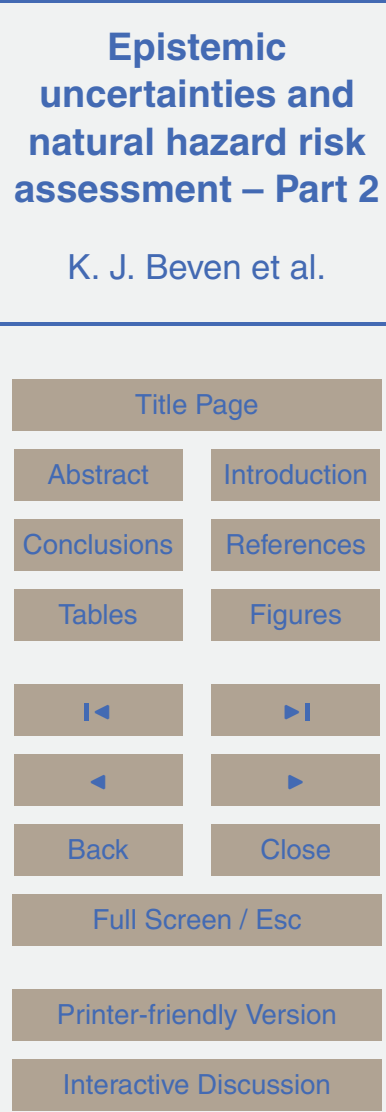
instance, distributional expressions for uncertainties on pyroclastic flow run-out distances, peak pressures and temperatures were obtained by elicitation, after detailed consideration of the few simulation model results that were achievable, and of field evidences, old and new.

One significant source of epistemic uncertainty in this context is the role which the actual topography of Somma-Vesuvius will play in the occurrence of a future central eruption from the present Gran Cono of Vesuvius. After analysing several different options, the EXPLORIS group envisaged a subdivision of the Vesuvian Area into two main sectors, Sectors A and B, delimited by the two red lines on Fig. 4a (Sector A includes 10 the area "not protected" by Mt. Somma, and Sector B, the area which is "protected") representing a first-order source of epistemic uncertainty in respect of the extent to which the presence of the Mt. Somma topography could determine which areas could be invaded by flows, or modify properties of the flows that might affect the two sectors. More detailed analysis of modelled effects within Sector A suggested a sub-division 15 into Sectors A1, A2, A3 and A4, as delineated by the yellow lines on Fig. 4a, with the aim of reducing overall epistemic uncertainty in relation to directional influences on PDC propagation, by allowing more precise analysis of the spatial hazard in the region not protected by Mt. Somma. The bracketed values in each sector show elicited modal probabilities that a PDC will affect that sector, given a Sub-Plinian I scale eruption occurs (probabilities expressed in percentage terms) together with the corresponding credible intervals, in quantile form (5th, 50th, 95th percentiles). From the elicitation outcomes it is evident that the presence of Mt. Somma is expected to reduce, by a factor of about two, the probability of flow invasion into the northern sector. Nevertheless, the associated credible interval results are quite large, reflecting the significant uncertainty associated with judgments about column collapse and PDC phenomena. That said, the elicited probabilities of invasion of the different sub-sectors of Area A are each very similar, and apparently only weakly affected by the preferential propagation directions shown by some of the 3-D simulations (Esposti Ongaro et al., 2008) or by reconstructions of past Sub-Plinian events (Rosi et al., 1993; Cioni et al., 2008).
NHESSD

doi:10.5194/nhess-2015-295
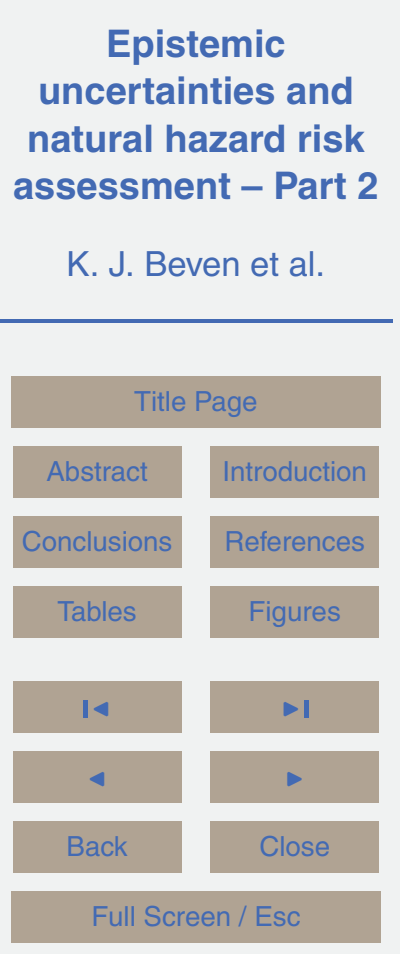

Printer-friendly Version

Interactive Discussion 
Even more critical information, relating to PDC hazards and hence risk mitigation, is represented in the assessed run-outs of PDC, which directly determine the extent of the Emergency Plan Red Zone, i.e. the size of the region that should be evacuated in advance of an eruption, and where about half million people currently live. Figure $4 \mathrm{~b}$ 5 shows the elicited judgements of maximum run-out distances (in $\mathrm{km}$ ) for PDCs occurring during a Sub-Plinian I eruption, by sector. Inner arcs (blue) are $95 \%$ confidence levels for a run-out exceeding the distance shown (e.g. $2.5 \mathrm{~km}$ for Sector A1), central arcs (green) are the modal (50th percentile) values, and outer arcs (orange) are the runout distances assessed has having only a $5 \%$ chance of being exceeded (e.g. $13.3 \mathrm{~km}$ 10 for A1). A significant difference in anticipated run-outs is again shown for Sectors $A$ and B (a gap of about $2 \mathrm{~km}$ between the 50th percentiles), but perhaps the most striking and important - feature of the results are the large credible intervals associated with these run-out estimates. This outcome was actually expected, given the complexity of the phenomenon being investigated and recognition of the technical limitations of the approaches adopted. In fact, the mechanism and degree of column collapse, i.e. the percentage of mass collapsing back to the ground, can significantly affect the mobility and dispersal of PDCs. On the other hand, reconstructions of the maximum extent of PDCs that occurred during past events are limited by the incomplete preservation of the products, as well as by partial access to the deposits (Cioni et al., 2008). Similarly, the adopted PDAC 3-D code is limited by the vertical resolution of the computational grid, which does not allow accurate modelling of the lower denser portion of the flow (Esposti Ongaro et al., 2007, 2008).

The large epistemic uncertainties regarding the directional controls on PDC probabilities and likely run-outs also influence the expected values of the main physical variables that can be associated with a PDC scenario: e.g. peak dynamic pressure and peak flow temperature. The fact that the EXPLORIS exercise also resulted in large credible intervals associated with these parameter estimates, as well as with the PDC run-outs, clearly reflects expert perceptions of the significant degree to which epistemic uncertainties must affect current attempts to forecast the complex hazard pro-
NHESSD

doi:10.5194/nhess-2015-295

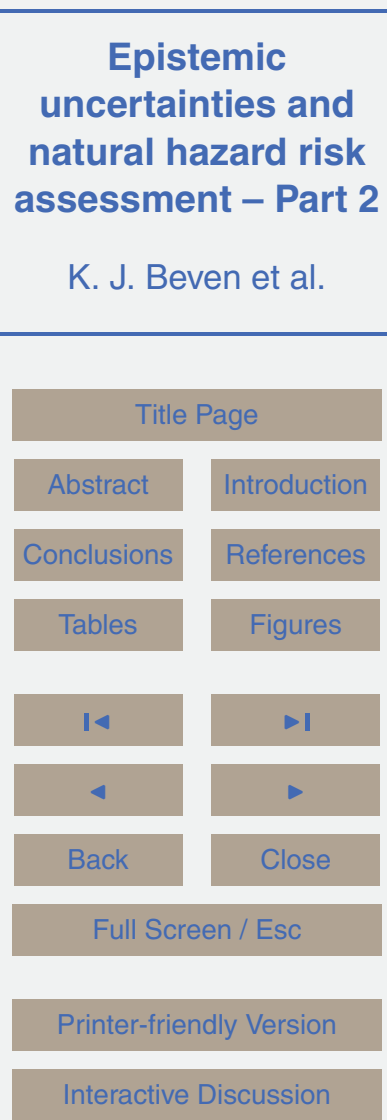


cesses being considered. One conclusion is that more field and more numerical work is needed in order to further constrain the areas likely to be affected by future PDCs at Vesuvius.

\section{European windstorms}

5 Weather hazards are a major source of societal risk causing death, destruction to infrastructure and disruption to transport and business. Insured losses, currently estimated to cost USD 200 billion annually, are expected to rise dramatically due to climate-change related trends in weather extremes, increasing exposure in developing countries, and increasing world population. Extra-tropical cyclones (also known 10 as windstorms) are major contributors to this impact e.g. insured losses in Europe of USD 9 billion for windstorm Daria (25 January 1990). Furthermore, windstorms often arrive in close succession, which enhances the risk of large aggregate losses e.g. the winter 2013/14 cluster of European windstorms Christian, Xavier, Dirk and Tini caused insured losses of USD 1.38, $0.96,0.47$ and 0.36 billion totalling USD 3.3 billion (source: 5 www.perils.org).

Windstorm loss distributions are inferred from historical weather measurement data (mainly available since 1950) and also increasingly from storm data simulated ab initio from numerical weather and climate prediction models (Schwierz et al., 2010; Pinto et al., 2010; Della-Marta et al., 2010; Renggli et al., 2011; Karremann et al., 2014). The loss distributions are estimated by Monte Carlo simulation using ad hoc combinations of various statistical, dynamical and engineering type models: statistical models for estimating trends and correcting inhomogeneities in the historical data (Barredo, 2010), either low-order parametric stochastic models (the traditional basis of many catastrophe models), or more recently, numerical weather and climate models for simulating large sets of artificial hazard events, statistical models for adjusting biases in numerical model output, and stochastic models for simulating losses from the artificial windstorm events (e.g. compound-Poisson event-loss table models).

\section{NHESSD}

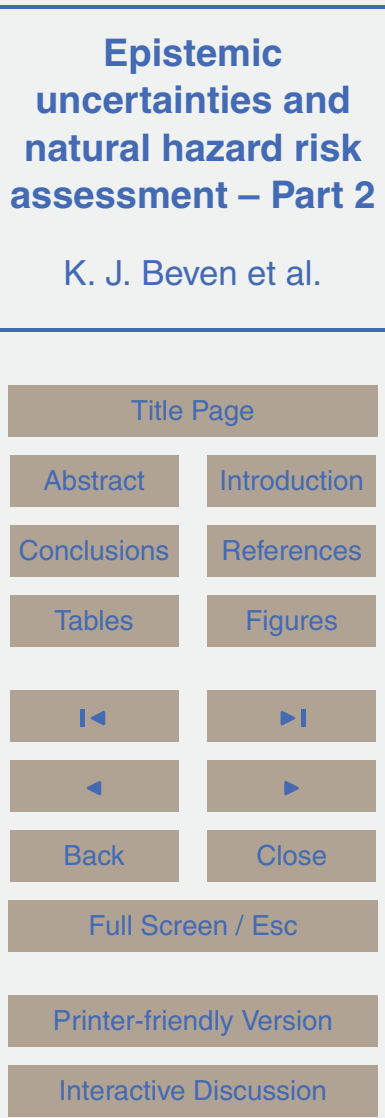

Interactive Discussion 
Since many choices are required to develop these models, there are many sources of epistemic uncertainty. To list just a few of the major uncertainties in each type of model:

- Stochastic hazard and loss models often use highly idealised non-physical description of complex storm processes (e.g. polynomial representation of storm tracks). There is the possibility of over-fitting to the data available from relatively short historical periods. There are often overly restrictive assumptions in simulating losses e.g. homogeneity in time, independence of events, independence of frequency and severity.

- Statistical models require distributional assumptions e.g. extreme value models (Brodin and Rootzén 2009; Della-Marta et al., 2009), assumptions about modeldependence of simulated storms (Sansom et al., 2013), and assumptions about dependency in space-time and between events (Bonazzi et al., 2012; Economou et al., 2014).

- Numerical weather and climate models show biases in storm properties that have resisted model improvements over the past 40 years e.g. too zonal storm track over W. Europe (Zappa et al., 2013), poor representation of small horizontal scale processes even at very high resolution e.g. wind gusts (Ólafsson and Ágústsson, 2007), missing processes e.g. sting jets caused by mesoscale features such as stratospheric intrusions (Catto et al., 2010) and non-adiabatic forcing of storms by anomalous oceanic conditions (Ludwig et al., 2014).

Finally, there is also a major overarching source of epistemic uncertainty in how these different model components should be coupled together. At present there is no accepted theory for how one should and should not do this.

Clustering of windstorms provides a good example of an epistemic uncertainty that has recently received much attention and thereby led to model developments. Analysis of historical reanalysis data revealed that windstorm modulation by large-scale climate
NHESSD

doi:10.5194/nhess-2015-295

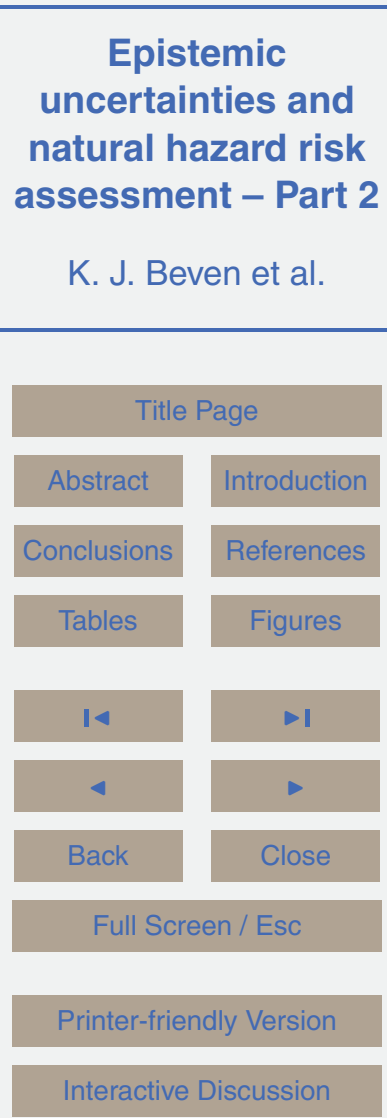


modes leads to more clustering over Europe than one can expect by chance i.e. from an homogeneous Poisson process (Mailier et al., 2006). Furthermore, clustering was also found to increase for more extreme wind speeds (Vitolo et al., 2009), in contradiction to the assumption often made by actuaries suitable for identically distributed variables. 5 This research raised much awareness about clustering in the natural catastrophe insurance industry that has led to major developments in windstorm catastrophe models (Khare et al., 2014). The findings are also stimulating new research into mechanisms for clustering of extreme storms (e.g. Rossby wave breaking; Pinto et al., 2014).

\section{Generalisations across hazard areas}

In reviewing the way in which epistemic uncertainties are handled in each of these natural hazard areas, certain commonalities are apparent. Most notable is the tendency for treating all sources of uncertainty as aleatory variables, for both the hazard and the consequences or impacts that make up the risk equation. In most hazard areas, probabilistic methods are replacing older deterministic probable maximum event methods.

15 The probabilistic approach is attractive in that the power of statistical theory, including the use of judgement-based probabilities in a Bayesian framework, can be employed. However, when used to represent epistemic uncertainties such an approach will be subject to limitations that would include:

- not allowing for the incompleteness of probability assessments (including the probabilities associated with the branches of logic trees)

- the potential of over-fitting to limited historical records in estimating the frequencies of extreme events of unknown (and potentially non-stationary) distributional form, and

- the limitations of expert elicitation of prior probability and scenario information.
NHESSD

doi:10.5194/nhess-2015-295
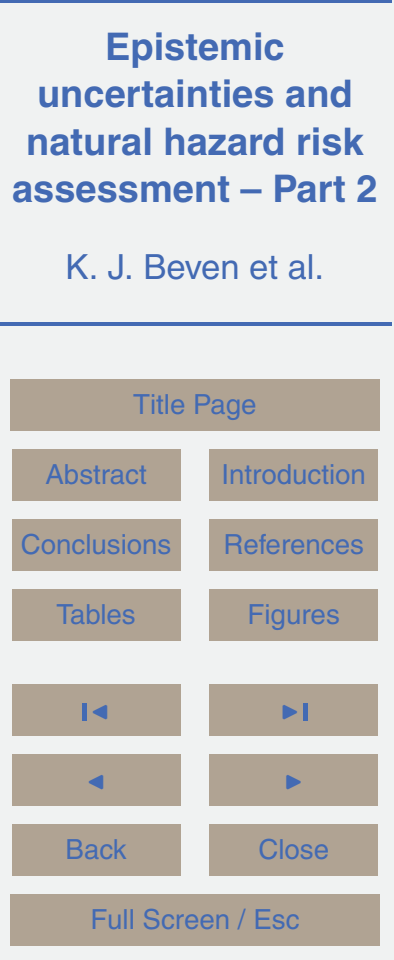

Printer-friendly Version

Interactive Discussion 
In natural hazards we are always interested in the extreme events, and the analysis of the risk of such events for use in decision making will depend heavily on the tail assumptions that result from the choice of particular distributional forms in representing the uncertain quantities as aleatory variables. But both parts of the risk equation are 5 subject to significant epistemic uncertainties that are commonly ignored in practice or, at best, treated as if simple stationary statistical assumptions are valid. Natural hazard risk assessments have muddled along for many decades on this basis without undue criticism, except from communities that get impacted either because no protection has been provided, or because that protection has been exceed. In this situation, there 10 has always been some protection for the analyst against the impacts of uncertainty. This is because when the magnitude of a particular event is evaluated in terms of its frequency of occurrence (as a "return period" or "annual exceedance probability"), then if a new event comes along that is bigger than that estimated as the standard event for a risk analysis, it has, by definition, a lower probability of exceedance. It 15 may be a surprise if two events of low probability occur in quick succession, but even then there is always a small but finite statistical probability of that occurring under the assumptions of the analysis. Effectively, the analyst cannot be wrong, even if the assessment of frequencies might prove to be wrong given the additional data. Posthoc, of course, the new event(s) can also be used to revise the risk analysis. This has, perhaps, been one reason why there has been little pressure to treat epistemic uncertainties more explicitly when, again for good epistemic reasons, it is difficult to know what assumptions to make.

This suggests that an extension to a more explicit recognition of epistemic uncertainties might be necessary in future. One way of doing so is to frame the epistemic uncertainties as potential future scenarios. Scenario planning is commonly used in policy formulation and event management as a way of allowing for unknown futures. Assessment of each of those scenarios will result in multiple risk exceedance probabilities. While each scenario assessment might be of unknown probability, considering the range of possibilities might still be useful in decision making (Rougier and Beven,
NHESSD

doi:10.5194/nhess-2015-295

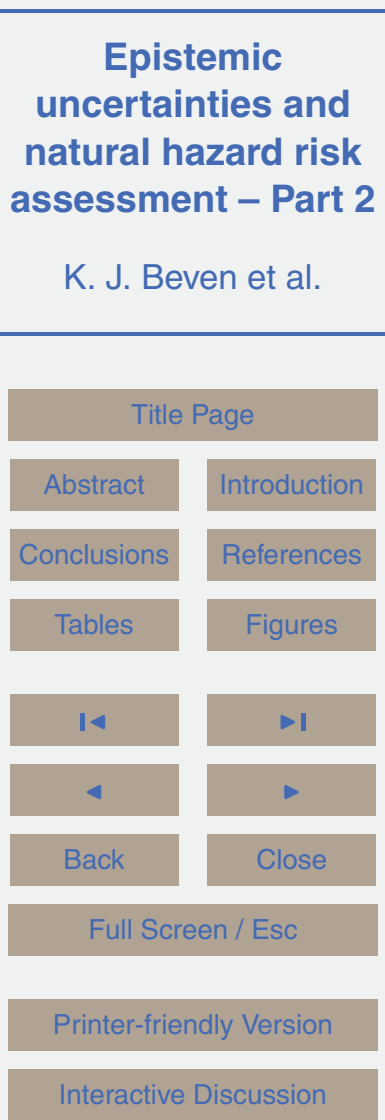


2013). There will remain the possibility, however, that not all possible scenarios are included in such an analysis and there is still the potential for future surprise. This might be mitigated against by carrying out a wider sensitivity analysis (e.g. Pianosi et al., 2014) such as the scenario neutral assessments of the impacts of future change developed by Prudhomme et al. (2009, 2010).

Some differences in practice between different hazard areas are also evident, in part dependent on the availability of data and the potential for doing useful forecasting as well as simulation. It is useful to distinguish three types of uncertainty analysis (e.g. Beven, 2009). The first is a forward analysis where the outputs depend entirely 10 on propagating prior assumptions about the sources of uncertainty, albeit that those prior assumptions might be derived from historical sequences. Risk assessments of droughts, dam safety, landslides, ground motion from earthquakes, and tsunamis tend to be of this type.

The second form of analysis involves conditioning the prior estimates of uncertainty 15 for a simulation model on observational data. Flood inundation maps (using historical flood outlines and discharge estimates), and the inversion methods used for identifying earthquake ruptures, and source terms for ash cloud simulations are of this type. In general such methods will help to constrain model uncertainties, but will dependent on both the range of models considered and the way in which they are evaluated relative to the available observations. A number of conditioning methodologies are available including formal Bayes methods (Bernado and Smith, 2009); Bayes linear methods (Goldstein and Wooff, 2007); Approximate Bayesian Computation (ABC, Vrugt and Sadegh, 2013; Nott et al., 2014) and Generalised Likelihood Uncertainty Estimation (GLUE, Beven and Binley, 1992, 2014; Blazkova and Beven, 2009). The latter can make use of formal and informal likelihood measures and limits of acceptability, as well as alternatives to Bayes equation in combining different model evaluations.

Because epistemic uncertainties are involved, including the potential for nonstationary bias and error characteristics and unknown commensurability errors between observed and predicted variables, it might not always be good practice to use

\section{NHESSD}

doi:10.5194/nhess-2015-295

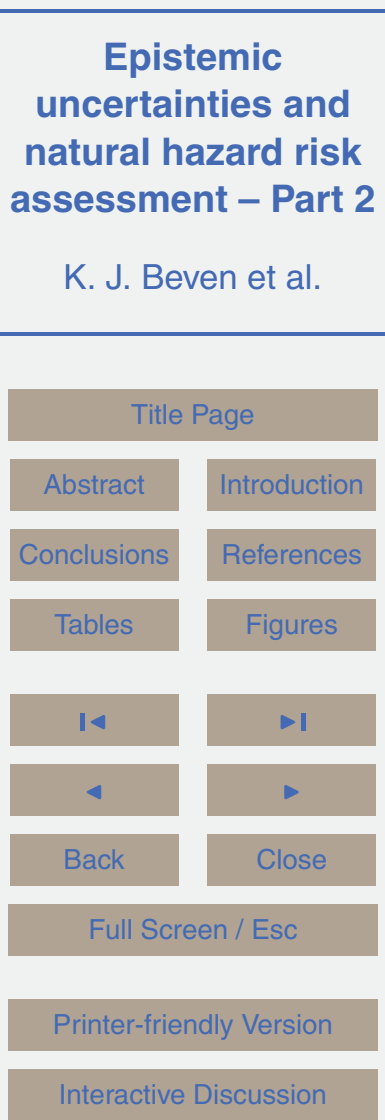

Interactive Discussion 
formal statistical likelihood measures in such evaluations. Indeed, epistemic uncertainties make it difficult to test such models as hypotheses in rigorous ways, and may mean that multiple model structures might be consistent with the available observations (e.g. Beven, 2006, 2012). There may also be issues of whether the available models are fit5 for-purpose when compared with observations, even when the uncertainty associated with those observations is taken into account. It will always be good practice to make explicit the assumptions made in such an analysis. In Paper 1 we have suggested that this might be constructed as a form of Condition Tree.

The third form of uncertainty analysis can be used when the interest is in forecast10 ing a hazard into the near future and when observables are available in real time to allow the use of data assimilation to constrain prediction uncertainties. A variety of data assimilation methods are available from the variational methods commonly used in weather forecasting, to ensemble Kalman filters and Particle filters. Such methods are used in real time forecasting of floods, ash clouds and wind storms. It is perhaps instructive in the context of a discussion of epistemic uncertainties that in generating an ensemble of future weather forecasts, singular vector techniques are used to choose more extreme perturbations in formulating the members of the ensemble, so as to stand a greater chance of bracketing the potential range of future weather over the lead time of a few days. The ensemble members should therefore be considered to be of unknown probability, even if the outputs are sometimes interpreted in probabilistic ways (such as in decisions about alert status in the European Flood Awareness System based on simulated river flows forced by ECMWF ensemble predictions of rainfalls).

\section{Co-emergent and cascading hazards}

The earlier discussion has mostly been concerned with the characteristics of individual 25

hazards but it is clear that an assessment of risk very often needs to allow for the joint occurrences of multiple hazards, either for hazards of different types affecting a single location, or the joint occurrence of a hazard at multiple locations simultaneously (e.g.

\section{NHESSD}

doi:10.5194/nhess-2015-295
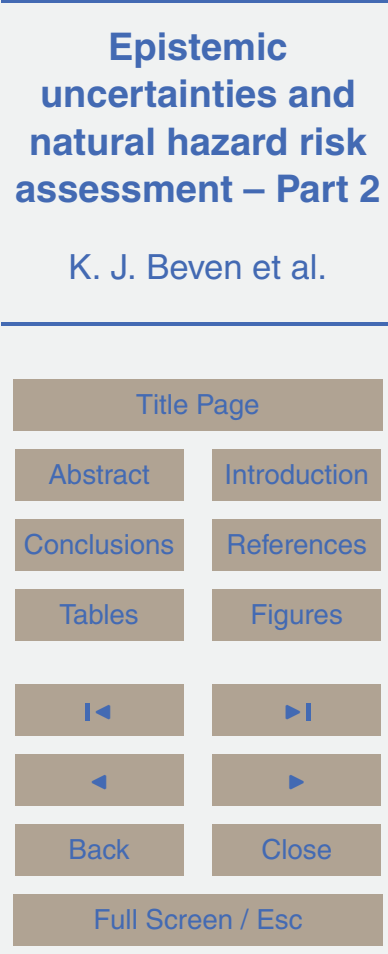

Printer-friendly Version

Interactive Discussion 
Lamb et al., 2010; Gill and Malamud, 2014). Both will affect the assessment of the joint risk. In some cases the joint risk may be causative, including the dependence of tsunamis on ocean floor earthquakes and landslides; the landslide and avalanches that result directly from earthquakes; and the potential for landslide as well as flood 5 impacts on dam safety (an epistemic uncertainty that is usually neglected but which has caused past dam overtopping). In other cases independent occurrences might contribute to an increased risk, such as the joint occurrences of fluvial floods, high tides and atmospheric surge on the risk of estuarine and coastal flooding. Assessing the joint frequency of such events has been receiving increasing attention (e.g. Svensson and 10 Jones, 2004). In particular, the covariation of different causes of the hazard, and joint occurrences across multiple locations has been investigated using flexible functional relationships based on overlap likelihood relationships (Gill and Malamud, 2014) and copulas (e.g. Keef et al., 2013; Lamb et al., 2013). An interesting application of the latter was used to produce a probabilistic flood map of Fig. 1, which is affected by the 15 joint occurrences of high flows both in the mainstream river and two major tributaries entering from the south (Neal et al., 2013).

\section{Conclusions}

This paper has considered how uncertainties in general, and epistemic uncertainties in particular have been handled in assessments of risk associated with different natural hazards. In most cases, epistemic uncertainties are not considered explicitly, but are mostly treated as if they can be considered as aleatory variables of specified distributional form. This almost certainly leads to an underestimation of the uncertainty in the risk assessment, and might lead to future surprise. It is both possible and desirable to extend the analysis to include different scenarios of epistemic uncertainty. The analysis of different natural hazard areas presented above makes it clear that there are different degrees of appreciation for and approaches to dealing with epistemic uncertainty. We hope that in making this comparison it will be researchers in different areas to learn

\section{NHESSD}

doi:10.5194/nhess-2015-295

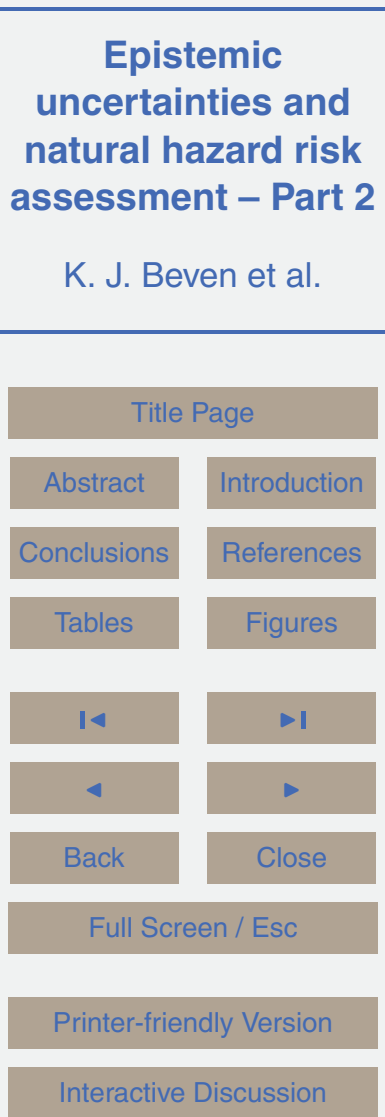


about structured approaches that are being used elsewhere, particularly in dealing with uncertainties that are less amenable to being treated probabilistically.

Where observational data are available that can be used to constrain the prediction uncertainties in an application, then care should be taken in the form of model eval5 uation. Treating a residual series as a simple aleatory variable can be used to define a formal statistical likelihood function, but if the uncertainties are dominated by epistemic sources the result may be overconfidence in model selection and over-constraint of the predictive uncertainty. Data assimilation in real-time forecasting however, can be used to adaptively compensate for unknown uncertainties in improving forecasts and constraining forecast uncertainties over the lead times of interest, at least where the data can be processed within the time scale of the system response or at a temporal resolution useful to decision makers.

The variety of assumptions and approaches being used in different hazard application areas reinforce the discussion in Paper 1 about the importance of a framework for structuring and communicating the assumptions and meaning of an uncertainty analysis, particular to the decision makers and other users. The condition tree approach discussed there is one approach to moving towards clarity of assumptions and providing an audit trail for future evaluation of the appropriateness of given sets of assumptions. There will be no single way of assessing the impacts of epistemic uncertainties on risk, but we can at least demand clarity in the assumptions that are made, with the possibility that this then might lead to some consideration of alternative assumptions and a consequent reduction in the potential for future surprise.

Acknowledgements. This work is a contribution to the CREDIBLE consortium funded by the UK Natural Environment Research Council (Grant NE/J017299/1). Jeff Neal and Dave Leedal

\section{NHESSD}

doi:10.5194/nhess-2015-295
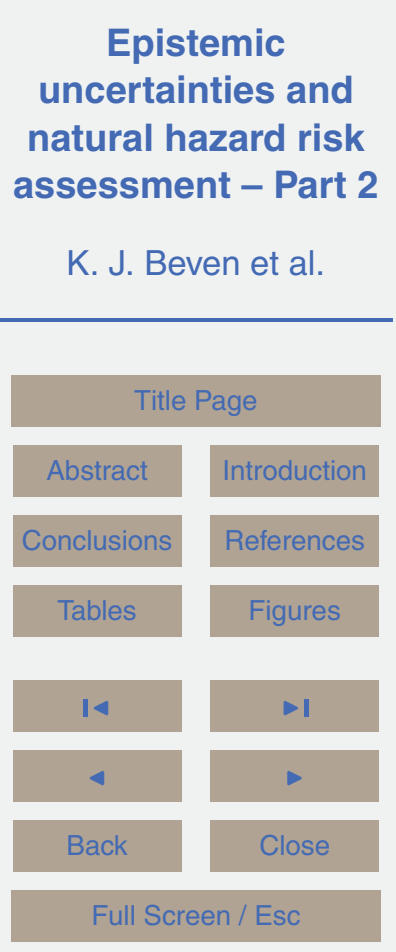

Printer-friendly Version

Interactive Discussion 


\section{References}

Abrahamson, N. A. and Bommer, J. J.: Probability and uncertainty in seismic hazard analysis, Earthq. Spectra, 21, 603-607, 2005.

AIR Worldwide: Study of Impact and the Insurance and Economic Cost of a Major Earthquake in British Columbia and Ontario/Québec, Insurance Bureau of Canada, Toronto, Canada, 345 p., 2013.

Aleotti, P.: A warning system for rainfall-induced shallow failures, Eng. Geol., 73, 247-265, doi:10.1016/j.enggeo.2004.01.007, 2004.

Alfieri, L., Smith, P. J., Thielen-del Pozo, J., and Beven, K. J.: A staggered approach to flash flood forecasting - case study in the Cévennes region, Adv. Geosci., 29, 13-20, doi:10.5194/adgeo-29-13-2011, 2011.

Alonso, E. E., Gens, A., and Delahaye, C. H.: Influence of rainfall on the deformation and stability of a slope in overconsolidated clays: a case study, Hydrogeol. J., 11, 174-192, doi:10.1007/s10040-002-0245-1, 2003.

Anderson, J. G. and Brune, J. N.: Probabilistic seismic hazard analysis without the ergodic assumption, Seismol. Res. Lett., 70, 19-28, 1999.

Annaka, T., Satake, K., Sakakiyama, T., Yanagisawa, K., and Shuto, N.: Logic-tree approach for probabilistic tsunami hazard analysis and its applications to the Japanese coasts, Pure Appl. Geophys., 164, 577-592, 2007.

20 Arason, P., Petersen, G. N., and Bjornsson, H.: Observations of the altitude of the volcanic plume during the eruption of Eyjafjallajökull, April-May 2010, Earth Syst. Sci. Data, 3, 9-17, doi:10.5194/essd-3-9-2011, 2011.

Aronica, G., Hankin, B. G., and Beven, K. J.: Uncertainty and equifinality in calibrating distributed roughness coefficients in a flood propagation model with limited data, Adv. Water

25 Resour., 22, 349-365, 1998.

Atkinson, G. M.: Single-station sigma, B. Seismol. Soc. Am., 96, 446-455, 2006.

Barmah, D. and Varley, I.: Hydrologic Modelling Practices for Estimating Low Flows - Guidelines, National Water Commission, Canberra, 2012.

Barredo, J. I.: No upward trend in normalised windstorm losses in Europe: 1970-2008, Nat. Hazards Earth Syst. Sci., 10, 97-104, doi:10.5194/nhess-10-97-2010, 2010.
NHESSD

doi:10.5194/nhess-2015-295

Epistemic

uncertainties and natural hazard risk

assessment - Part 2

K. J. Beven et al.

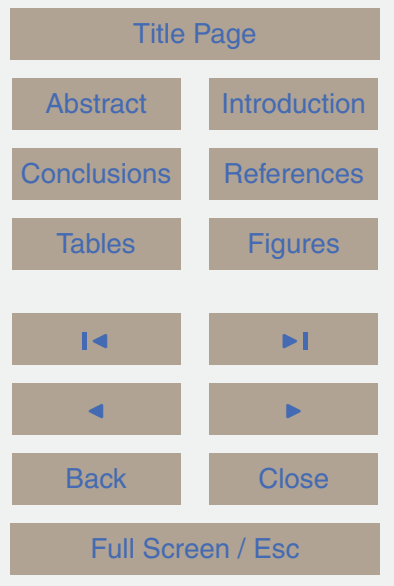

Printer-friendly Version

Interactive Discussion 
Bartholmes, J. C., Thielen, J., Ramos, M. H., and Gentilini, S.: The european flood alert system EFAS - Part 2: Statistical skill assessment of probabilistic and deterministic operational forecasts, Hydrol. Earth Syst. Sci., 13, 141-153, doi:10.5194/hess-13-141-2009, 2009.

Bates, P. D., Pappengberger, F., and Romanowicz, R. J.: Uncertainties in flood inundation modelling, in: Applied Uncertainty Analysis for Flood Risk Management, edited by: Beven, K. J. and Hall, J. W., Imperial College Press, London, 232-269, 2014.

Begnudelli, L. and Sanders, B. F.: Simulation of the St. Francis dam-break flood, J. Eng. Mech.ASCE, 133, 1200-1212, 2007.

Bernardo, J. M. and Smith, A. F.: Bayesian Theory, in: Vol. 405, John Wiley and Sons, Chichester, 2009.

Berry, R., Horritt, M., Dewar, C., Baigent, S., and Martin, J.: Development of flood mapping formats for the Lee catchment flood risk assessment and management study, in: Proc. National Hydrology Seminar, Hydrology in Spatial Planning and Development, Irish National Committee IHP, available at: http://tinyurl.com/d9sbtps (last access: 8 December 2015), 2008.

Beven, K. J.: Towards the use of catchment geomorphology in flood frequency predictions, Earth Surf. Proc. Land., 12, 69-82, 1987.

Beven, K. J.: A manifesto for the equifinality thesis, J. Hydrol., 320, 18-36, 2006.

Beven, K. J.: Environmental Modelling - An Uncertain Future?, Routledge, London, 2009.

Beven, K. J.: Preferential flows and travel time distributions: defining adequate hypothesis tests for hydrological process models, Hydrol. Process., 24, 1537-1547, 2010.

Beven, K. J.: Causal models as multiple working hypotheses about environmental processes, CR Geosci., 344, 77-88, doi:10.1016/j.crte.2012.01.005, 2012.

Beven, K. J. and Binley, A. M.: The future of distributed models: model calibration and uncertainty prediction, Hydrol. Process., 6, 279-298, 1992.

Beven, K. J. and Binley, A. M.: GLUE: 20 years on, Hydrol. Process., 28, 5897-5918, 2014.

Beven, K. J. and Lamb, R.: The uncertainty cascade in model fusion, in: Integrated Environmental Modelling to Solve Real World Problems: Methods, Vision and Challenges, edited by: Riddick, A. T., Kessler, H., and Giles, J. R. A., Geological Society, London, Special Publications, 408, doi:10.1144/SP408.3, 2016.

30 Beven, K. J., Lamb, R., Leedal, D. T., and Hunter, N.: Communicating uncertainty in flood risk mapping: a case study, Int. J. River Basin Manage., 13, 285-296, doi:10.1080/15715124.2014.917318, 2014.
NHESSD

Epistemic

uncertainties and natural hazard risk

assessment - Part 2

K. J. Beven et al.

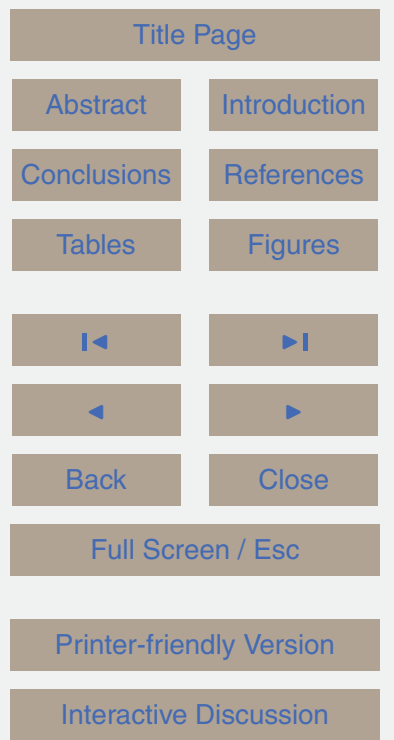


Blazkova, S. and Beven, K. J.: Flood frequency estimation by continuous simulation of subcatchment rainfalls and discharges with the aim of improving dam safety assessment in a large basin in the Czech Republic, J. Hydrol., 292, 153-172, 2004.

Blazkova, S. and Beven, K. J.: A limits of acceptability approach to model evaluation and uncertainty estimation in flood frequency estimation by continuous simulation: Skalka catchment, Czech Republic, Water Resour. Res., 45, W00B16, doi:10.1029/2007WR006726, 2009.

Bloomfield, J. P. and Marchant, B. P.: Analysis of groundwater drought using a variant of the Standardised Precipitation Index, Hydrol. Earth Syst. Sci. Discuss., 10, 7537-7574, doi:10.5194/hessd-10-7537-2013, 2013.

10 Blöschl, G., Sivapalan, M., and Wagener, T.: Runoff Prediction in Ungauged Basins: Synthesis across Processes, Places and Scales, Cambridge University Press, Cambridge, 2013.

Bommer, J. J.: Challenges of building logic trees for probabilistic seismic hazard analysis, Earthq. Spectra, 28, 1723-1735, 2012.

Bonadonna, C. and Houghton, B. F.: Total grain-size distribution and volume of tephra-fall de15 posits, B. Volcanol., 67, 441-456, 2005.

Bonazzi, A., Cusack, S., Mitas, C., and Jewson, S.: The spatial structure of European wind storms as characterized by bivariate extreme-value Copulas, Nat. Hazards Earth Syst. Sci., 12, 1769-1782, doi:10.5194/nhess-12-1769-2012, 2012.

Borgomeo, E., Hall, J. W., Fung, F., Watts, G., Colquhoun, K., and Lambert, C.: Risk-based water resources planning: incorporating probabilistic nonstationary climate uncertainties, Water Resour. Res., 50, 6850-6873, doi:10.1002/2014WR015558, 2014.

Brodin, E. and Rootzén, H.: Univariate and bivariate GPD methods for predicting extreme wind storm losses, Insur. Math. Econ., 44, 345-356, 2009.

Budnitz, R. J., Apostolakis, G., Boore, D. M., Cluff, L. S., Coppersmith, K. J., Cornell, C. A., and Morris, P. A.: Recommendations for probabilistic seismic hazard analysis: guidance on the uncertainty and use of experts, NUREG/CR-6372, US Nuclear Regulatory Commission, Washington, D.C., 1997.

Bursik, M. I., Carey, S. N., and Sparks, R. S. J.: A gravity current mode for the May 18, 1980 Mount St. Helens plume, Geophys. Res. Lett., 19, 1663-1666, 1992a.

30 Bursik, M. I., Sparks, R. S. J., Gilbert, J. S., and Carey, S. N.: Sedimentation of tephra by volcanic plumes: I. Theory and its comparison with a study of the Fogo A plinian deposit, Sao Miguel (Azores), B. Volcanol., 54, 329-344, 1992b.
NHESSD

doi:10.5194/nhess-2015-295
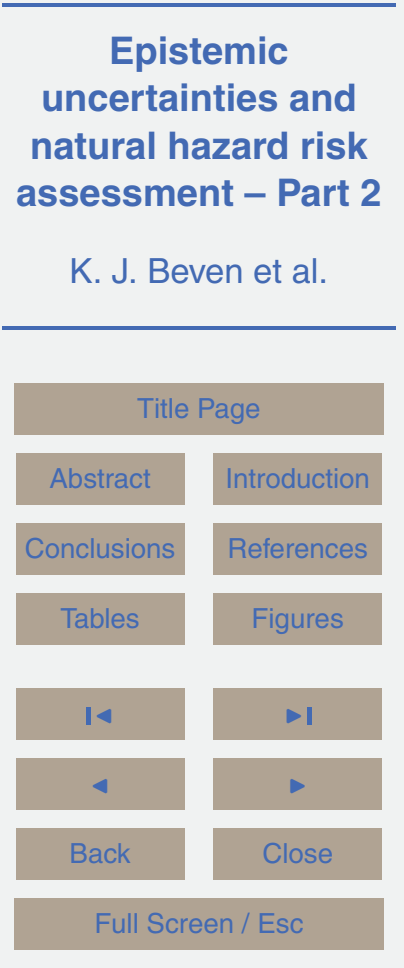

Printer-friendly Version

Interactive Discussion 
Cameron, D., Beven, K., and Naden, P.: Flood frequency estimation by continuous simulation under climate change (with uncertainty), Hydrol. Earth Syst. Sci., 4, 393-405, doi:10.5194/hess-4-393-2000, 2000.

Cao, Z., Pender, G., Wallis, S., and Carling, P.: Computational dam-break hydraulics over erodible sediment bed, J. Hydraul. Eng.-ASCE, 130, 689-703, 2004.

Catto, J. L., Shaffrey, L. C., and Hodges, K. I.: Can climate models capture the structure of extratropical cyclones?, J. Climate, 23, 1621-1635, 2010.

Chandler, R. E., Isham, V. S., Northrop, P. J., Wheater, H. S., Onof, C. J., and Leith, N. A.: Uncertainty in rainfall inputs, in: Applied Uncertainty Analysis for Flood Risk Management, edited by: Beven, K. J. and Hall, J. W., Imperial College Press, London, 101-152, 2014.

Chatterton, J., Penning-Rowsell, E., and Priest, S.: The many uncertainties in flood loss assessments, in: Applied Uncertainty Analysis for Flood Risk Management, edited by: Beven, K. J. and Hall, J. W., Imperial College Press, London, 335-356, 2014.

Cho, S. E.: Effects of spatial variability of soil properties on slope stability, Eng. Geol., 92, 97109, doi:10.1016/j.enggeo.2007.03.006, 2007.

Christian, J. T., Ladd, C. C., and Baecher, G. B.: Reliability applied to slope stability analysis, J. Geotech. Eng.-ASCE, 120, 2180-2207, doi:10.1061/(asce)0733-9410(1994)120:12(1280), 1994.

Cioni, R., Bertagnini, A., Santacroce, R., and Andronico, D.: Explosive activity and eruption scenarios at Somma-Vesuvius (Italy): towards a new classification scheme, J. Volcanol. Geoth. Res., 178, 331-346, doi:10.1016/j.jvolgeores.2008.04.024, 2008.

Cornell, C. A.: Engineering seismic risk analysis, B. Seismol. Soc. Am., 58, 1583-1606, 1968.

Cornell, C. A. and Winterstein, S. R.: Temporal and magnitude dependence in earthquake recurrence models, B. Seismol. Soc. Am., 78, 1522-1537, 1988.

Corominas, J., Van Westen, C., Frattini, P., Cascini, L., Malet, J. P., Fotopoulou, S., Catani, F., Van Den Eeckhaut, M., Mavrouli, O., Agliardi, F., and Pitilakis, K.: Recommendations for the quantitative analysis of landslide risk, B. Eng. Geol. Environ., 73, 209-263, doi:10.1007/s10064-013-0538-8, 2014.

Costa, A., Folch, A., and Macedonio, G.: Density-driven transport in the umbrella region of volcanic clouds: implications for tephra dispersion models, Geophys. Res. Lett., 40, 48234827, 2013.
NHESSD

doi:10.5194/nhess-2015-295
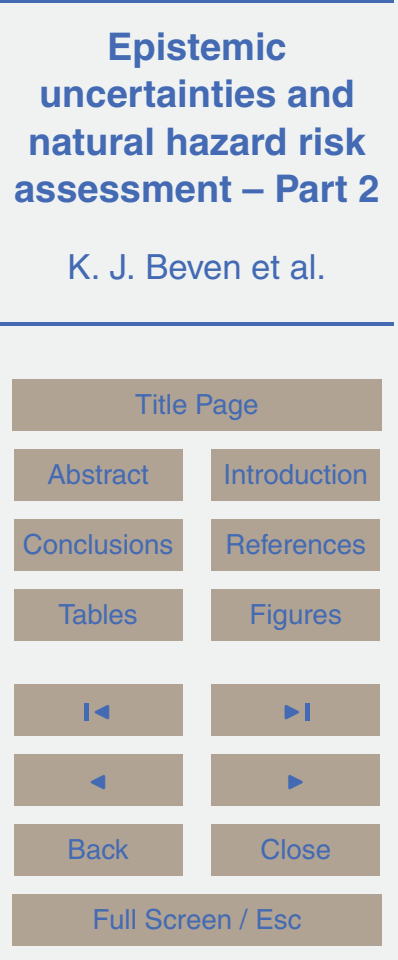

Printer-friendly Version

Interactive Discussion 
Crovelli, R. A.: Probabilistic models for estimation of number and cost of landslides, OpenFile Report 00-249, US Geological Survey, available at: http://pubs.usgs.gov/of/2000/ ofr-00-0249/ProbModels.html (last access: 8 December 2015), 2000.

Dacre, H. F., Grant, A. L. M., Hogan, R. J., Belcher, S. E., Thomson, D. J., Devenish, B. J., Marenco, F., Hort, M. C., Haywood, J. M., Ansmann, A., Mattis, I., and Clarisse, L.: Evaluating the structure and magnitude of the ash plume during the initial phase of the 2010 Eyjafjallajökull eruption using lidar observations and NAME simulations, J. Geophys. Res., 116, D00U03, doi:10.1029/2011JD015608, 2011.

Dacre, H. F., Grant, A. L. M., Harvey, N. J., Thomson, D. J., Webster, H. N., and Marenco, F.: 10 Volcanic ash layer depth?: processes and mechanisms, Geophys. Res. Lett., 42, 637-645, 2014.

Degruyter, W. and Bonadonna, C.: Improving on mass flow rate estimates of volcanic eruptions, Geophys. Res. Lett., 39, L16308, doi:10.1029/2012GL052566, 2012.

Della-Marta, P. M., Mathis, H., Frei, C., Liniger, M. A., Kleinn, J., and Appenzeller, C.: The return period of wind storms over Europe, Int. J. Climatol., 29, 437-459, 2009.

Della-Marta, P. M., Liniger, M. A., Appenzeller, C., Bresch, D. N., Köllner-Heck, P., and Muccione, V.: Improved estimates of the European winter windstorm climate and the risk of reinsurance loss using climate model data, J. Appl. Meteorol. Clim., 49, 2092-2120, 2010.

Denlinger, R. P., Pavolonis, M. J., and Sieglaff, J.: A robust method to forecast volcanic ash clouds, J. Geophys. Res., 117, D13208, doi:10.1029/2012JD017732, 2012.

De Roo, A., Thielen, J., Salamon, P., Bogner, K., Nobert, S., Cloke, H., Demeritt, D., and Pappenberger, F.: Quality control, validation and user feedback of the European Flood Alert System (EFAS), Int. J. Digit. Earth, 4, 77-90, 2011.

Devenish, B. J., Francis, P. N., Johnson, B. T., Sparks, R. S. J., and Thomson, D. J.: Sensitivity analysis of dispersion modeling of volcanic ash from Eyjafjallajökull in May 2010, J. Geophys. Res., 117, D00U21, doi:10.1029/2011JD016782, 2012a.

Devenish, B. J., Thomson, D. J., Marenco, F., Leadbetter, S. J., Ricketts, H., and Dacre, H. F.: A study of the arrival over the United Kingdom in April 2010 of the Eyjafjallajökull ash cloud using ground-based lidar and numerical simulations, Atmos. Environ., 48, 152-164, 2012b.

30 DPC: Pianificazione Nazionale d'Emergenza dell'Area Vesuviana, Dipartimento della Protezione Civile, Presidenza del Consiglio dei Ministri, Rome, 157 pp., 1995.
NHESSD

doi:10.5194/nhess-2015-295
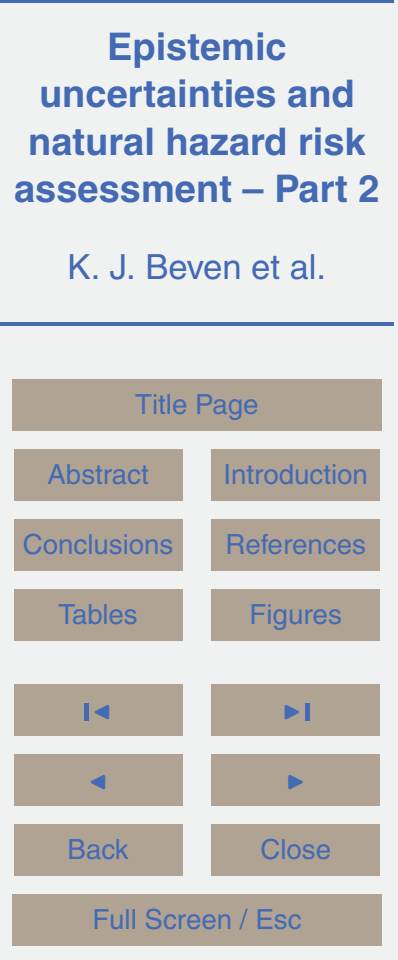

Printer-friendly Version

Interactive Discussion 
DPC: Proposta di aggiornamento della Pianificazione Nazionale d'Emergenza dell'Area Vesuviana, Dipartimento della Protezione Civile, Presidenza del Consiglio dei Ministri, Rome, 55 pp., 2001.

Duan, K. and Mei, Y.: Comparison of meteorological, hydrological and agricultural drought responses to climate change and uncertainty assessment, Water Resour. Manage., 28, 50395054, 2014.

Duffaut, P.: The traps behind the failure of Malpasset arch dam, France, in 1959, J. Rock Mech. Geotech. Eng., 5, 335-341, 2013.

Dussauge-Peisser, C., Helmstetter, A., Grasso, J.-R., Hantz, D., Desvarreux, P., Jeannin, M., and Giraud, A.: Probabilistic approach to rock fall hazard assessment: potential of historical data analysis, Nat. Hazards Earth Syst. Sci., 2, 15-26, doi:10.5194/nhess-2-15-2002, 2002.

Eastoe, E. F. and Tawn, J. A.: Statistical models for over-dispersion in the frequency of peaks over threshold data from UK flow series, Water Resour. Res., 46, W02510, doi:10.1029/2009WR007757, 2010.

Economou, T., Stephenson, D. B., and Ferro, C. A.: Spatio-temporal modelling of extreme storms, Ann. Appl. Stat., 8, 2223-2246, 2014.

El-Ramly, H., Morgenstern, N. R., and Cruden, D. M.: Probabilistic slope stability analysis for practice, Can. Geotech. J., 39, 665-683, doi:10.1139/T02-034, 2002.

Ercanoglu, M. and Gokceoglu, C.: Assessment of landslide susceptibility for a landslideprone area (north of Yenice, NW Turkey) by fuzzy approach, Environ. Geol., 41, 720-730, doi:10.1007/s00254-001-0454-2, 2002.

Esposti Ongaro, T., Cavazzoni, C., Erbacci, G., Neri, A., and Salvetti, M. V.: A parallel multiphase flow code for the 3D simulation of explosive volcanic eruptions, Parallel Comput., 33, 541-560, 2007.

Esposti Ongaro, T., Neri, A., Menconi, G., De'Michieli Vitturi, M., Marianelli, P., Cavazzoni, C., Erbacci, G., and Baxter, P. J.: Transient 3D numerical simulations of column collapse and pyroclastic flow scenarios at Vesuvius, J. Volcanol. Geoth. Res., 178, 378-396, doi:10.1016/j.jvolgeores.2008.06.036, 2008.

Folch, A., Costa, A., and Basart, S.: Validation of the FALL3D ash dispersion model using observations of the 2010 Eyjafjallajökull volcanic ash clouds, Atmos. Environ., 48, 165-183, 2012.
NHESSD

doi:10.5194/nhess-2015-295

Epistemic

uncertainties and

natural hazard risk

assessment - Part 2

K. J. Beven et al.

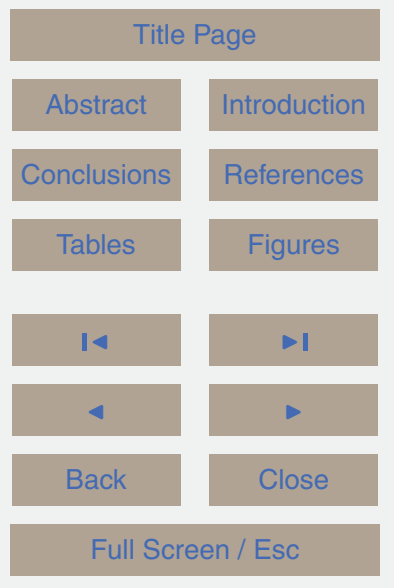

Printer-friendly Version

Interactive Discussion 
Francis, P. N., Cooke, M. C., and Saunders, R. W.: Retrieval of physical properties of volcanic ash using Meteosat: a case study from the 2010 Eyjafjallajökull eruption, J. Geophys. Res., 117, D00U09, doi:10.1029/2011JD016788, 2012.

Gallegos, H. A., Schubert, J. E., and Sanders, B. F.: Two-dimensional, high-resolution modeling of urban dam-break flooding: a case study of Baldwin Hills, California, Adv. Water Resour., 32, 1323-1335, 2009.

Geist, E. L.: Complex earthquake rupture and local tsunamis, J. Geophys. Res., 107, ECV 11-ECV 1-28, doi:10.1029/2000JB000139, 2002.

Gens, A.: Soil-environment interactions in geotechnical engineering, Geotechnique, 60, 3-74, doi:10.1680/Geot.9.P.109, 2010.

Gill, J. C. and Malamud, B.: Reviewing and visualizing the interactions of natural hazards, Rev. Geophys. 52, 680-722, 2014.

Goda, K. and Atkinson, G. M.: Variation of site-to-source distance for mega-thrust subduction earthquakes: effects on ground motion prediction equations, Earthq. Spectra, 30, 845-866, 2014

Goda, K. and Hong, H. P.: Optimal seismic design for limited planning time horizon with detailed seismic hazard information, Struct. Saf., 28, 247-260, 2006.

Goda, K., Mai, P. M., Yasuda, T., and Nobuhito Mori, N.: Sensitivity of tsunami wave profile and inundation simulations to earthquake slip and fault geometry for the 2011 Tohoku earthquake, Earth Planets Space, 66, 1-20, doi:10.1186/1880-5981-66-105, 2014.

Goda, K., De Risi, R., and Rossetto, T.: Coupled simulation of ground shaking and tsunami for mega-thrust subduction earthquakes, 12th International Conference on Applications of Statistics and Probability in Civil Engineering (ICASP12), Vancouver, Canada, 2015.

Goldfinger, C., Nelson, C. H., Morey, A. E., Johnson, J. E., Patton, J., Karabanov, E., GutierrezPastor, J., Eriksson, A. T., Gracia, E., Dunhill, G., Enkin, R. J., Dallimore, A., and Vallier, T.: Turbidite event history - methods and implications for Holocene paleoseismicity of the Cascadia subduction zone, US Geological Survey Professional Paper 1661-F, US Geological Survey, Washington, D.C., p. 170, 2012.

Goldstein, M. and Wooff, D.: Bayes Linear Statistics, Theory and Methods, in: Series in Probability and Statistics, Vol. 716, John Wiley and Sons, Chichester, 2007.

Gouldby, B. P., Sayers, P. B., Panzeri, M. C., and Lanyon, J. E.: Development and application of efficient methods for the forward propagation of epistemic uncertainty and sensitivity analysis
NHESSD

doi:10.5194/nhess-2015-295

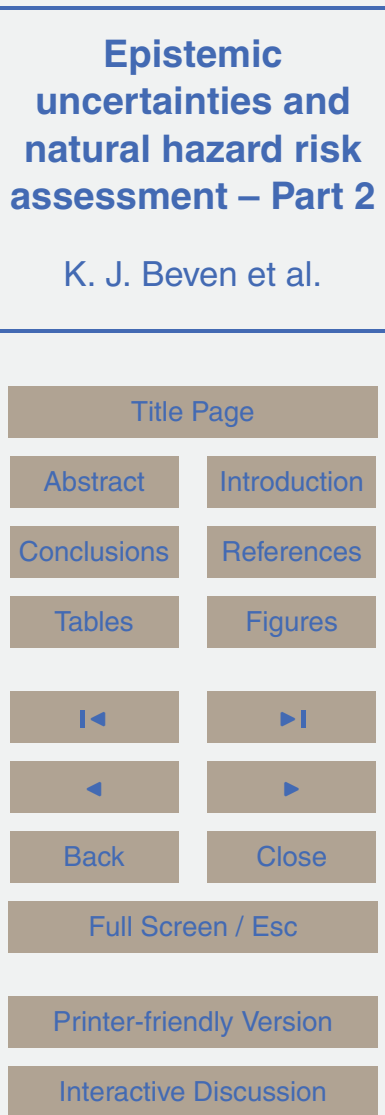


within complex broad-scale flood risk system models T, Can. J. Civil Eng., 37, 955-967, 2010.

Grant, A. L. M., Dacre, H. F., Thomson, D. J., and Marenco, F.: Horizontal and vertical structure of the Eyjafjallajökull ash cloud over the UK: a comparison of airborne lidar observations and simulations, Atmos. Chem. Phys., 12, 10145-10159, doi:10.5194/acp-12-10145-2012, 2012.

Griffiths, D. V. and Fenton, G. A.: Probabilistic slope stability analysis by finite elements, J. Geotech. Geoenviron., 130, 507-518, doi:10.1061/(ASCE)1090-0241(2004)130:5(507), 2004.

10 Griffiths, D. V., Huang, J. S., and Fenton, G. A.: Influence of spatial variability on slope reliability using 2-D random fields, J. Geotech. Geoenviron., 135, 1367-1378, doi:10.1061/(asce)gt.1943-5606.0000099, 2009.

Guzzetti, F., Carrara, A., Cardinali, M., and Reichenbach, P.: Landslide hazard evaluation: a review of current techniques and their application in a multi-scale study, Central Italy, Geomorphology, 31, 181-216, doi:10.1016/S0169-555x(99)00078-1, 1999.

Guzzetti, F., Reichenbach, P., Cardinali, M., Galli, M., and Ardizzone, F.: Probabilistic landslide hazard assessment at the basin scale, Geomorphology, 72, 272-299, doi:10.1016/j.geomorph.2005.06.002, 2005.

Guzzetti, F., Reichenbach, P., Ardizzone, F., Cardinali, M., and Galli, M.: Estimating the quality of landslide susceptibility models, Geomorphology, 81, 166-184, doi:10.1016/j.geomorph.2006.04.007, 2006.

Hall, J. W., Rubio, E., and Anderson, M. G.: Random sets of probability measures in slope hydrology and stability analysis, ZAMM: J. Appl. Math. Mech., 84, 710-720, 2004.

Hall, J. W., Manning, L. J., and Hankin, R. K.: Bayesian calibration of a flood inundation model using spatial data, Water Resour. Res., 47, W05529, doi:10.1029/2009WR008541, 2011.

Hall, J. W., Watts, G., Keil, M., de Vial, L., Street, R., Conlan, K., O'Connell, P. E., Beven, K. J., and Kilsby, C. G.: Towards risk-based water resources planning in England and Wales under a changing climate, CIWEM Water Environ. J., 26, 118-129, doi:10.1111/j.17476593.2011.00271.x, 2012.

30 Haneberg, W. C.: A rational probabilistic method for spatially distributed landslide hazard assessment, Environ. Eng. Geosci., 10, 27-43, doi:10.2113/10.1.27, 2004.

Harou, J. J., Medellín-Azuara, J., Zhu, T., Tanaka, S. K., Lund, J. R., Stine, S., Olivares, M. A., and Jenkins, M. W.: Economic consequences of optimized water manage-
NHESSD

doi:10.5194/nhess-2015-295

Epistemic

uncertainties and

natural hazard risk

assessment - Part 2

K. J. Beven et al.

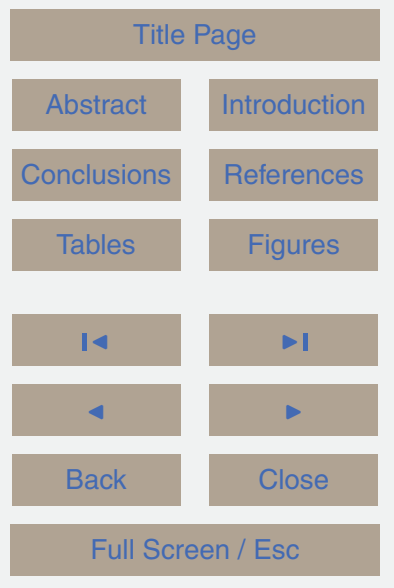

Printer-friendly Version

Interactive Discussion 
ment for a prolonged, severe drought in California, Water Resour. Res., 46, W05522, doi:10.1029/2008WR007681, 2010.

Hencher, S. R.: Preferential flow paths through soil and rock and their association with landslides, Hydrol. Process., 24, 1610-1630, 2010.

5 Hervouet, J. M. and Petitjean, A.: Malpasset dam-break revisited with two-dimensional computations, J. Hydraul. Res., 37, 777-788, 1999.

Hobbs, P. V., Radke, L. F., Lyons, J. H., Ferek, R. J., Coffman, D. J., and Casadevall, T. J.: Airbourne measurements of particle and gas emissions from the 1990 volcanic eruptions of Mount Redoubt, J. Geophys. Res., 96, 735-752, 1991.

10 Hodge, M., Biggs, J., Goda, K., and Aspinall, W. P.: Assessing infrequent large earthquakes using geomorphology and geodesy: the Malawi Rift, Nat. Hazards, 76, 1781-1806, doi:10.1007/s11069-014-1572-y, 2015.

Hong, X., Guo, S., Zhou, Y., and Xiong, L.: Uncertainties in assessing hydrological drought using streamflow drought index for the upper Yangtze River basin, Stoch. Env. Res. Risk A, 29, 1235-1247, doi:10.1007/s00477-014-0949-5, 2014.

Horspool, N., Pranantyo, I., Griffin, J., Latief, H., Natawidjaja, D. H., Kongko, W., Cipta, A., Bustaman, B., Anugrah, S. D., and Thio, H. K.: A probabilistic tsunami hazard assessment for Indonesia, Nat. Hazards Earth Syst. Sci., 14, 3105-3122, doi:10.5194/nhess-14-31052014, 2014.

20 House-Peters, L. A. and Chang, H.: Urban water demand modeling: review of concepts, methods, and organizing principles, Water Resour. Res., 47, W05401, doi:10.1029/2010WR009624, 2011.

Hrachowitz, M., Savenije, H. H. S., Bloschl, G., McDonnell, J., Sivapalan, M., Pomeroy, J., Arheimer, B., Blume, T., Clark, M., Ehret, U., Fenicia, F., Freer, J., Gelfan, A., Gupta, H., Hughes, D., Hut, R., Montanari, A., Pande, S., Tetzlaff, D., Troch, P., Uhlenbrook, S., Wagener, T., Winsemius, H., Woods, R., Zehe, E., and Cudennec, C.: A decade of Predictions in Ungauged Basins (PUB) - a review, Hydrolog. Sci. J., 58, 1-58, doi:10.1080/02626667.2013.803183, 2013.

Hu, Y.-M., Liang, Z.-M., Liu, Y.-W., Wang, J., Yao, L., and Ning, Y.: Uncertainty analysis of SPI calculation and drought assessment based on the application of Bootstrap. Int. J. Climatol., 35, 1847-1857, doi:10.1002/joc.4091, 2014.

\section{Epistemic \\ uncertainties and natural hazard risk \\ assessment - Part 2 \\ K. J. Beven et al.}

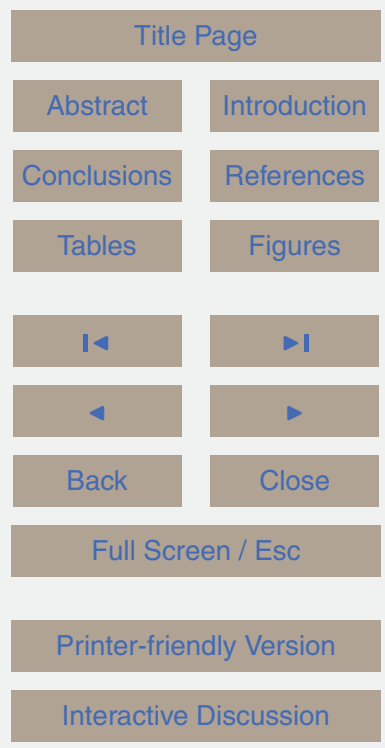


Hungr, O., Evans, S. G., and Harzard, J.: Magnitude and frequency of rock falls and rock slides along the main transportation corridors of southwestern British Columbia, Can. Geotech. J., 36, 224-238, doi:10.1139/Cgj-36-2-224, 1999.

Hürlimann, M., Rickenmann, D., Medina, V., and Bateman, A.: Evaluation of approaches to calculate debris-flow parameters for hazard assessment, Eng. Geol., 102, 152-163, 2008.

ICOLD: Dam Failures, Statistical Analysis, Bulletin 99, Commission Internationale des Grands Barrages, Paris, 73 pp., 1995.

Johnes, M.: Aberfan and the Management of Trauma, Disasters, 24, 1-17, doi:10.1111/14677717.00128, 2000.

10 Jones, A. R., Thomson, D. J., Hort, M. C., and Devenish, B. J.: The, U.K. Met Offices NextGeneration Atmospheric Dispersion Model, NAME III. Air Pollut. Model. Appl., XVII, 580-589, 2007.

Jongman, B., Kreibich, H., Apel, H., Barredo, J. I., Bates, P. D., Feyen, L., Gericke, A., Neal, J., Aerts, J. C. J. H., and Ward, P. J.: Comparative flood damage model assessment: towards a European approach, Nat. Hazards Earth Syst. Sci., 12, 3733-3752, doi:10.5194/nhess-123733-2012, 2012.

Jorgensen, B., Graymore, M., and O'Toole, K.: Household water use behaviour: an integrated model, J. Environ. Manage., 91, 227-236, 2009.

Kagan, Y. Y. and Jackson, D. D.: Tohoku earthquake: a surprise?, B. Seismol. Soc. Am., 103, 1181-1191, 2013.

Kaiser, G., Scheele, L., Kortenhaus, A., Løvholt, F., Römer, H., and Leschka, S.: The influence of land cover roughness on the results of high resolution tsunami inundation modeling, Nat. Hazards Earth Syst. Sci., 11, 2521-2540, doi:10.5194/nhess-11-2521-2011, 2011.

Karremann, M. K., Pinto, J. G., Reyers, M., and Klawa, M.: Return periods of losses associated with European windstorm series in a changing climate, Environ. Res. Lett., 9, 124016, doi:10.1088/1748-9326/9/12/124016, 2014.

Kasprzyk, J. R., Reed, P. M., Kirsch, B. R., and Characklis, G. W.: Managing population and drought risks using many-objective water portfolio planning under uncertainty, Water Resour. Res., 45, W12401, doi:10.1029/2009WR008121, 2009.

30 Keef, C., J. A. Tawn, and Lamb, R.: Estimating the probability of widespread flood events, Environmetrics, 24.1, 13-21, 2013.

\section{NHESSD}

doi:10.5194/nhess-2015-295

\section{Epistemic \\ uncertainties and natural hazard risk \\ assessment - Part 2 \\ K. J. Beven et al.}

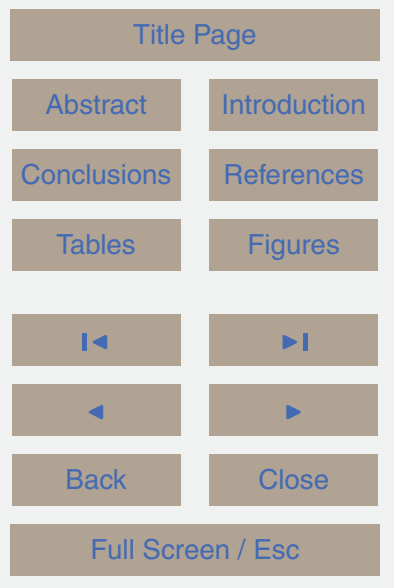

Printer-friendly Version

Interactive Discussion 
Keefer, D. K., Wilson, R. C., Mark, R. K., Brabb, E. E., Brown, W. M., Ellen, S. D., Harp, E. L., Wieczorek, G. F., Alger, C. S., and Zatkin, R. S.: Real-time landslide warning during heavy rainfall, Science, 2384829, 921-925, doi:10.1126/science.238.4829.921, 1987.

Kenney, D. S., Goemans, C., Klein, R., Lowrey, J., and Reidy, K.: Residential water demand 5 management: lessons from Aurora, Colorado, J. Am. Water Resour. As., 44, 192-207, doi:10.1111/j.1752-1688.2007.00147.x, 2008.

Khare, S., Bonazzi, A., Mitas, C., and Jewson, S.: A framework for modeling clustering in natural hazard catastrophe risk management and the implications for re/insurance loss perspectives, Nat. Hazards Earth Syst. Sci. Discuss., 2, 5247-5285, doi:10.5194/nhessd-2-5247-2014, 2014.

Koshimura, S., Oie, T., Yanagisawa, H., and Imamura, F.: Developing fragility functions for tsunami damage estimation using numerical model and post-tsunami data from Banda Aceh, Indonesia, Coast. Eng. J., 51, 243-273, 2009.

Koutsoyiannis, D: Climate change, the Hurst phenomenon, and hydrological statistics, Hy15 drolog. Sci. J., 48, 3-24, doi:10.1623/hysj.48.1.3.43481, 2003.

Koutsoyiannis, D.: HESS Opinions "A random walk on water", Hydrol. Earth Syst. Sci., 14, 585-601, doi:10.5194/hess-14-585-2010, 2010.

Koutsoyiannis, D.: Hydrology and change, Hydrolog. Sci. J., 58, 1177-1197, doi:10.1080/02626667.2013.804626, 2013.

20 Koutsoyiannis, D. and Montanari, A.: Statistical analysis of hydroclimatic time series: uncertainty and insights, Water Resour. Res., 43, W05429, doi:10.1029/2006WR005592, 2007.

Kristiansen, N. I., Stohl, A., Prata, A. J., Bukowiecki, N., Dacre, H. F., Eckhardt, S., Henne, S., Hort, M. C., Johnson, B. T., Marenco, F., Neininger, B., Reitebuch, O., Seibert, P., Thomson, D. J., Webster, H. N., and Weinzierl, B.: Performance assessment of a volcanic ash transport model mini-ensemble used for inverse modeling of the 2010 Eyjafjallajökull eruption, J. Geophys. Res., 117, D00U11, doi:10.1029/2011JD016844, 2012.

Kulkarni, R. B., Youngs, R. R., and Coppersmith, K. J.: Assessment of confidence intervals for results of seismic hazard analysis, Proc. of the Eighth World Conf. on Earthquake Engineering, Vol. 1, San Francisco, CA, 263-270, 1984.

30 Lamb, R. and Kay, A. L.: Confidence intervals for a spatially generalized, continuous simulation flood frequency model for Great Britain, Water Resour. Res., 40, W07501, doi:10.1029/2003WR002428, 2004.
NHESSD

doi:10.5194/nhess-2015-295
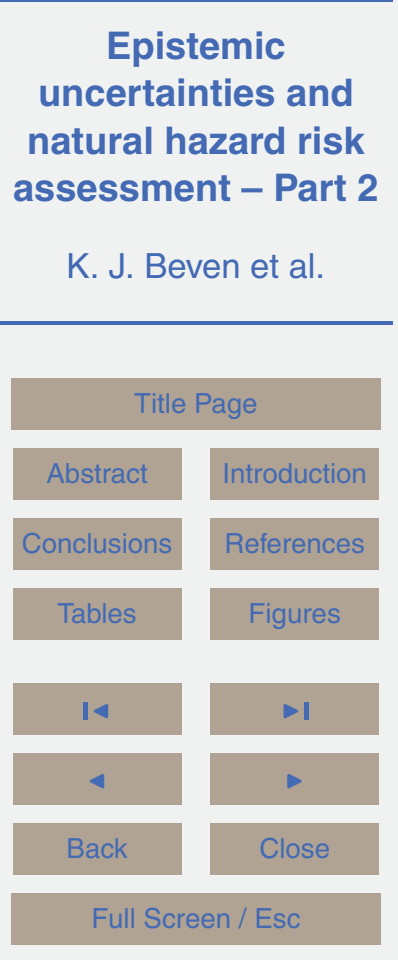

Printer-friendly Version

Interactive Discussion 
Lamb, R., Keef, C., Tawn, J., Laeger, S., Meadowcroft, I., Surendran, S., and Batstone, C.: A new method to assess the risk of local and widespread flooding on rivers and coasts, J. Flood Risk Manage., 3, 323-336, 2010.

Lavallee, D., Liu, P., and Archuleta, R. J.: Stochastic model of heterogeneity in earthquake slip spatial distributions, Geophys. J. Int., 165, 622-640, 2006.

Lee, E. M. and Jones, D. K. C.: Landslide Risk Assessment, Thomas Telford Publishing, London, 2004.

Lee, K. H., Wong, M. S., Chung, S.-R., and Sohn, E.: Improved volcanic ash detection based on a hybrid reverse absorption technique, Atmos. Res., 143, 31-42, 2014.

10 Lin, J. W., Chen, C. W., and Peng, C. Y.: Potential hazard analysis and risk assessment of debris flow by fuzzy modeling, Nat. Hazards, 64, 273-282, doi:10.1007/s11069-012-0236-z, 2012.

Londe, P.: The Malpasset dam failure, Eng. Geol., 24, 295-329, 1987.

Ludwig, P., Pinto, J. G., Reyers, M., and Gray, S. L.: The role of anomalous SST and surface 15 fluxes over the southeastern North Atlantic in the explosive development of windstorm Xynthia, Q. J. Roy. Meteorol. Soc., 140, 1729-1741, 2014.

Løvholt, F., Pedersen, G., Bazin, S., Kuhn, D., Bredesen, R. E., Harbitz, C.: Stochastic analysis of tsunami runup due to heterogeneous coseismic slip and dispersion, J. Geophys. Res., 117, C03047, doi:10.1029/2011JC007616, 2012.

20

Løvholt, F., Glimsdal, S., Harbitz, C. B., Horspool, N., Smebye, H., de Bono, A., and Nadim, F.: Global tsunami hazard and exposure due to large co-seismic slip, Int. J. Disast. Risk Reduct., 10, 406-418, 2014.

Mackie, S. and Watson, I. M.: The atmospheric dependency of the sensitivity of infrared satellite observations to thin volcanic ash clouds, J. Appl. Remote Sens., 9, 095080, doi:10.1117/1.JRS.9.095080, 2015.

Mackie, S., Millington, S. C., and Watson, I. M.: How assumed composition affects the interpretation of satellite observations of volcanic ash, Meteorol. Appl., 21, 20-29, 2014.

Mai, P. M. and Beroza, G. C.: A spatial random field model to characterize complexity in earthquake slip, J. Geophys. Res.-Sol. Ea., 107, 2308, doi:10.1029/2001JB000588, 2002.

30 Mailier, P. J., Stephenson, D. B., Ferro, C. A., and Hodges, K. I.: Serial clustering of extratropical cyclones, Mon. Weather Rev., 134, 2224-2240, 2006.

Manzella, I., Bonadonna, C., Phillips, J. C., and Monnard, H.: The role of gravitational instabilities in deposition of volcanic ash, 43, 211-214, Geology, doi:10.1130/G36252.1, 2015.
NHESSD

doi:10.5194/nhess-2015-295

Epistemic

uncertainties and

natural hazard risk

assessment - Part 2

K. J. Beven et al.

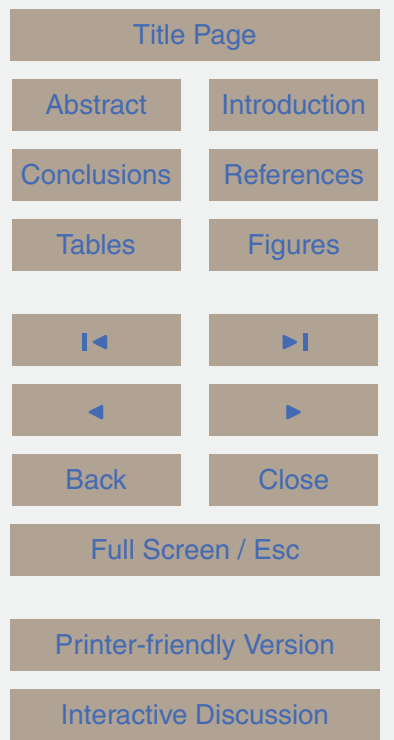


Marsh, T., Cole, G., and Wilby, R.: Major droughts in England and Wales, 1800-2006, Weather, 62, 87-93, doi:10.1002/wea.67, 2007.

Mastin, L. G., Guffanti, M., Servranckx, R., Webley, P. W., Barsotti, S., Dean, K., Durant, A., Ewert, J. W., Neri, A., Rose, W. I., Schneider, D. J., Siebert, L., Stunder, B., Swanson, G.,

5 Tupper, A., Volentik, A., and Waythomas, C. F.: A multidisciplinary effort to assign realistic source parameters to models of volcanic ash-cloud transport and dispersion during eruptions, J. Volcanol. Geoth. Res., 186, 10-21, 2009.

Matthews, M. V., Ellsworth, W. L., and Reasenberg, P. A.: A Brownian model for recurrent earthquakes, B. Seismol. Soc. Am., 92, 2233-2250, 2002.

10 McCloskey, J., Antonioli, A., Piatanesi, A., Sieh, K., Steacy, S., Nalbant, S., Cocco, M., Giunchi, C., Huang, J. D., and Dunlop, P.: Tsunami threat in the Indian Ocean from a future megathrust earthquake west of Sumatra, Earth Planet. Sc. Lett., 265, 61-81, 2008.

McGuire, R. K.: Deterministic vs Probabilistic Earthquake Hazards and Risks, Soil Dyn. Earthq. Eng., 21, 377-384, 2001.

McGuire, R. K.: Seismic Hazard and Risk Analysis, Earthquake Engineering Research Institute, Oakland, 2004.

McGuire, R. K., Cornell, C. A., and Toro, G. R.: The case for using mean seismic hazard, Earthq. Spectra, 21, 879-886, 2005.

McIntyre, N., Lee, H., Wheater, H. S., Young, A., and Wagener, T.: Ensemble prediction of runoff in ungauged watersheds, Water Resour. Res., 41, W12434, doi:10.1029/2005WR004289, 2005.

McMillan, H. K. and Westerberg, I. K.: Rating curve estimation under epistemic uncertainty, Hydrol. Process., 29, 1873-1882, 2015.

Mechler, R., Hochrainer, S., Aaheim, A., Salen, H., and Wreford, A.: Modelling economic impacts and adaptation to extreme events: insights from European case studies, Mitig. Adapt. Strateg. Glob. Change, 15, 737-762, 2010.

Millington, S. C., Saunders, R. W., Francis, P. N., and Webster, H. N.: Simulated volcanic ash imagery: a method to compare NAME ash concentration forecasts with SEVIRI imagery for the Eyjafjallajökull eruption in 2010, J. Geophys. Res., 117, D00U17, doi:10.1029/2011JD016770, 2012.

Montanari, A. and Koutsoyiannis, D.: A blueprint for process-based modeling of uncertain hydrological systems, Water Resour. Res., 48, W09555, doi:10.1029/2011WR011412, 2012. 
Montgomery, D. R., Schmidt, K. M., Dietrich, W. E., and McKean, J.: Instrumental record of debris flow initiation during natural rainfall: implications for modeling slope stability, J. Geophys. Res.-Earth, 114, F01031, doi:10.1029/2008JF001078, 2009.

Moxnes, E. D., Kristiansen, N. I., Stohl, A., Clarisse, L., Durant, A., Weber, K., and Vogel, A.: 5 Separation of ash and sulfur dioxide during the 2011 Grímsvötn eruption, J. Geophys. Res.Atmos., 119, 7477-7501, doi:10.1002/2013JD021272, 2014.

Narasimhan, B. and Srinivasan, R.: Development and evaluation of Soil Moisture Deficit Index (SMDI) and Evapotranspiration Deficit Index (ETDI) for agricultural drought monitoring, Agr. Forest Meteorol., 133, 69-88, 2005.

10 Neal, J., Keef, C., Bates, P., Beven, K., and Leedal, D.: Probabilistic flood risk mapping including spatial dependence, Hydrol. Process., 27, 1349-1363, 2013.

Neri, A., Esposti Ongaro, T., Macedonio, G., and Gidaspow, D.: Multiparticle simulation of collapsing volcanic columns and pyroclastic flows, J. Geophys. Res. Lett., 108, 2202, doi:10.1029/2001JB000508, 2003.

Neri, A., Aspinall, W. P., Cioni, R., Bertagnini, A., Baxter, P. J., Zuccaro, G., Andronico, D., Barsotti, S., Cole, P. D., Esposti Ongaro, T., Hincks, T. K., Macedonio, G., Papale, P., Rosi, M., Santacroce, R., and Woo, G.: Developing an Event Tree for Probabilistic Hazard and Risk Assessment at Vesuvius. J. Volcanol. Geoth. Res., 178, 397-415, doi:10.1016/j.jvolgeores.2008.05.014, 2008.

20 Nott, D. J., Fan, Y., Marshall, L., and Sisson, S. A.: Approximate Bayesian computation and Bayes' linear analysis: toward high-dimensional ABC, J. Comput. Graph. Stat., 23, 65-86, 2014.

Nyambayo, V. P. and Potts, D. M.: Numerical simulation of evapotranspiration using a root water uptake model, Comput. Geotech., 37, 175-186, doi:10.1016/j.compgeo.2009.08.008, 2010.

Ólafsson, H. and Ágústsson, H.: The Freysnes downslope windstorm, Meteorol. Z., 16, 123130, 2007.

Oxford-Economics: The Economic Impacts of Air Travel Restrictions Due to Volcanic Ash, Report for Airbus Industries, Abbey House, Oxford, UK, 2010.

Pappenberger, F., Beven, K. J., Frodsham, K., Romanovicz, R., and Matgen, P.: Grasping the unavoidable subjectivity in calibration of flood inundation models: a vulnerability weighted approach, J. Hydrol., 333, 275-287, 2007.

\section{NHESSD}

doi:10.5194/nhess-2015-295
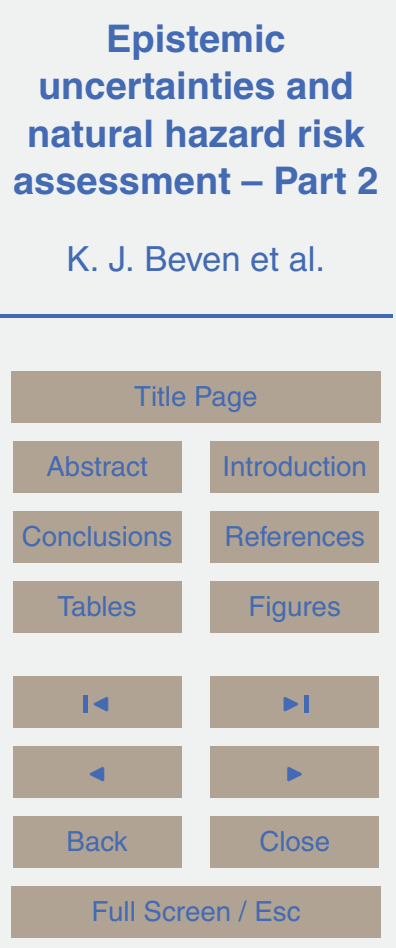

Printer-friendly Version

Interactive Discussion 
Paton, F. L., Maier, H. R., and Dandy, G. C.: Relative magnitudes of sources of uncertainty in assessing climate change impacts on water supply security for the southern Adelaide water supply system, Water Resour. Res., 49, 1643-1667, doi:10.1002/wrcr.20153, 2013.

Pavolonis, M. J., Feltz, W. F., Heidinger, A. K., and Gallina, G. M.: A daytime complement to the reverse absorption technique for improved automated detection of volcanic ash, J. Atmos. Ocean. Tech., 23, 1422-1444, 2006.

Pavolonis, M. J., Heidinger, A. K., and Sieglaff, J.: Automated retrievals of volcanic ash and dust cloud properties from upwelling infrared measurements, J. Geophys. Res.-Atmos., 118, 1436-1458, 2013.

10 Pelletier, J. D. and Turcotte, D. L.: Long-range persistence in climatological and hydrological time series: analysis, modeling and application to drought hazard assessment, J. Hydrol., 203, 198-208, 1997.

Penning-Rowsell, E. C.: A realistic assessment of fluvial and coastal flood risk in England and Wales, T. I. Brit. Geogr., 40, 44-61, doi:10.1111/tran.12053, 2015.

Penning-Rowsell, E. C., Priest, S., Parker, D., Morris, J., Tunstall, S., Viavattene, C., Chatterton, J., and Owen, D.: Flood and Coastal Erosion Risk Management: A Manual for Economic Appraisal, Routledge, London, 2013.

Petley, D.: Global patterns of loss of life from landslides, Geology, 40, 927-930, doi:10.1130/G33217.1, 2012.

20 Pianosi, F., Wagener, T., Rougier, J., Freer, J., and Hall, J.: Sensitivity analysis of environmental models: a systematic review with practical workflows, ASCE Int. Conf. Vulnerability, Uncertainty, and Risk, 290-299, doi:10.1061/9780784413609.030, 2015.

Pinto, J. G., Neuhaus, C. P., Leckebusch, G. C., Reyers, M., and Kerschgens, M.: Estimation of wind storm impacts over Western Germany under future climate conditions using a statistical-dynamical downscaling approach, Tellus A, 62, 188-201, 2010.

Pinto, J. G., Gómara, I., Masato, G., Dacre, H. F., Woollings, T., and Caballero, R.: Large-scale dynamics associated with clustering of extratropical cyclones affecting Western Europe, J. Geophys. Res.-Atmos., 119, 13704-13719, 2014.

Potts, D. M., Dounias, G. T., and Vaughan, P. R.: Finite element analysis of progressive failure of Carsington embankment, Geotechnique, 40, 79-101, doi:10.1680/geot.1990.40.1.79, 1990.

Prata, A. J.: Observations of volcanic ash clouds in the 10-12 $\mu \mathrm{m}$ window using AVHRR/2 data, Int. J. Remote Sens., 10, 751-761, 1989.
NHESSD

doi:10.5194/nhess-2015-295
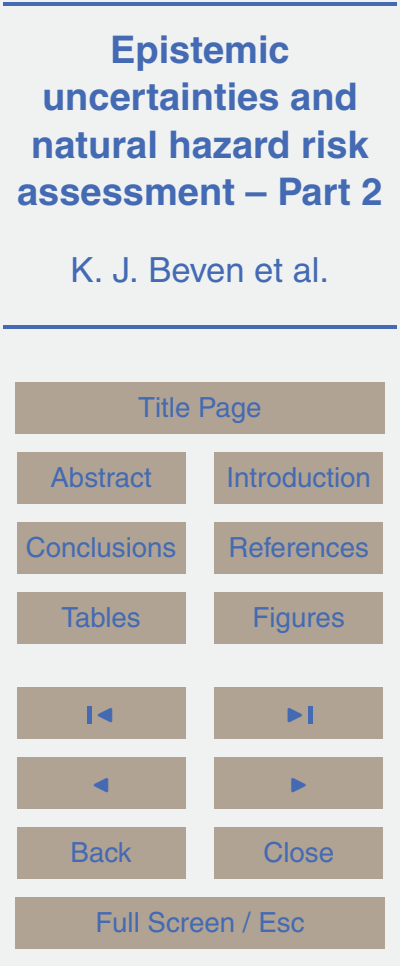

Printer-friendly Version

Interactive Discussion 
Prata, F., Bluth, G. J. S., Rose, W. I., Schneider, D. J., and Tupper, A.: Comments on "Failures in detecting volcanic ash from a satellite-based technique", Remote Sens. Environ., 78, 341346, 2001.

Prudhomme, C. and Davies, H.: Assessing uncertainties in climate change impact analyses on the river flow regimes in the UK. Part 2: future climate, Climatic Change, 93, 197-222, 2009.

Prudhomme, C., Wilby, R. L., Crooks, S., Kay, A. L., and Reynard, N. S.: Scenario-neutral approach to climate change impact studies: application to flood risk, J. Hydrol., 390, 198209, 2010.

Prudhomme, C., Crooks, S., Jackson, C., Kelvin, J., and Young, A.: Future Flows Final Technical Report, SC090016/PN9, Centre for Ecology and Hydrology, Wallingford, 2012.

Prudhomme, C., Haxton, T., Crooks, S., Jackson, C., Barkwith, A., Williamson, J., Kelvin, J., Mackay, J., Wang, L., Young, A., and Watts, G.: Future Flows Hydrology: an ensemble of daily river flow and monthly groundwater levels for use for climate change impact assessment across Great Britain, Earth Syst. Sci. Data, 5, 101-107, doi:10.5194/essd-5-101-2013, 2013.

Renggli, D., Leckebusch, G. C., Ulbrich, U., Gleixner, S. N., and Faust, E.: The skill of seasonal ensemble prediction systems to forecast wintertime windstorm frequency over the North Atlantic and Europe, Mon. Weather Rev., 139, 3052-3068, 2011.

Ries III, K. G. and Friesz, P. J.: Methods for estimating low-flow statistics for Massachusetts streams, US Geological Survey Water-Resources Investigations Report 00-4135, available from: http://water.usgs.gov/pubs/wri/wri004135/ (last access: 8 December 2015), 2000.

Robine, J. M., Cheung, S. L. K., Le Roy, S., Van Oyen, H., Griffiths, C., Michel, J. P., and Herrmann, F. R.: Death toll exceeded 70,000 in Europe during the summer of 2003, C. R. Biol., 331, 171-178, 2008.

Romanowicz, R. and Beven, K. J.: Bayesian estimation of flood inundation probabilities as conditioned on event inundation maps, Water Resour. Res., 39, W01073, doi:10.1029/2001WR001056, 2003.

Romanowicz, R., Beven, K. J., and Tawn, J.: Bayesian calibration of flood inundation models, in: Floodplain Processes, edited by: Anderson, M. G., Walling, D. E., and Bates, P. D., Wiley, Chichester, 333-360, 1996.

30 Rose, W. I., Delene, D. J., Schneider, D. J., Bluth, G. J. S., Krueger, A. J., Sprod, I. E., McKee, C., Davies, H. L., and Ernst, G. G. J.: Ice in the 1994 Rabaul eruption cloud: implications for volcano hazard and atmospheric effects, Nature, 375, 477-479, 1995.
NHESSD

doi:10.5194/nhess-2015-295
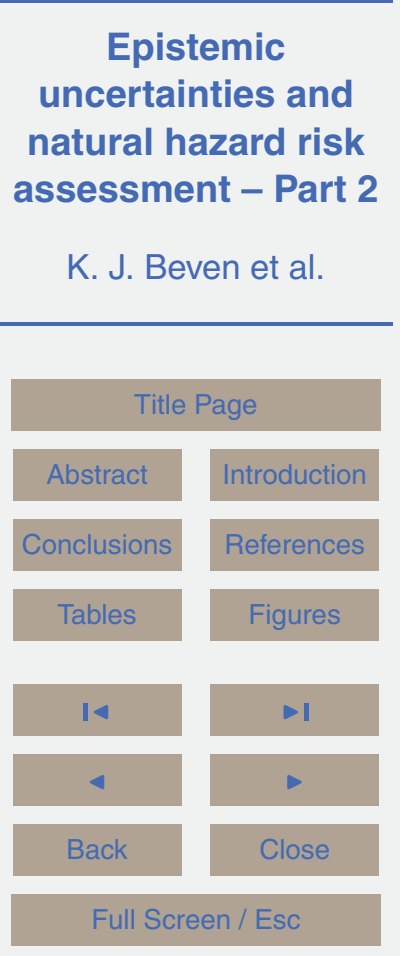

Printer-friendly Version

Interactive Discussion 
Rose, W. I., Bluth, G. J. S., Schneider, D. J., Ernst, G. G. J., Riley, M., Henderson, L. J., and Mcgimsey, R. G.: Observations of Volcanic Clouds in Their First Few Days of Atmospheric Residence: the 1992 Eruptions of Crater Peak, Mount Spurr Volcano, Alas, J. Geol., 109, 677-694, 2001.

5 Rosi, M., Principe, C., and Vecci, R.: The 1631 eruption of Vesuvius reconstructed from the review of chronicles and study of deposits, J. Volcanol. Geoth. Res., 58, 151-182, 1993.

Rougier, J. and Beven, K. J.: Model limitations: the sources and implications of epistemic uncertainty, in: Risk and Uncertainty Assessment for Natural Hazards, edited by: Rougier, J., Sparks, S., and Hill, L., Cambridge University Press, Cambridge, UK, 40-63, 2013.

10 Rubio, E., Hall, J. W., and Anderson, M. G.: Uncertainty analysis in a slope hydrology and stability model using probabilistic and imprecise information, Comput. Geotech., 31, 529536, 2015.

Samaniego, L., Kumar, R., and Zink, M.: Implications of parameter uncertainty on soil moisture drought analysis in Germany, J. Hydrometeorol., 14, 47-68, 2013.

Sampson, C. C., Fewtrell, T. J., Duncan, A., Shaad, K., Horritt, M. S., and Bates, P. D.: Using terrestrial laser scanning data to drive decimetric resolution urban inundation models, Adv. Water Resour., 41, 1-17, doi:10.1016/j.advwatres.2012.02.010, 2012.

Sansom, P. G., Stephenson, D. B., Ferro, C. A., Zappa, G., and Shaffrey, L.: Simple uncertainty frameworks for selecting weighting schemes and interpreting multimodel ensemble climate change experiments, J. Climate, 26, 4017-4037, 2013.

Satake, K., Wang, K., and Atwater, B. F.: Fault slip and seismic moment of the 1700 Cascadia earthquake inferred from Japanese tsunami descriptions, J. Geophys. Res.-Sol. Ea., 108, 2535, doi:10.1029/2003JB002521, 2003.

Satake, K., Fujii, Y., Harada, T., and Namegaya, Y.: Time and space distribution of coseismic slip of the 2011 Tohoku earthquake as inferred from tsunami waveform data, B. Seismol. Soc. Am., 103, 1473-1492, 2013.

Sayers, P. B., Hall, J. W., and Meadowcroft, I. C.: Towards risk-based flood hazard management in the UK, Proc. ICE-Civ. Eng., 150, 36-42, 2002.

Schmehl, K. J., Haupt, S. E., and Pavolonis, M. J.: A genetic algorithm variational approach to data assimilation and application to volcanic emissions, Pure Appl. Geophys., 169, 519-537, 2011.

\section{NHESSD}

doi:10.5194/nhess-2015-295

\section{Epistemic \\ uncertainties and \\ natural hazard risk \\ assessment - Part 2 \\ K. J. Beven et al.}

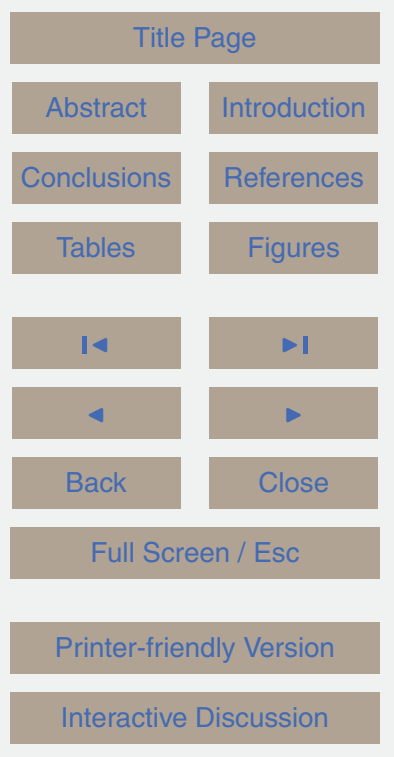


Schwierz, C., Köllner-Heck, P., Mutter, E. Z., Bresch, D. N., Vidale, P. L., Wild, M., and Schär, C.: Modelling European winter wind storm losses in current and future climate, Climatic Change, 101, 485-514, 2010.

Sene, K., Weerts, A. H., Beven, K. J., Moore, R. J., Whitlow, C., Laeger, S., and Cross, R.: Uncertainty estimation in fluvial flood forecasting applications, in: Applied Uncertainty Analysis for Flood Risk Management, edited by: Beven, K. J. and Hall, J. W., Imperial College Press, London, 462-498, 2014.

Shcherbakov, R., Nguyen, M., and Quigley, M.: Statistical analysis of the 2010 MW 7.1 Darfield earthquake aftershock sequence, New Zeal. J. Geol. Geop., 55, 305-311, 2012.

Shimazaki, K. and Nakata, T.: Time predictable recurrence for large earthquakes, Geophys. Res. Lett., 7, 279-282, 1980.

Simpson, J. J., Hufford, G., Pieri, D., and Berg, J.: Failures in detecting volcanic ash from a satellite-based technique, Remote Sens. Environ., 72, 191-217, 2000.

Smith, A. D., Goff, C. A., and Panzeri, M.: Enhancements in reservoir flood risk mapping: example application for Ulley, in: Maintaining the Safety of our Dams and Reservoirs, edited by: Pepper, A., ICE Publishing, London, 295-306, 2014.

Smith, P. J., Beven, K. J., Weerts, A. H., and Leedal, D.: Adaptive correction of deterministic models to produce probabilistic forecasts, Hydrol. Earth Syst. Sci., 16, 2783-2799, doi:10.5194/hess-16-2783-2012, 2012.

20 Smith, P. J., Beven, K. J., and Horsburgh, K.: Data Based Mechanistic modelling of tidally affected river reaches for flood warning purposes: an example on the River Dee, UK, Q. J. Roy. Meteorol. Soc., 139, 340-349, doi:10.1002/qj.1926, 2013a.

Smith, P. J., Panziera, L., and Beven, K. J.: Forecasting flash floods using Data Based Mechanistic models and NORA radar rainfall forecasts, Hydrolog. Sci. J., 59, 1403-1417, doi:10.1080/02626667.2013.842647, 2013b.

Sparks, R. S. J.: The dimensions and dynamics of volcanic eruption columns, B. Volcanol., 48, 3-15, 1986.

Sparks, R. S. J., Bursik, M. I., Carey, S. N., Gilbert, J. S., Glaze, L. S., Sigurdsson, H., and Woods, A. W.: Volcanic Plumes, John Wiley and Sons, Chichester, UK, 1997.

30 Stafford, P. J.: Crossed and nested mixed-effects approaches for enhanced model development and removal of the ergodic assumption in empirical ground-motion models, B. Seismol. Soc. Am., 104, 702-719, 2014.
NHESSD

Epistemic

uncertainties and natural hazard risk

assessment - Part 2

K. J. Beven et al.

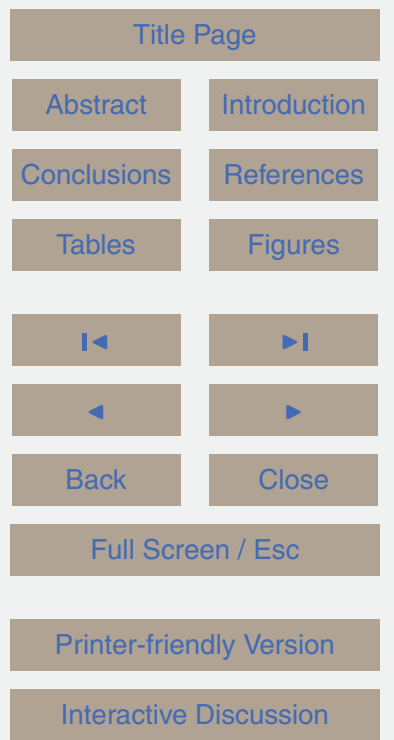


Stein, S. and Stein, J. L.: Shallow versus deep uncertainties in natural hazard assessments, EOS, 94, 133-134, 2013.

Stevenson, J. A., Millington, S. C., Beckett, F. M., Swindles, G. T., and Thordarson, T.: Big grains go far: reconciling tephrochronology with atmospheric measurements of volcanic ash,

$5 \quad$ Atmos. Meas. Tech. Discuss., 8, 65-120, doi:10.5194/amtd-8-65-2015, 2015.

Stohl, A., Prata, A. J., Eckhardt, S., Clarisse, L., Durant, A., Henne, S., Kristiansen, N. I., Minikin, A., Schumann, U., Seibert, P., Stebel, K., Thomas, H. E., Thorsteinsson, T., Tørseth, K., and Weinzierl, B.: Determination of time- and height-resolved volcanic ash emissions and their use for quantitative ash dispersion modeling: the 2010 Eyjafjallajökull eruption, Atmos. Chem. Phys., 11, 4333-4351, doi:10.5194/acp-11-4333-2011, 2011.

Svensson, C. and Jones, D. A.: Dependence between sea surge, river flow and precipitation in south and west Britain, Hydrol. Earth Syst. Sci., 8, 973-992, doi:10.5194/hess-8-973-2004, 2004.

Sykes, L. R. and Menke, W.: Repeat times of large earthquakes: implications for earthquake mechanics and long-term prediction, B. Seismol. Soc. Am., 96, 1569-1596, 2006.

Taddeucci, J., Scarlato, P., Montanaro, C., Cimarelli, C., Del Bello, E., Freda, C., Andronico, D., Gudmundsson, M. T., and Dingwell, D. B.: Aggregation-dominated ash settling from the Eyjafjallajökull volcanic cloud illuminated by field and laboratory high-speed imaging, Geology, 39, 891-894, 2011.

20 Tappin, D. R., Grilli, S. T., Harris, J. C., Geller, R. J., Masterlark, T., Kirby, J. T., Shi, F., Ma, G., Thingbaijam, K. K. S., and Mai, P. M.: Did a submarine landslide contribute to the 2011 Tohoku tsunami?, Mar. Geol., 357, 344-361, 2014.

Thio, H. K., Somerville, P., and Ichinose, G.: Probabilistic analysis of strong ground motion and tsunami hazards in southeast Asia, J. Earthq. Tsunami, 1, 119-137, 2007.

Tiampo, K. F., Rundle, J. B., Klein, W., Holliday, J., Sá Martins, J. S., and Ferguson, C. D.: Ergodicity in natural earthquake fault networks, Phys. Rev. E, 75, 066107, doi:10.1103/PhysRevE.75.066107, 2007.

Tomkins, K. M.: Uncertainty in streamflow rating curves: methods, controls and consequences, Hydrol. Process., 28, 464-481, doi:10.1002/hyp.9567, 2014.

30 van Gelder, P. and Vrijling, H.: Flood defence reliability analysis, in: Applied Uncertainty Analysis for Flood Risk Management, edited by: Beven, K. J. and Hall, J. W., Imperial College Press, London, 270-296, 2014.

\section{NHESSD}

doi:10.5194/nhess-2015-295
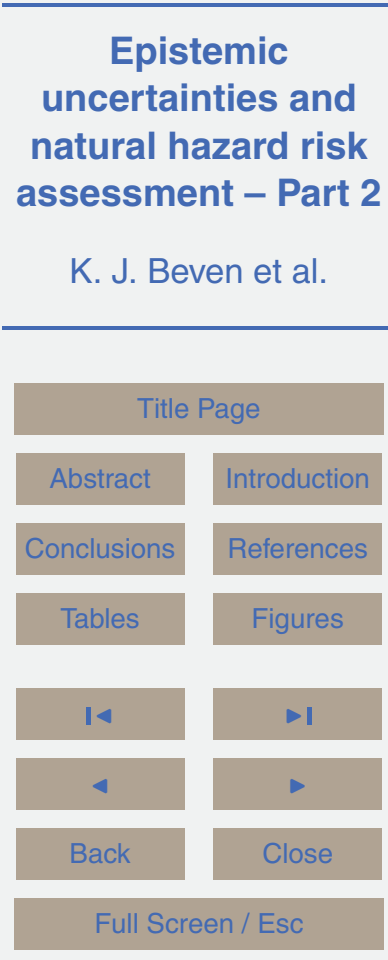

Printer-friendly Version

Interactive Discussion 
Vitolo, R., Stephenson, D. B., Cook, I. M., and Mitchell-Wallace, K.: Serial clustering of intense European storms, Meteorol. Z., 18, 411-424, 2009.

Vogel, A.: The bibliography of the history of dam failures - an event based accident data collection, edited by: Zio, E., Demichela, M., and Piccini, N., Proc. European Safety and Reliability Conference, v.2, Politecnico di Torino, Torino, Italy, 1361-1366, 2001.

Vrugt, J. A. and Sadegh, M.: Toward diagnostic model calibration and evaluation: approximate Bayesian computation, Water Resour. Res., 49, 4335-4345, 2013.

Wagener, T. and Wheater, H. S.: Parameter estimation and regionalization for continuous rainfall-runoff models including uncertainty, J. Hydrol., 320, 132-154, 2006.

10 Walker, G.: A critical examination of models and projections of demand in water utility resource planning in England and Wales, Int. J. Water Resour. D., 29, 352-372, 2012.

Webster, H. N., Thomson, D. J., Johnson, B. T., Heard, I. P. C., Turnbull, K., Marenco, F., Kristiansen, N. I., Dorsey, J., Minikin, A., Weinzierl, B., Schumann, U., Sparks, R. S. J., Loughlin, S. C., Hort, M. C., Leadbetter, S. J., Devenish, B. J., Manning, A. J., Witham, C. S., Haywood, J. M., and Golding, B. W.: Operational prediction of ash concentrations in the distal volcanic cloud from the 2010 Eyjafjallajökull eruption, J. Geophys. Res., 117, D00U08, doi:10.1029/2011JD016790, 2012.

Wesselink, A., Challinor, A. J., Watson, J., Beven, K. J., Allen, I., Hanlon, H., Lopez, A., Lorenz, S., Otto, F., Morse, A., Rye, C., Saux-Picard, S., Stainforth, D., and Suckling, E.: Equipped to deal with uncertainty in climate and impacts predictions: lessons from internal peer review, Climatic Change, 132, 1-14, doi:10.1007/s10584-014-1213-1, 2014.

Western, L. M., Watson, M., and Francis, P.: Uncertainty in two-channel infrared remote sensing retrievals of a well-characterised volcanic ash cloud, B. Volcanol., 77, 67, doi:10.1007/s00445-015-0950-y, 2015.

Wilby, R. L. and Dessai, S.: Robust adaptation to climate change, Weather, 65, 180-185, 2010.

Wilkins, K. L., Mackie, S., Watson, I. M., Webster, H. N., Thomson, D. J., and Dacre, H. F.: Data insertion in volcanic ash cloud forecasting, Ann. Geophys., 57, 1-6, 2014.

Wilkins, K. L., Watson, I. M., Kristiansen, N. I., Dacre, H. F., Webster, H. N., Thomson, D. J., and Prata, A. J.: Using data insertion with the NAME model to simulate the 8 May 2010 Ey30 jafjallajökull volcanic ash cloud, J. Geophys. Res.-Atmos., 120, doi:10.1002/2015JD023895, 2015.

Wilkins, K. L., Benedetti, A., Kristiansen, N. I., and Lange, A. C.: Applications of satellite observations of volcanic ash in atmospheric dispersion modelling, in: Volcanic Ash: Hazard

\section{NHESSD}

doi:10.5194/nhess-2015-295
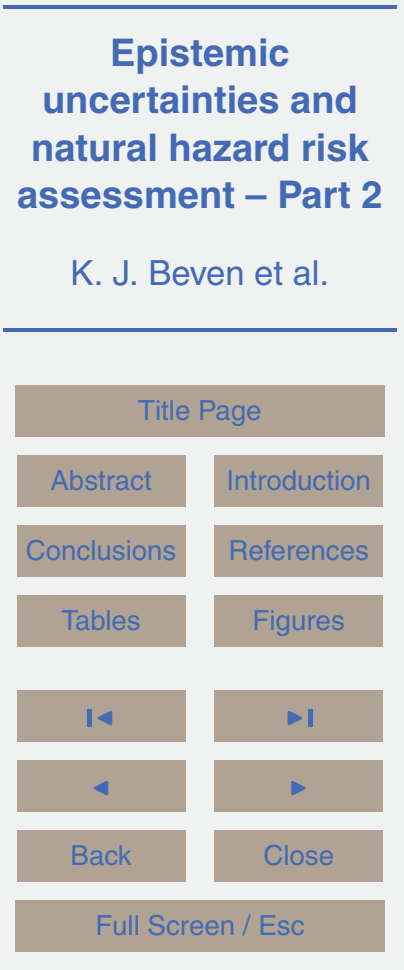

Printer-friendly Version

Interactive Discussion 
Observation, edited by: Mackie, S., Watson, I. M., Ricketts, H., Cashman, K. V., and Rust, A., Elsevier, Amsterdam, 2016.

Woo, G.: Calculating catastrophe, Imperial College Press, London, UK, 2011.

Woo, G. and Aspinall, W. P.: Thirty-Year Bayesian Updating of PSHA for Hinkley Point NPP, Pa5 per presented to CSNI Workshop on "Testing PSHA Results and Benefit of Bayesian Techniques for Seismic Hazard Assessment”, 4-6 February 2015, Eucentre Foundation, Pavia, Italy, 13 pp., 2015.

Woodhouse, M. J., Hogg, A. J., Phillips, J. C., and Sparks, R. S. J.: Interaction between volcanic plumes and wind during the 2010 Eyjafjallajökull eruption, Iceland, J. Geophys. Res.-Sol. Ea., 118, 92-109, 2013.

Woodhouse, M. J., Hogg, A. J., Phillips, J. C., and Rougier, J. C.: An uncertainty analysis of an integral model for wind-blown volcanic plumes using radar observations of plume height, $\mathrm{B}$. Volcanol., 77, 83, 2015.

$\mathrm{Wu}$, T. H. and Abdel-Latif, M. A.: Prediction and mapping of landslide hazard, Can. Geotech. J., $15 \quad 37$, 781-795, doi:10.1139/cgj-37-4-781, 2000.

Xia, J., Lin, B., Falconer, R. A., and Wang, G.: Modelling dam-break flows over mobile beds using a 2D coupled approach, Adv. Water Resour., 33, 171-183, 2010.

Yeo, G. L. and Cornell, C. A.: A probabilistic framework for quantification of aftershock groundmotion hazard in California: methodology and parametric study, Earthq. Eng. Struct. D., 38, $20 \quad 45-60,2009$.

Young, P. C., Romanowicz, R. J., and Beven, K. J.: A data-based mechanistic modelling approach to real-time flood forecasting, in: Applied Uncertainty Analysis for Flood Risk Management, edited by: Beven, K. J. and Hall, J. W., Imperial College Press, London, 407-461, 2014.

Yu, C., Li, C., Xin, Q., Chen, H., Zhang, J., Zhang, F., Li, X., Clinton, N., Huang, X., Yue, Y., Gong, P.: Dynamic assessment of the impact of drought on agricultural yield and scaledependent return periods over large geographic regions, Environ. Model. Softw., 62, 454464, 2014.

Zappa, G., Shaffrey, L. C., and Hodges, K. I.: The Ability of CMIP5 Models to Simulate North

30 Atlantic Extratropical Cyclones, J. Climate, 26, 5379-5396, 2013.

Zuccolo, E., Vaccari, F., Peresan, A., and Panza, G. F.: Neo-deterministic and probabilistic seismic hazard assessments: a comparison over the Italian territory, Pure Appl. Geophys., 168, 69-83, 2011.
NHESSD

doi:10.5194/nhess-2015-295

Epistemic

uncertainties and

natural hazard risk

assessment - Part 2

K. J. Beven et al.

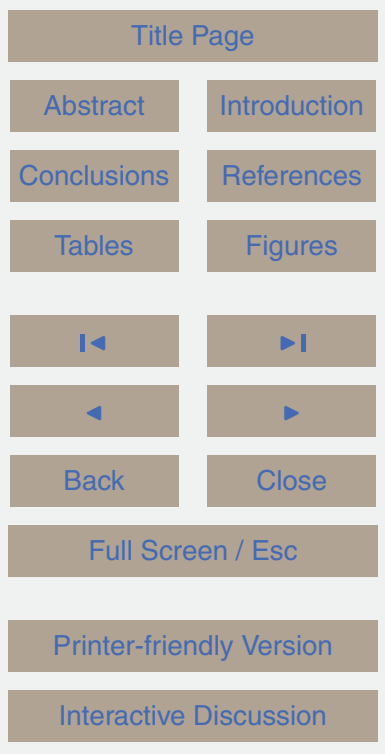



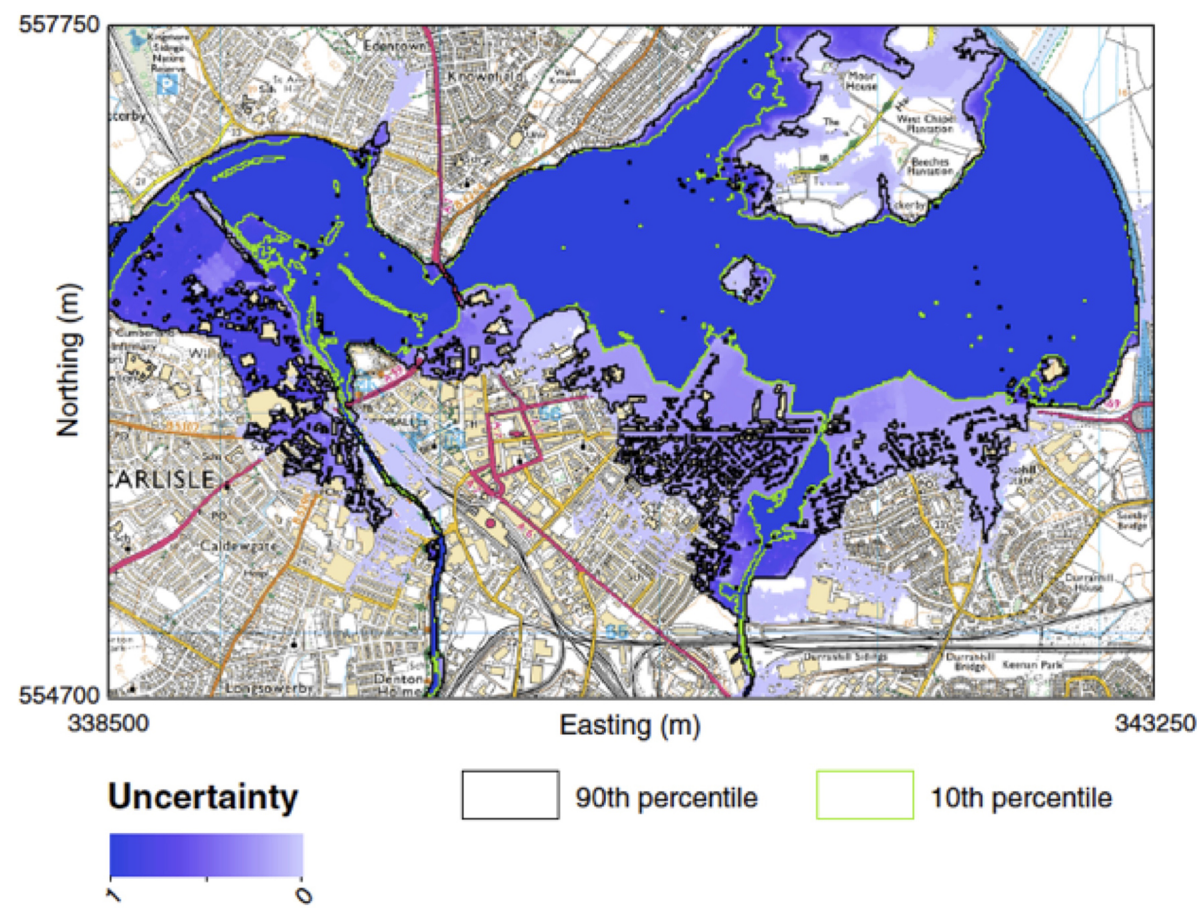

Figure 1. Uncertainty in inundation extent, as colour coded chance of flooding, resulting from the flood with annual exceedance probability 0.01, River Eden valley in the vicinity of Carlisle, Cumbria, UK (after Neal et al., 2013).

\section{NHESSD}

doi:10.5194/nhess-2015-295

\section{Epistemic}

uncertainties and natural hazard risk assessment - Part 2

\section{K. J. Beven et al.}

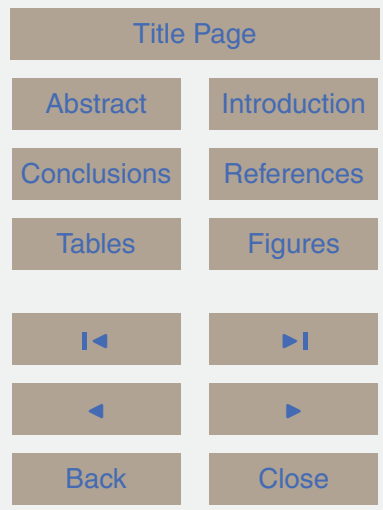

Full Screen / Esc

Printer-friendly Version

Interactive Discussion 
(a)

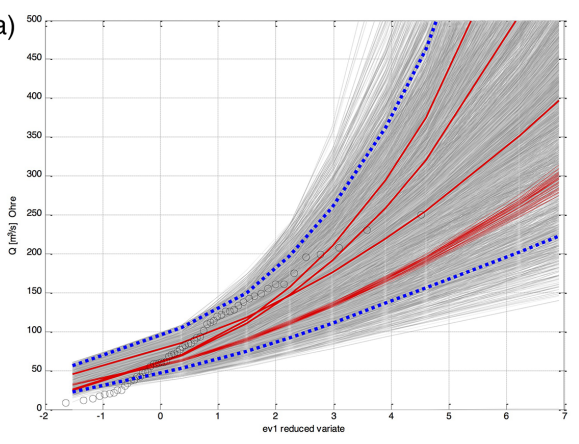

(b)
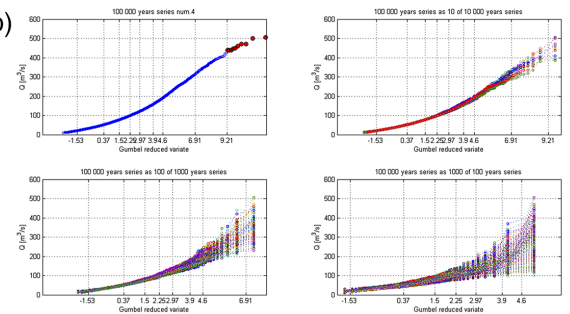

(c)
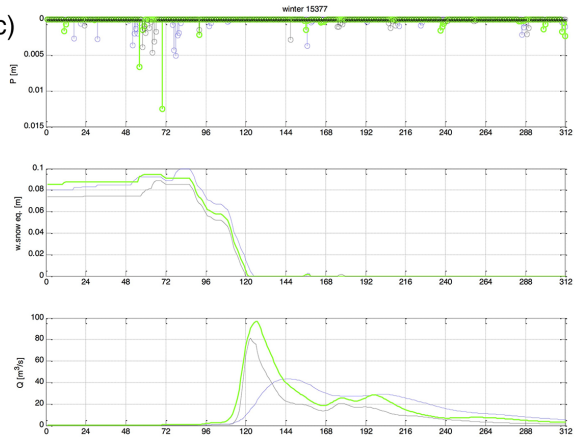

\section{NHESSD}

doi:10.5194/nhess-2015-295

Epistemic uncertainties and natural hazard risk assessment - Part 2

K. J. Beven et al.

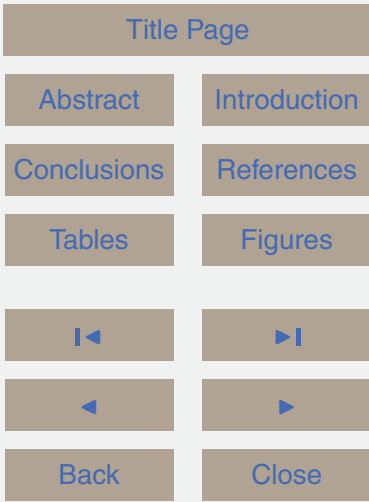

Full Screen / Esc

Printer-friendly Version

Interactive Discussion 
Figure 2. (a) Flood frequency curves for 4192 model runs of reservoir inflows for the Skalka Dam site, Czech Republic retained after evaluation in the GLUE methodology. Blue dotted lines represent 5 and 95 quantiles of weighted simulations for each frequency. Each run is a single realisation of 1000 years with an hourly time step using different input and rainfall-runoff parameters. The model components are described in Blazkova and Beven (2009). Circles are observed flood peaks for the Cheb gauging station for the period prior to the construction of the Skalka Dam. These data were not used in the GLUE conditioning. (b) Generated flood discharges for a single model run of 100000 years of simulated time for the Skalka Dam reservoir inflows on a Gumbel extreme value plot, showing the variability when broken down into shorter periods. (c) Realisation of rainfalls, snowpack water equivalent, reservoir inputs, water levels and overflows for the Skalka dam, Czech Republic.

\section{NHESSD}

doi:10.5194/nhess-2015-295

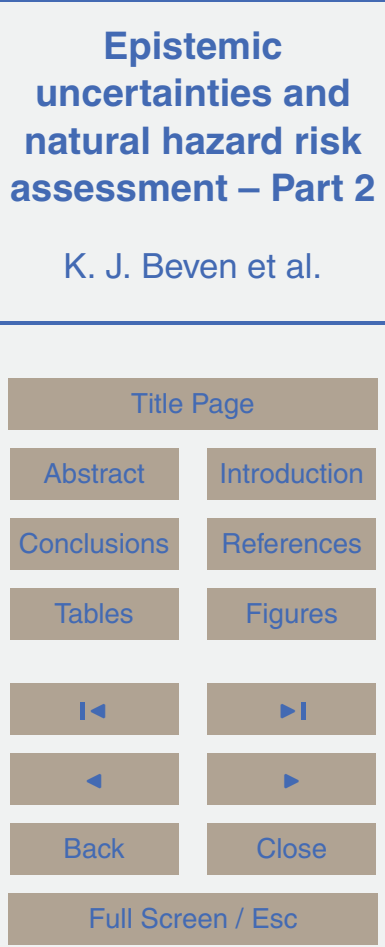

Printer-friendly Version

Interactive Discussion 


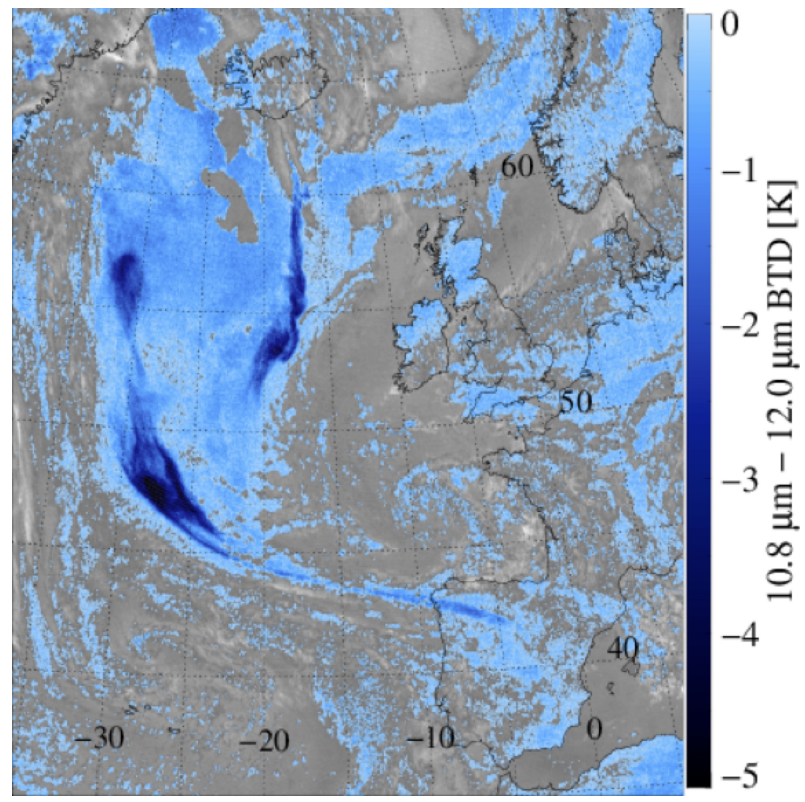

Figure 3. Meteosat Second Generation Spinning Enhanced Visible and InfraRed Imager (SEVIRI) brightness temperature difference image (BT at $10.8 \mu \mathrm{m}$ channel - BT at $12 \mu \mathrm{m}$ channel) showing the Eyjafjallajökull ash cloud at 03:00 UTC 8 May 2010. A likely false negative ash signal can be seen south of Iceland where the ash plume appears to be obscured, possibly by meteorological cloud, due to the high ash concentration causing opaqueness, a large fraction of large particles or the presence of water in the plume. A negative BTD signal can be seen over North Africa/south eastern Spain, possibly due to a night-time clear arid land surface. Raw data supplied by EUMETSAT.

\section{NHESSD}

\section{Epistemic \\ uncertainties and natural hazard risk assessment - Part 2 \\ K. J. Beven et al.}

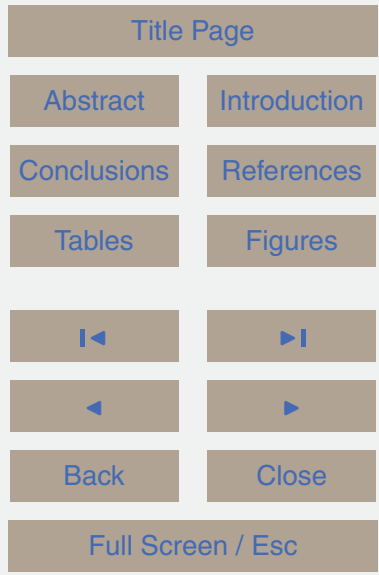

Printer-friendly Version

Interactive Discussion 

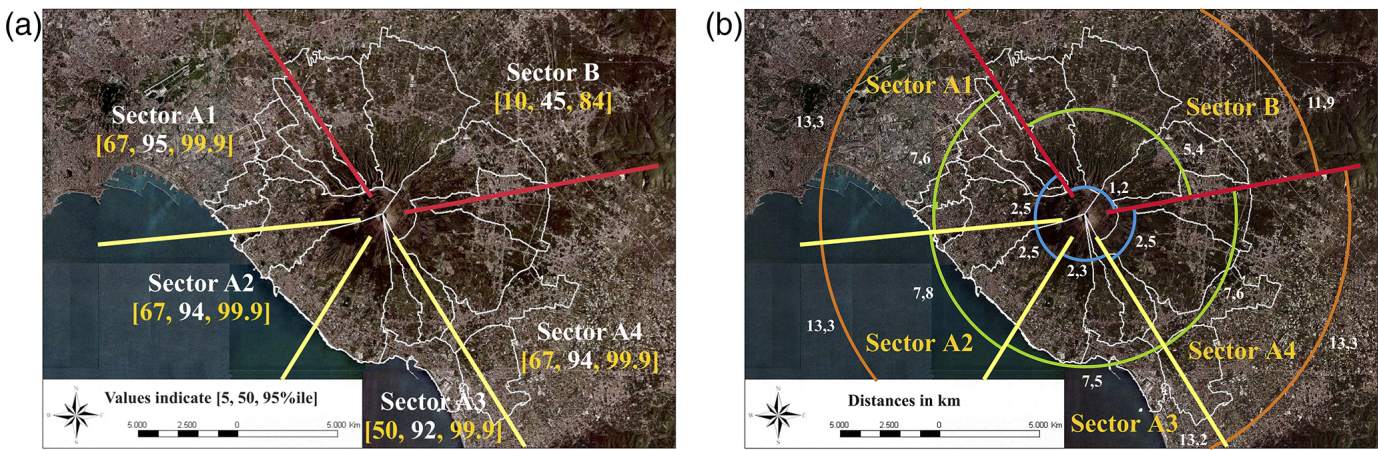

\section{NHESSD}

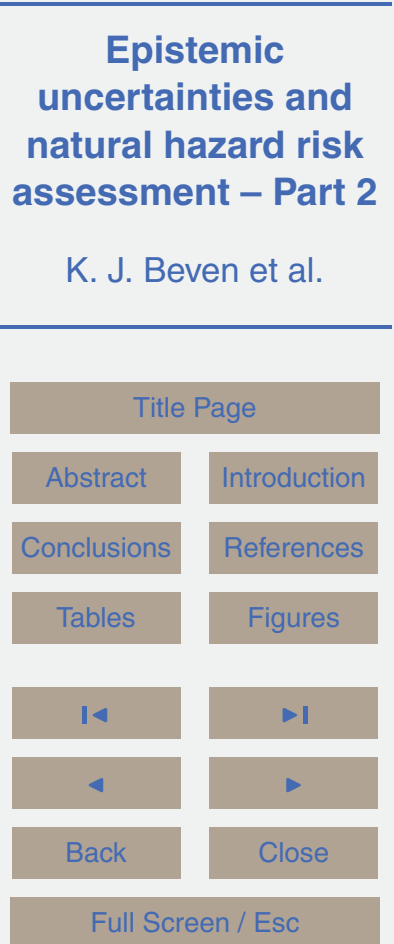

Figure 4. (a) Broad segmentation of area around Vesuvius recognizing the first-order effect of Mt. Somma topography in determining areas that might be invaded by pyroclastic density current flows (PDC) as the result of a Sub-Plinian I eruption. The bracketed values in each sector show elicited modal probabilities that a PDC will affect that sector (expressed in percentage terms) together with the corresponding credible intervals, in quantile form (5th, 50th, 95th percentiles). (b) Elicited estimates of maximum run-out distances (in $\mathrm{km}$ ) for PDCs occurring during a Sub-Plinian I eruption, by sector. Inner arcs (blue) are $95 \%$ confidence levels for exceeding distance shown (e.g. $2.5 \mathrm{~km}$ for Sector A1), central arcs (green) are expected (50th percentile) values, and outer arcs (orange) are the run-out distances assessed has having only a $5 \%$ chance of being exceeded (from Neri et al. (2008), with permission).

Full Screen / Esc

Printer-friendly Version

Interactive Discussion 